\title{
The effects of biodiversity and natural environment on satisfaction
}

\author{
by \\ Lauren Hepburn
}

A thesis submitted to the Faculty of Graduate and Postdoctoral

Affairs in partial fulfillment of the requirements for the degree of

\author{
Masters of Science \\ in \\ Biology
Carleton University
Ottawa, Ontario \\ August, 2018 \\ (C) 2018 \\ Lauren Hepburn
}




\begin{abstract}
This project focused on how the nature in city neighbourhoods influences the satisfaction of residents. Residents of Ottawa $(n=1035)$ were surveyed about their life satisfaction and their thoughts of the environment surrounding their homes. The survey responses were compared to nature near their homes, including bird diversity, tree canopy cover, and distance to water. Neighbourhood satisfaction was positively related to bird species richness, even before participants were prompted to consider nature. In addition, satisfaction with the local nature increased with bird species richness and tree canopy cover. The quality rating of local nature in comparison to other areas increased with tree canopy cover and nearness to water. Nature was considered more important when choosing where to live for participants living in neighborhoods with high tree canopy cover and close to water. The results create a compelling argument for city planners to maintain urban nature.
\end{abstract}




\section{Acknowledgments}

First and foremost, I would also like to thank my supervisors Lenore Fahrig, Adam Smith, and John Zelenski for all their guidance in making this project go from an idea to a reality. Additional thanks to Dr. Joseph Bennett and Dr. Julie Morand-Ferron for their helpful comments and suggestions in the committee meetings. I do not know how I would have finished surveying without the tireless dedication of my field assistants, Madison Donoghue and Kayla Attinello.

I'd like to thank all the people who took the time to do my survey over the summer, without their kindness and patience this project would not have been possible. Thank you to the staff and volunteers at the Ottawa Bird Count for all their hard work collecting and compiling all of the bird surveys over the years. Likewise, thanks to the city of Ottawa for providing map data for the area.

This work was funded by a Natural Sciences and Engineering Research Council of Canada Grant to Lenore Fahrig.

Lastly I would like to thank my friends and family for their unconditional love and support. 


\section{Table of Contents}

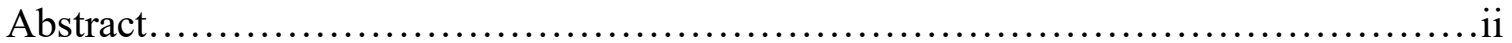

Acknowledgements........................................................

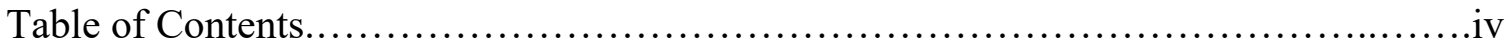

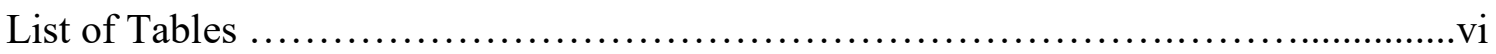

List of Figures.............................................................

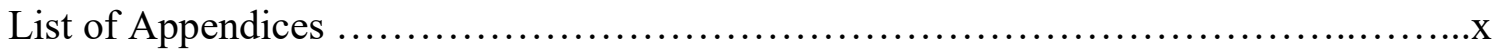

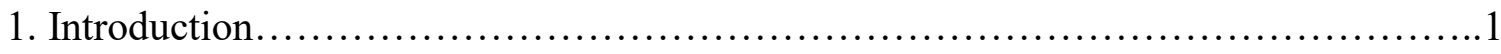

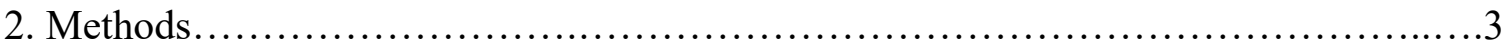

2.1 Overview.........................................................

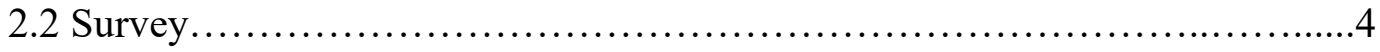

2.3 Site Selection..................................................6

2.4 Sampling Order.................................................. 7

2.5 Bird Data........................................................ 7

2.6 Tree Canopy Cover................................................ 8

2.7 Distance to Water.................................................... 8

2.8 Median Income.....................................................

2.9 Data Analyses..........................................................

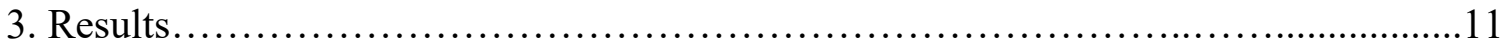

3.1 Overview.......................................................11

3.2 Models with Disposition......................................... 11

3.3 Models without Disposition ...................................... 12

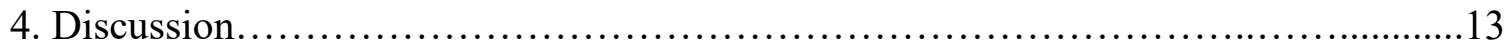




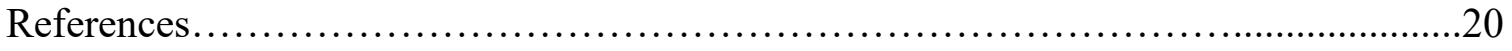

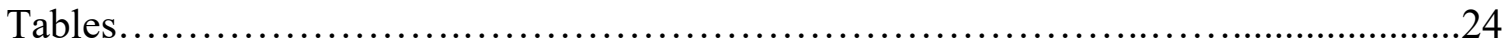

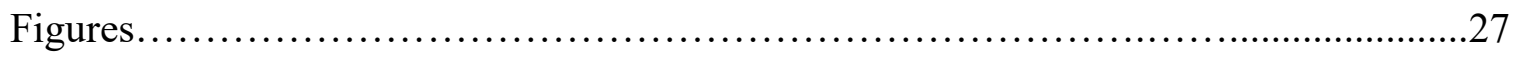

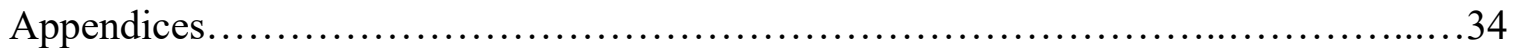




\section{List of Tables}

Table 1: List of 8 survey questions and possible responses. Participants were residents in Ottawa who lived within $250 \mathrm{~m}$ of a pre-existing bird point count location of the Ottawa Bird Count (OBC). Participants were recruited door-to-door and through flyers during

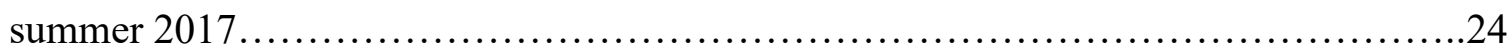

Table 2: Spearman correlation values between the participant responses to each question. There were a total of 1035 participants, who were residents in Ottawa who were recruited door-to-door and through flyers during summer 2017. Full questions and possible

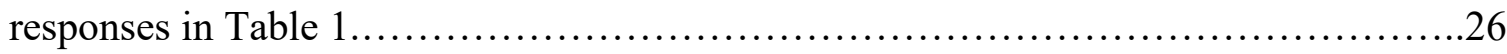




\section{List of Figures}

Figure 1: Location of the study region in Ottawa, Canada (A), showing the distribution of 100 study sites across residential Ottawa (B). Sites were centered on pre-existing bird point count locations from the Ottawa Bird Count (OBC) and had a 250m radius. Tree canopy cover and water data were provided by the city of Ottawa. Within the sites residents were surveyed door-to-door about their life satisfaction and thoughts about their local environment. The study area was divided into quadrants (straight lines) for sampling. Each day two sites in the same quadrant were visited, with the surveyed quadrant changing every day in a clockwise pattern..............................27

Figure 2: Histograms of predictor measurements for the 1035 door-to-door surveys, with bivariate plots and Pearson correlation values for all pairs of covariates. Variables include bird abundance and species richness (number of bird species) measured at the nearest Ottawa Bird Count (OBC) site to each participant, tree canopy cover in hectares within $250 \mathrm{~m}$ radius of the participant, Euclidean distance in kilometers between the participant and the nearest body of water, and median individual yearly income in the Canadian

Census dissemination area of the participant...................................28

Figure 3: The independent effects of each of four predictor variables, after controlling for the effects of all other variables, on the probability (+/- 95\% credible intervals) of a participant answering the most positive option ("Extremely happy”) in response to question 1 (“How would you best describe your disposition?”). The predictor variables in the model include bird species richness, tree canopy cover, distance to water, and median income. Each plot shows the effect of one predictor, while all other predictors are held 
constant at their means. Effects are plotted in blue if the $95 \%$ credible intervals around

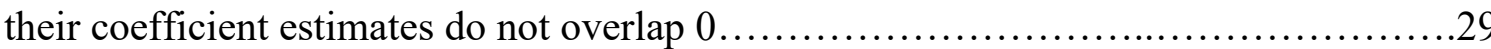

Figure 4: The independent effects of each of four predictor variables, after controlling for the effects of all other variables, on the probability $(+/-95 \%$ credible intervals $)$ of a participant answering the most positive option ("Extremely satisfied") to question 2 (“How would you best describe your satisfaction with your life as a whole?"), question 3 ("How would you best describe your satisfaction with your neighbourhood (i.e. the immediate area surrounding your residence, usually within a few hundred metres)?"), and question 4 ("How would you best describe your satisfaction with the natural environment in your neighbourhood?"). The predictor variables in the model include bird species richness, tree canopy cover, distance to water, median income, and disposition (taken from question 1). Each plot shows the effect of one predictor, while all other predictors are held constant at their means (median for disposition). Effects are plotted in blue if the $95 \%$ credible intervals around their coefficient estimates do not overlap $0 \ldots \ldots \ldots \ldots . \ldots 30$

Figure 5: The independent effects of each of four predictor variables, after controlling for the effects of all other variables, on the probability (+/- 95\% credible intervals) of a participant answering the most positive option ("Far above average" or "Extremely important") for question 5 ("How would you rate the quality of your neighbourhood's natural environment compared to other areas in Ottawa?") and question 6 ("How important a factor was the quality of the natural environment when you were choosing where to live?"). The predictor variables in the model include bird species richness, tree canopy cover, distance to water, median income, and disposition (taken from question 1). Each plot shows the effect of one predictor, while all other predictors are held constant at 
their means (median for disposition). Effects are plotted in blue if the $95 \%$ credible intervals around their coefficient estimates do not overlap $0 \ldots \ldots \ldots \ldots \ldots \ldots \ldots \ldots \ldots . \ldots \ldots 32$

Figure 6: The independent effects of each of four predictor variables, after controlling for the effects of all other variables, on the probability ( $+/-95 \%$ credible intervals) of a participant answering the most positive option ("Strongly agree") for question 7 ("How do you feel about the statement "My relationship to nature is an important part of who I am"?") and question 8 ("How do you feel about the statement "I feel very connected to all living things and the earth"?"). The predictor variables in the model include bird species richness, tree canopy cover, distance to water, median income, and disposition (taken from question 1). Each plot shows the effect of one predictor, while all other predictors are held constant at their means (median for disposition). Effects are plotted in blue if the $95 \%$ credible intervals around their coefficient estimates do not overlap $0 \ldots .33$ 


\section{List of Appendices}

Figure A: In-person surveys were conducted between May 4, 2017 and August 17, 2017. A few on-line surveys were returned after August $17^{\text {th }}$. The sequence of surveys was designed avoid any confounding of sampling date with any of the predictor variables...34

Table A: Survey results recorded during study. A total of 1035 people were surveyed across 100 sites located in Ottawa, Canada (Figure 1). Site corresponds to the site designation used in this study. Easting and Northing are the co-ordinates of the survey site (NAD 83 UTM Zone 18). User ID is a unique identifier for each participant. IDs with four numbers were surveys completed in-person, the first two digits correspond to the site and the second two to the sample number. IDs with a letter prefix were respondents to a flyer. Date is the recorded month and day of the survey submission, all in 2017. Predictor variables include bird abundance (Abun.) and species richness (Rich.) measured at the nearest Ottawa Bird Count (OBC) point to each participant, tree canopy cover in hectares within $250 \mathrm{~m}$ radius of the participant (Tree), Euclidean distance in kilometers between the participant and the nearest body of water (Water), and median individual yearly income in the dissemination area of the participant (Inc.). Q1-Q8 correspond to the survey questions described in Table 1. Responses are coded so that the least positive answer is 1. Q1-Q5 have a 7-point scale and Q6-Q8 have a 5-point scale...............35

Table B: Parameter values used for predicting probabilities as seen in Figures 3-6. Data sets were created where each parameter is held constant except for the parameter of interest. Intercept was set to 1. Bird abundance and species richness, tree canopy cover (ha), distance to water $(\mathrm{km})$, and median yearly income were set at the mean of all 1035 
samples. Disposition $1-6$ was evaluated at the median answer ("Moderately happy") using orthogonal polynomial contrast coding ............................................. 77

Figure B: Histograms of participant responses to survey questions 1-8 (see Table 1). Responses are scored with 1 being the least positive response. Residents in Ottawa, Canada were surveyed about their life satisfaction and their thoughts about their local environment. Participants were surveyed at 100 sites distributed across the city (Figure 1). Each site had a $250 \mathrm{~m}$ radius centred around a pre-existing bird point count location from the Ottawa Bird Count (OBC). Sites were chosen to reduce correlation between predictor values (bird abundance and species richness, tree canopy cover, distance to

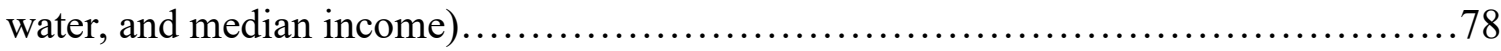

Table C: Pearson correlation coefficients between site predictor variables and response rates. There were 100 total sites distributed across the residential Ottawa area. Each site had a $250 \mathrm{~m}$ radius and was centred on a pre-existing bird point count location from the Ottawa Bird Count (OBC). Predictor variables measured at the site include bird abundance and species richness, tree canopy cover (ha), distance to water $(\mathrm{km})$, and median individual yearly income. Residents who lived in the site were surveyed door-todoor and flyers were distributed to boost sample size. Sites were surveyed until either there were 10 participants or until there were no more residential addresses to visit. Inperson response rate is the number of individuals who participated from door-to-door surveying divided by the total number of people who were spoken to. The flyer response rate is the number of individuals who responded to the flyer divided by the total number of flyers left at residences. The overall response rate is the total number of participants divided by the total number of people contacted (either in-person or by flyer)....... 79 
Table D: Parameter coefficients for all models. Models were fit using ordered probit mixed models where site was treated as a random effect. Predictor variables included bird abundance and species richness, tree canopy cover (ha), distance to water $(\mathrm{km})$, median individual yearly income and disposition. Models either included disposition as a predictor or did not. Disposition was measured as the participant's response to question 1 (Table 1) If disposition was included as a predictor it was coded using orthogonal polynomial contrasts up to the sixth power. Each model only included one bird variable at a time, either bird abundance or bird species richness. Significance level is denoted by

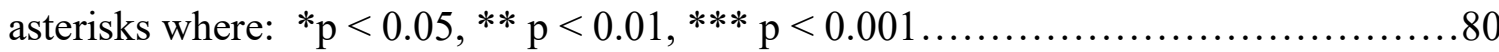

Figure C: Comparison between the models with and without disposition for the bird variables. The independent effects of each of bird abundance and species richness, after controlling for the effects of tree canopy cover, distance to water and income, on the probability $(+/-95 \%$ credible intervals) of a participant answering the most positive option ("Far above average") for question 5 ("How would you rate the quality of your neighbourhood's natural environment compared to other areas in Ottawa?"). Each plot shows the effect of one predictor, while all other predictors are held constant at their means (median for disposition). Effects are plotted in blue if the $95 \%$ credible intervals around their coefficient estimates do not overlap $0 \ldots \ldots \ldots \ldots \ldots \ldots \ldots \ldots \ldots \ldots \ldots \ldots \ldots$ 


\section{Introduction}

There is growing evidence that exposure to nature has positive effects on human well-being (Sandifer et al., 2015). Nature has been related to a broad variety of wellness traits, such as improved mood, increased cognitive function, and overall general health (Park et al., 2011; Berman et al., 2008; de Vries et al., 2003). A seminal study by Fuller et al. (2007) found that psychological well-being, such as reflection, distinct identity and place attachment of people who visited a community garden was related to plant and bird species richness. Dallimer et al. (2012) used a similar methodology and found positive effects of bird diversity, but negative effects of plant diversity, indicating that patterns are not clear and need further study. More specifically, nature has also been found to be related to the happiness of people (Nisbet et al., 2011; Mackerron \& Mourato, 2013). While well-being can refer to any positive condition; psychologists typically describe the specific concept of happiness using one or more indicators of well-being. Subjective well-being is a construct commonly used to describe happiness based on cognitive evaluations on a person's overall life satisfaction, satisfaction with different facets of their life, and positive emotional balance (Diener, 2000). Mackerron \& Mourato (2013) surveyed people through a phone app in the United Kingdom about their happiness and related that to measures of nature based on their geolocation. They found that people outside in natural environments at the time of the survey had significantly higher experienced subjective well-being at the time of the survey. Nisbet et al. (2009) introduced the concept of nature relatedness, which measures the connection between an individual and nature. People who spend more time outdoors in nature demonstrate higher nature relatedness, as well as more pro-environmental behaviours (Nisbet et al., 
2009). Individuals with higher nature relatedness were found to have higher well-being (Nisbet et al., 2011).

There is concern that people who live in cities are becoming disconnected from nature and that this may negatively impact their well-being (Kellert \& Wilson, 1993). Investigating the relationship between well-being and biodiversity is a time sensitive issue due to rapid urbanization. Urban areas are associated with lower biodiversity than rural areas, especially in extreme cases such as downtown cores (McKinney, 2008). It is estimated that $55 \%$ of the world's population currently lives in urban areas and that number is expected to increase to $68 \%$ by 2050 (United Nations, 2018) indicating that determining the effects of nature on urban dwellers is a pressing concern.

Many studies that attempt to measure the effect of nature on humans focus on greenspaces, such as urban parks and gardens (Fuller et al., 2007; Park et al., 2011; Dallimer et al., 2013; Carrus et al., 2014). This could lead to a biased sample, as people who feel less connected to nature may be less likely to visit a park and would be underrepresented in the study. There is considerably less focus on the role of nature that is not dedicated to recreation, such as tree-lined streets in residential neighbourhoods. Kardan et al. (2015) found that people with higher tree canopy cover in their neighbourhoods had fewer reported health problems and higher perceived health. This suggests that not only large greenspaces are of importance to well-being and that biodiversity outside of parks should be considered.

The focus of my study was on determining if a positive affiliation towards local nature was present in residents in urban and suburban areas. I tested the relationship between local environment and a person's happiness by surveying people and comparing 
their responses to measures of nature near their homes. The survey measured happiness using questions about life satisfaction and satisfaction with their neighbourhoods (Diener, 2000). Additionally, the survey included context questions about their perceptions of their local nature and their relationship with nature. The nature predictor variables were bird abundance, bird species richness (i.e. number of bird species), tree canopy cover (ha), and distance to water $(\mathrm{km})$. I visited 100 sites spread across the residential Ottawa area that had varying measures of each of the predictor variables. I predicted that people living in areas with higher measures of nature (i.e. higher bird abundance and species richness, higher tree canopy cover, and smaller distance to water) would have more positive responses to the survey questions.

\section{Methods}

\subsection{Overview}

I surveyed residents in Ottawa about their life satisfaction and their thoughts about their local environment and related the survey results to independent data on the natural environment near the participants' residences. Participants were not told in advance that this study was about nature, to avoid biasing their answers to early questions about their overall satisfaction and neighbourhood satisfaction. Participant responses were compared to measures of nature around their homes while controlling for the potentially confounding variable of income. I used four measures of nature which included: 1) bird abundance, 2) bird species richness, 3) tree canopy cover and 4) distance to water. Distance to water was added as a variable post hoc as many participants explicitly mentioned the importance of being near to water in responses to questions about the natural environment of their neighbourhoods. I selected 100, 250m 
radius sites across the residential parts of Ottawa, Canada (Figure 1). These sites were centred around pre-existing bird count locations ( $75 \mathrm{~m}$ radius each) from the Ottawa Bird Count (www.ottawabirds.ca).

\subsection{Survey}

The survey contained eight questions (Table 1). It was designed so that questions started broad and gradually became more specific. The first question asked about the participant's disposition, similar to the subjective happiness scale (Lyubomirsky \& Lepper, 1999). This study treats disposition as being a personal character trait inherent of the participant. It is used as both a response variable and as a predictor for other questions. Questions two through four were about life satisfaction and were adapted from the World Values Survey (Diener et al., 1985; Inglehart et al., 2014). This study treats life satisfaction as distinct from disposition and includes the participant's circumstances in addition to their inherent character. Questions five and six focused on how conscious the participants were of the nature around them. The goal of theses questions was to determine how they perceived the environment and whether or not they made a deliberate choice to live near nature. Questions seven and eight were adapted from the Nature Relatedness Scale (Nisbet et al., 2009). These questions determined the participant's relationship and connectivity to nature. Carleton University Research Ethics Board approved all methods and survey questions (Project \# 106476).

I created the survey using the software Qualtrics ${ }^{\mathrm{TM}}$ (Qualtrics, 2017), which hosted the survey on its platform. For in-person surveying, the participants used a tablet to read and submit their answers. To increase sample size, flyers were left at residences inviting the occupants to participate online if they were not available for an in-person 
survey. Participants were asked if they would be willing to participate in a study on "resident life satisfaction". I intentionally did not mention the environment until later in the survey as I did not want to bias their responses to the questions about general satisfaction with life and with their neighbourhood. Those who answered affirmatively were given consent information to review. Once participants electronically submitted their consent, each participant was assigned a unique User ID. This ID was coded to the participant's location so that the variables around their residence - bird abundance and richness, tree canopy cover, distance to water, and median income - could be measured. The survey then began. The survey showed one question at a time and participants were not able to change their answers after they were given. Again, this was to avoid the later mention of the environment having an influence on participants' answers to questions about general satisfaction with life and with their neighbourhood. After the last question, participants were shown debriefing information describing the purpose of the study and asked to reaffirm their consent. Participants were given the option to withdraw from the survey, even after competition, however no participants chose this option.

I surveyed people door-to-door, visiting all study sites between May and August, 2017. In-person surveying took place Monday through Friday (excluding holidays) between 9:30am and 4:30pm. For each 250m radius site, sampling continued until either 10 surveys had been achieved or until there were no more residential addresses to visit within the site. If a site could not be completed, it was revisited at the end of the sampling period. Residences were prioritized for sampling based on how close they were to the bird point. Residences within the $75 \mathrm{~m}$ radius were highest priority, followed by those within $150 \mathrm{~m}$, and lastly within $250 \mathrm{~m}$. The study period was chosen to bracket the mean 
leaf out and leaf senescence dates as recorded at the Ottawa Arboretum (Panchen et al., 2014; Panchen et al., 2015). This was done so that the tree canopy cover would be consistent throughout the field season. The final online survey was collected October 1, 2017.

\subsection{Site Selection}

I selected 100 survey sites, from among the 928 Ottawa Bird Count locations distributed across Ottawa, to represent gradients of my predictor variables: bird abundance and richness, tree cover, distance to water, and median income (Figure 1). The sites were centred around the pre-existing bird count locations from the Ottawa Bird Count program and had a radius of $250 \mathrm{~m}$ from the centres of the bird count locations. Sites with fewer than 10 residential properties were excluded due to low potential sample size. The centroid co-ordinates of each residential property were determined by publicly available data (City of Ottawa, 2017). Any potential sites that had missing or incomplete data for any of the predictor variables were excluded from consideration. This left a total of 221 candidate sites of the 928 Ottawa Bird Count sites. Sites that were overlapping at the $250 \mathrm{~m}$ radius extent were eliminated one by one, keeping sites that had the lowest correlation between predictor variables and favouring more evenly distributed sites across the study area. To ensure a relatively low correlation between tree canopy cover and median income, I categorized candidate sites based on whether they were above or below the median value of income or tree canopy cover (e.g., high or low tree cover). A roughly even number of sites of each combination were included (29 high median income-high tree canopy cover, 20 high median income-low tree canopy cover, 24 low median income-high tree canopy cover, and 27 low median income-low tree canopy cover). 
However, a perfectly balanced sample could not be obtained because some combinations are relatively rare (e.g., high income and low canopy cover).

\subsection{Sampling Order}

I determined the order to visit sites using a structured framework to make sure that there was no relationship between season and any of the predictor variables. I did this because seasonality has been shown to affect people's moods (Murray, 2003) and mood can affect subjective well-being (Diener, 2000). To spatially distribute my sampling, I

divided the study area into quadrants (Figure 1). Sampling started in the western quadrant and changed every day moving clockwise. I chose the order of sites by their median income and tree canopy cover values. Each day I sampled two sites in the same category of median income level, switching daily from high median income to low then reversing the pattern each cycle around the quadrants. Each day one high tree canopy cover area site was paired with one low tree canopy cover area until all possible pairs were exhausted. This approach successfully avoided any seasonal pattern in the predictor variables of the sampled sites (Figure A in Appendix).

\subsection{Bird Data}

The bird data I used for this project were provided by the Ottawa Bird Count. This is a breeding season monitoring program for birds that takes place within the city of Ottawa, Canada. Volunteers make bird observations between half an hour before sunrise and 8:00am at designated locations across the city, by taking 10 -minute, $75 \mathrm{~m}$ fixed-radius point counts, during peak breeding season (June 3 to July 7). The bird count locations are randomly distributed across the Ottawa region in publicly accessible locations. I used the 
most recent measure of bird abundance and species richness at each site. This measure includes only birds that were observed using the space in the site, excluding birds flying far overhead. The bird data was collected at the $75 \mathrm{~m}$ radius center of each $250 \mathrm{~m}$ radius survey site (Table A in Appendix).

\subsection{Tree Canopy Cover}

The map of tree canopy cover was provided by the City of Ottawa. It was created using Stereo Compilation of 6-cm aerial photography. The map is updated by the city every 2 to 3 years, most recently November 2015. During the survey period, field assistants updated the tree canopy cover data for each site by comparing the map data to trees present at the site and noting any discrepancies. I updated the map in ArcGIS version 10.5.1 (ESRI, 2018) before analysis. For site selection, I calculated the total amount of tree canopy cover within a $250 \mathrm{~m}$ radius of the centre of each site. For analysis, I calculated the surrounding tree canopy cover within a $250 \mathrm{~m}$ radius for each individual survey, centred around the participant's location (Table A in Appendix).

\subsection{Distance to Water}

In response to questions 4,5 and 6 of the survey, many participants said that being close to the water was one of the key features that they enjoyed about their neighbourhood. To reflect this, I included distance to water as a predictor variable in the models. The map of waterbodies was from the city of Ottawa, last updated April 2018. The map is derived from an Ontario Base Map created using aerial imagery at a scale of 1:10,000. I calculated the Euclidean distance from each participant's location to the nearest major waterbody (Table A in Appendix). 


\subsection{Median Income}

Previous studies have indicated that higher relative income has a positive effect on a person's life satisfaction (Clark et al., 2008). As well, property values tend to increase with greater neighbourhood tree canopy cover (Sanders et al., 2010). Therefore, it is expected that income may be correlated to both life satisfaction and tree canopy cover. I therefore included median income as a variable in my site selection and data analysis to control for this potentially confounding effect.

I used income data from the Canadian National Household Survey (Statistics Canada, 2013) from the Canadian Census of 2011. Median individual yearly income was treated as an indicator of the area's relative wealth. For broad scale site selection, I assigned each site the median income of the Census Tract (area representing a population of approximately 2500 to 8000 ) within which it was located. For analysis, I assigned each participant's location the median income of the Dissemination Area (area representing a population of approximately 400 to 700 ), i.e., the smallest possible Census division (Table A in Appendix).

\subsection{Data Analysis}

The responses to each survey question were analysed with a hierarchical Bayesian, ordered probit mixed model using the software R version 3.4.3 (R Core Team, 2018), and the package MCMCglmm (Hadfield, 2010). Site was treated as a random effect, to control for the non-independence of survey responses within sites, while all other variables were fixed effects. Bird abundance and species richness were highly correlated $(\mathrm{r}=0.736)$, so models for each measure were run separately. I ran two formats 
of models, one that included disposition (from question 1) as a predictor for questions 2-8 and one that did not. A person's disposition is expected to influence their subjective wellbeing (Kozma et al., 2000) and might be a better predictor of a participant's answers than their local environment. Disposition was an ordinal variable, so in the models a series of orthogonal polynomials were fit up to the sixth power $(k-1$, where $k$ was the number of response levels in question 1). This is a conservative approach as it reduces the amount of variation available for the nature predictors (bird abundance/richness, tree canopy cover, and distance to water) to explain.

So the final model for each response, including disposition, was as follows:

$$
\text { Survey }_{i j}=\left(\beta_{0}+\text { Site }_{j}\right)+\beta_{1} \text { Bird }_{i j}+\beta_{2} \text { Tree }_{i j}+\beta_{3} \text { Water }_{i j}+\beta_{4} \text { Income }_{i j}+
$$
$\beta_{5}$ Disposition $1-6 i j+e_{j}$

where Survey is the response of the $i$-th participant of the $j$-th site level to survey a question, Site is the site number, Bird is either bird abundance or species richness, Tree is tree canopy cover within a $250 \mathrm{~m}$ radius in hectares, Water is the Euclidean distance to the nearest waterbody in kilometers, Income is the median income of the dissemination area, and Disposition $1-6$ represent a matrix of the $6^{\text {th }}$-degree, orthogonal polynomial contrasts of a participant's disposition (taken from question 1).

I ran models using vague priors, with residual variance fixed at 1 . I used a burn in of 60,000 , a thinning factor of 30 , and 360,000 total iterations. I tested convergence using a Gelman-Rubin diagnostic, which assesses convergence by comparing multiple Markov chains. The Gelman-Rubin diagnostic compares the estimated within-chain and betweenchains variances for each model parameter, with large differences between these variances indicating nonconvergeance (Gelman \& Rubin, 1992). A total of 4 chains for each model were run and the multivariate potential scale reduction factor was less than 
1.1 (indicating convergence by the Gelman-Rubin diagnostic). The postMCMCglmm R package (Wiley, 2013) was used to predict the probability of each participant answering the most positive option for questions. For each plot, all values were held constant in the model at their mean (median for disposition) except for the predictor of interest (Table B in Appendix).

\section{Results}

\subsection{Overview}

A total of 1035 surveys were collected (886 in-person, 149 from flyers) (Table B in Appendix). The overall response rate was $16.7 \%$ (64.7\% in-person, 3\% from flyer). The responses for every question were skewed, so that most responses were from the more positive options (Figure B in Appendix). There was a moderate correlation between response rate per site and median income $(\mathrm{r}=0.358)$, and there were low correlations between the response rate per site and all other predictors (Table C in Appendix). The site selection procedure resulted in low correlations among all pairs of the predictors (Figure 2), except for bird abundance and species richness $(r=0.736)$ and tree canopy cover and median income $(r=0.363)$. The predictor variables were sampled evenly across the field season (Figure A in Appendix).

\subsection{Models Including Disposition}

The signs of the significant coefficients across all models were consistent with our predictions: positive relationships for bird species richness, trees and median income, and negative relationships for distance to water on participant responses to every question (Table D in Appendix). Bird abundance was not significant in any of the models that also 
included disposition. At least one disposition contrast was significant in models of responses to questions $2-5$, supporting the decision to include disposition as a predictor in the models. The Spearman correlation between the participant's disposition (question 1) and the participant's overall life satisfaction (question 2) was $r=0.574$ (Table 2). The differentiation between disposition (question 1) and overall life satisfaction (question 2) is supported by the models for those questions having different results.

There was no clear evidence in any of the models for a relationship between a participant's overall disposition as the response variable (question 1) and any of the predictor variables (Figure 3). Overall life satisfaction (question 2) was positively related to median income (Figure 4). Neighbourhood satisfaction (question 3) was positively related to bird species richness and median income (Figure 4). Satisfaction with local nature (question 4) was positively related to bird species richness and tree canopy cover (Figure 4). The rating of local nature in comparison to other areas (question 5) increased with tree canopy cover, income, and closeness to water (Figure 5). The importance of nature when choosing a place to live (question 6) increased with tree canopy cover and closeness to water (Figure 5). A participant's relationship and connectivity to nature (questions 7 and question 8 respectively) had no significant predictors (Figure 6).

\subsection{Models Without Disposition}

Comparing the models that included disposition to those that did not, the results were similar for tree canopy cover, distance to water, and median income, but there were some differences for the bird predictors (Figure C in Appendix). Bird abundance became significant for neighbourhood satisfaction (question 3) and satisfaction with local nature (question 4) when disposition was not included in the model. For rating of local nature in 
comparison to other areas (question 5), bird abundance was marginally significant and species richness was not when disposition was not included in the model. Figure $\mathrm{C}$ shows the question 5 predictions for the bird variables for models with and without disposition as a predictor. Bird abundance and species richness had positive relationships to the participant's rating of local nature in comparison to other areas (question 5) in all models. Models without disposition had similar slopes to models with disposition, but slightly larger credible intervals.

\section{Discussion}

The positive association of bird species richness on resident well-being supports the hypothesis that there is a beneficial relationship between humans and nature. Neighbourhood satisfaction (question 3) was related to bird species richness, even before participants were prompted to think about nature (Figure 4). Although this study is correlational and cannot prove that the nature variables measured are the cause of the survey responses, it does indicate a positive association.. Bird species richness has been previously associated to human well-being (Fuller et al., 2007; Dallimer, et al., 2012). Bird song played after people were exposed to a negative stimulus lead to a more positive change in mood in comparison to anthropogenic noises (Benfield et al., 2014). Ratcliffe et al. (2013) conducted semi-structed interviews about stress reduction and attention restoration and found bird song to be commonly cited as positive by participants. The presence of charismatic species, including birds, lead to higher perceived benefit from nature areas (Bryce, 2016).

These results are consistent with the "biophilia hypothesis" (Kellert \& Wilson, 1984) which proposes that humans have an innate subconscious need to affiliate with 
other living things and that nature has a positive effect on human well-being. It is noteworthy that bird species richness was significant before participants learned that this study was about nature because it indicates that this result as that could indicate a subconscious response. It is possible that participants consciously thought about the birds in their neighbourhood when answering the question, but this seems unlikely based on participant feedback. People very rarely mentioned birds at any point during the survey, whereas trees and water were commonly mentioned by people. This is supported by the results from question 6 , where participants were asked about the importance of nature when they chose where to live. Neither bird species richness nor abundance was significant here (Figure 5). This suggests that people are not consciously seeking to live in high bird diversity areas, despite bird diversity having the largest impact on neighbourhood satisfaction.

Bird abundance and species richness were highly correlated in this study (Figure 2). For neighbourhood satisfaction (question 3) and satisfaction with local nature (question 4) species richness appears to be a better predictor than abundance (Table D in Appendix). When disposition was included in the models for the participant's rating of local nature in comparison to other areas (question 5) neither bird abundance nor species richness were significant. If disposition was excluded, then abundance became a marginally significant predictor of question 5 (Figure $\mathrm{C}$ in Appendix). This suggests that abundance might be better predictor for a participant's rating of local nature in comparison to other areas (question 5) than species richness. However, the significance of abundance is unclear as it relies on the removal of disposition (a significant predictor in the model). Studies frequently only use one indicator - either species abundance or 
species richness - making it difficult to determine which is the root cause (Fuller et al., 2007; Dallimer, et al., 2015; Marselle et al., 2015; Bryce 2016). A study by Wolf et al. (2017) addressed this by showing participants videos of birds and trees controlling for abundance and found that species richness positively affected mental well-being.

Tree canopy cover was positively related to satisfaction with local nature (question 4) and both tree canopy cover and distance to water were related to a participant's rating of local nature in comparison to other areas (question 5) and the importance of nature in choosing where to live (question 6) (Figures 4-5). These findings support the aesthetic preferences for vegetation and water as described by the biophilia hypothesis (Ulrich et al., 1993). Higher tree cover is preferred in residential neighbourhoods (Jiang, 2015). Spending time in treed areas has been found to improve happiness (Mackerron \& Mouroto, 2013). Similarly, coastal studies find that being near to waterbodies is perceived as beneficial by residents (Bryce, 2016). Viewing landscapes with water is associated with greater positive affect and higher perceived restorativeness (White et al., 2010). Based on the comments made by participants about their appreciation for trees and water in their neighbourhoods, it is unsurprising that participants considered trees and water to be important when rating local nature in comparison to other areas (question 5) and choosing where to live (question 6). Trees and water might be stronger predictors for these questions than the bird variables because they are larger features making them more apparent to people when making conscious comparisons.

Considering that people explicitly said trees and water mattered to them in their comments, it was unexpected that neither of these predictors was significant for 
neighbourhood satisfaction (question 3). The significant predictors of neighbourhood satisfaction were disposition, median income, and bird species richness (Figure 3). This difference between the answers to question 3, where people had not yet been prompted to think about their appreciation of or affiliation to nature, and their responses to questions 5 and 6 where they had, suggests that people may overestimate the effects of trees and water on their satisfaction relative to the other components of nature such as bird abundance or richness.

This study found no significant predictors of nature relatedness (questions 7 and 8). However, almost all responses to these questions were very positive. The majority of participants indicating that a relationship with nature was important to them (question 7) and that they had a strong connection to nature (question 8) (Figure 6). For questions 7 and $8,56.7 \%$ and $48.0 \%$ of people answered the most positive option "Strongly agree" respectively (Figure B in Appendix). The low level of variation in the data means that any effects of the predictors are difficult to detect. The low variation of participant responses to questions 7 and 8 may have been caused by the survey scale not being adequate to capture the full variation of the participant responses. If the survey scale had been extended to include even more positive options, then the participant responses may not have been condensed. Additionally, participants may have altered their behaviour to fit with their growing interpretation of the research goal, as they progressed through the questions (Orne, 1962). As the nature relatedness questions (questions 7 and 8) were the last items on the survey, by the time a participant got to these questions they may have thought that answering positively about nature was the expected result, which would bias the responses. As well, participants are prone to being agreeable to questions, which 
could explain why the data are skewed so positively (Johns, 2010). Even though the results for the two nature relatedness questions were not significantly related to local nature, they do indicate that residents in Ottawa view their relationship and connection with nature to be very important.

Another explanation why there were no significant effects of predictors on peoples' relationship and connection to nature (questions 7 and 8 ) is that the local nature around one's home may not be a strong predictor of nature relatedness. People who are highly connected to nature may be willing to live in lower nature areas, as long as they can travel to spend time in more natural settings. Ottawa has many large parks and waterfront areas nearby that would be considered high amenity and they might be having a stronger effect on the nature relatedness of residents than the nature directly surrounding residences. Participants also mentioned hiking, camping, and other nature recreation activities not associated with their homes. These activities would be connected to nature relatedness but would not be captured by measuring local nature around their homes.

The study had some demographic limitations that may reduce our ability to generalize from the results. Demographic measures such as age and gender were not included in the models. Some studies have found that different demographics show different relationships between well-being and nature (Luck et al., 2011). However, a meta-analysis of nature relatedness found age and gender to not be significant moderators of happiness (Capaldi et al., 2014). A second limitation is that the vast majority of participants in my study were people who were home during the day (except for people who responded to the flyer, $14.4 \%$ ). This would include people who were: stay-at-home 
parents, working from home, shift work employees, unemployed, or retired. This bias towards people at home during the day should be similar across all sites as the sampling times were kept consistent. Nonetheless, people who spend more time at home might have a different relationship to their local nature, meaning the results might be less applicable to the average day shift working population. Nature relatedness has been found to be correlated with time spent in nature (Nisbet \& Zelenski, 2013). People home during the day may spend more time in their neighbourhood strengthening their relationship and connection to their local nature. As well, most participants lived in detached or semi-detached housing as many apartment buildings had security preventing in-person surveying or flyers from being left. Those who live in apartment buildings may have less access to nature as they do not have a private yard. This could result in less time spent in nature potentially affecting their nature relatedness. Finally, this study and the majority of research on this topic are based in North America and Europe (Mutsuoko \& Kaplan, 2008), which may limit the applicability of the results to other parts of the world. For example, a study from Singapore did not find that access to greenspace affected wellbeing (Saw et al., 2015). They theorized that because the total amount of nature and biodiversity was much higher across the region in Singapore than in temperate regions the negative effects of being isolated from nature may not be as pronounced.

The results from this study indicate that maintaining nature in the city is beneficial to resident satisfaction. Interestingly, although participants frequently mentioned trees and water being key features of their neighbourhoods and rarely mentioned birds, the nature measure that best predicted neighbourhood satisfaction (questions 3) was bird species richness. This suggests that conserving bird diversity could 
be an important priority for urban planners. As well, many participants indicated that they strongly considered the quality of the environment when choosing where to live, and responses to this question were significantly related to tree canopy cover. City regulations should therefore discourage the removal of trees and encourage planting them, irrespective of the location, rather than focusing greenspace attention exclusively on parks. Real estate developers should consider that residential trees and street areas do attract buyers. Lastly, most participants indicated that their relationship and connection to nature were important to them. City governments should take into account that residents feel strongly about nature and make conserving urban biodiversity and the natural environment a priority. 


\section{References}

Benfield, J. A., Taff, B. D., Newman, P., \& Smyth, J. (2014). Natural sound facilitates mood recovery. Ecopsychology, 6(3), 183-188.

Berman, M. G., Jonides, J., \& Kaplan, S. (2008). The cognitive benefits of interacting with nature. Psychological science, 19(12), 1207-1212.

Bryce, R., Irvine, K. N., Church, A., Fish, R., Ranger, S., \& Kenter, J. O. (2016). Subjective well-being indicators for large-scale assessment of cultural ecosystem services. Ecosystem Services, 21, 258-269.

Capaldi, C. A., Dopko, R. L., \& Zelenski, J. M. (2014). The relationship between nature connectedness and happiness: a meta-analysis. Frontiers in psychology, 5, 976.

Carrus, G., Scopelliti, M., Lafortezza, R., Colangelo, G., Ferrini, F., Salbitano, F., ... \& Sanesi, G. (2015). Go greener, feel better? The positive effects of biodiversity on the well-being of individuals visiting urban and peri-urban green areas. Landscape and Urban Planning, 134, 221-228.

City of Ottawa. (2015). Tree Canopy Cover. GIS polygon shapefile. Ottawa, Canada. City of Ottawa. (2018). Major Waterbodies. GIS polygon shapefile. Ottawa, Canada.

Clark, A.E., Frijters, P., \& Shields, M. A. (2008). Relative income, happiness, and utility: An explanation for the Easterlin paradox and other puzzles. Journal of Economic literature, 46(1), 95-144.

Dallimer, M., Irvine, K. N., Skinner, A. M., Davies, Z. G., Rouquette, J. R., Maltby, L. L., ... \& Gaston, K. J. (2012). Biodiversity and the feel-good factor: understanding associations between self-reported human well-being and species richness. BioScience, 62(1), 47-55.

De Vries, S., Verheij, R. A., Groenewegen, P. P., \& Spreeuwenberg, P. (2003). Natural environments - healthy environments? An exploratory analysis of the relationship between greenspace and health. Environment and planning A, 35(10), 1717-1731.

Diener, E. D., Emmons, R. A., Larsen, R. J., \& Griffin, S. (1985). The satisfaction with life scale. Journal of personality assessment, 49(1), 71-75.

Diener, E. (2000). Subjective well-being: The science of happiness and a proposal for a national index. American psychologist, 55(1), 34.

ESRI. 2018. 10.5.1. Environmental Systems Research Institute, Redlands, California. 
Fuller, R. A., Irvine, K. N., Devine-Wright, P., Warren, P. H., \& Gaston, K. J. (2007). Psychological benefits of greenspace increase with biodiversity. Biology letters, 3(4), 390-394.

Gelman, A., \& Rubin, D. B. (1992). Inference from iterative simulation using multiple sequences. Statistical science, 7(4), 457-472.

Hadfield, J.D. (2010). MCMC Methods for Multi-Response Generalized Linear Mixed Models: The MCMCglmm R Package. Journal of Statistical Software, 33(2), 1-22.

Inglehart, R., C. Haerpfer, A. Moreno, C. Welzel, K. Kizilova, J. Diez-Medrano, M. Lagos, P. Norris, E. Ponarin \& B. Puranen et al. (eds.). 2014. World Values Survey: Round Six - Country-Pooled Datafile Version: www.worldvaluessurvey.org/WVSDocumentationWV6.jsp. Madrid: JD Systems Institute.

Jiang, B., Larsen, L., Deal, B., \& Sullivan, W. C. (2015). A dose-response curve describing the relationship between tree cover density and landscape preference. Landscape and Urban Planning, 139, 16-25.

Johns, R. (2010). Likert items and scales. Survey Question Bank: Methods Fact Sheet, 1, $1-11$.

Kardan, O., Gozdyra, P., Misic, B., Moola, F., Palmer, L. J., Paus, T., \& Berman, M. G. (2015). Neighborhood greenspace and health in a large urban center. Scientific reports, 5, 11610.

Kellert, S. R., \& Wilson, E. O. (Eds.). (1995). The biophilia hypothesis. Island Press.

Kozma, A., Stone, S., \& Stones, M. J. (2000). Stability in components and predictors of subjective well-being (SWB): Implications for SWB structure. In Advances in quality of life theory and research (pp. 13-30). Springer, Dordrecht.

Luck, G. W., Davidson, P., Boxall, D., \& Smallbone, L. (2011). Relations between urban bird and plant communities and human well-being and connection to nature.

Conservation Biology, 25(4), 816-826.

Lyubomirsky, S., \& Lepper, H. S. (1999). A measure of subjective happiness:

Preliminary reliability and construct validation. Social indicators research, 46(2), 137155.

MacKerron, G., \& Mourato, S. (2013). Happiness is greater in natural environments. Global Environmental Change, 23(5), 992-1000.

McKinney, M. L. (2008). Effects of urbanization on species richness: a review of plants and animals. Urban ecosystems, 11(2), 161-176. 
Murray, G. (2003). The Seasonal Pattern Assessment Questionnaire as a measure of mood seasonality: a prospective validation study. Psychiatry Research, 120(1), 53-59.

Matsuoka, R. H., \& Kaplan, R. (2008). People needs in the urban landscape: analysis of landscape and urban planning contributions. Landscape and urban planning, 84(1), 7-19.

Nisbet, E. K., Zelenski, J. M., \& Murphy, S. A. (2009). The nature relatedness scale: Linking individuals' connection with nature to environmental concern and behavior. Environment and Behavior, 41(5), 715-740.

Nisbet, E. K., Zelenski, J. M., \& Murphy, S. A. (2011). Happiness is in our nature: Exploring nature relatedness as a contributor to subjective well-being. Journal of Happiness Studies, 12(2), 303-322.

Nisbet, E. K., \& Zelenski, J. M. (2013). The NR-6: a new brief measure of nature relatedness. Frontiers in psychology, 4, 813.

Orne, M. T. (1962). On the social psychology of the psychological experiment: With particular reference to demand characteristics and their implications. American psychologist, 17(11), 776.

Panchen, Z. A., Primack, R. B., Gallinat, A. S., Nordt, B., Stevens, A. D., Du, Y., \& Fahey, R. (2015). Substantial variation in leaf senescence times among 1360 temperate woody plant species: implications for phenology and ecosystem processes. Annals of botany, mev015.

Panchen, Z. A., Primack, R. B., Nordt, B., Ellwood, E. R., Stevens, A. D., Renner, S. S., ... \& Davis, C. C. (2014). Leaf out times of temperate woody plants are related to phylogeny, deciduousness, growth habit and wood anatomy. New Phytologist, 203(4), 1208-1219.

Park, B. J., Furuya, K., Kasetani, T., Takayama, N., Kagawa, T., \& Miyazaki, Y. (2011). Relationship between psychological responses and physical environments in forest settings. Landscape and Urban Planning, 102(1), 24-32.

Qualtrics. 2017. www.qualtrics.com, Provo, United States.

R Core Team. 2018. R: A language and environment for statistical computing. $R$ Foundation for Statistical Computing, Vienna, Austria.

Ratcliffe, E., Gatersleben, B., \& Sowden, P. T. (2013). Bird sounds and their contributions to perceived attention restoration and stress recovery. Journal of Environmental Psychology, 36, 221-228.

Sander, H., Polasky, S., \& Haight, R. G. (2010). The value of urban tree cover: A hedonic property price model in Ramsey and Dakota Counties, Minnesota, USA. Ecological Economics, 69(8), 1646-1656. 
Sandifer, P. A., Sutton-Grier, A. E., \& Ward, B. P. (2015). Exploring connections among nature, biodiversity, ecosystem services, and human health and well-being: Opportunities to enhance health and biodiversity conservation. Ecosystem Services, 12, 1-15

Saw, L. E., Lim, F. K., \& Carrasco, L. R. (2015). The relationship between natural park usage and happiness does not hold in a tropical city-state. PloS one, 10(7), e0133781.

Statistics Canada. 2013. Ottawa - Gatineau, CMA, Ontario (Code 505) (table). National Household Survey (NHS) Profile. 2011 National Household Survey. Statistics Canada Catalogue no. 99-004-XWE. Ottawa. Released September 11, 2013. http://www12.statcan.gc.ca/nhs-enm/2011/dp-pd/prof/index.cfm?Lang=E (accessed November 20, 2016).

Ulrich, R. S. (1993). Biophilia, biophobia, and natural landscapes. The biophilia hypothesis, 7, 73-137.

United Nations. (2018). World Urbanization Prospects: The 2018 Revision. Available from: https://esa.un.org/unpd/wup/Publications/Files/WUP2018-KeyFacts.pdf.

White, M., Smith, A., Humphryes, K., Pahl, S., Snelling, D., \& Depledge, M. (2010). Blue space: The importance of water for preference, affect, and restorativeness ratings of natural and built scenes. Journal of Environmental Psychology, 30(4), 482-493.

Wiley, J. (2013). postMCMCglmm: Average marginal predicted probabilities from Bayesian ordered probit models. R package version 0.1-2.

Wolf, L. J., zu Ermgassen, S., Balmford, A., White, M., \& Weinstein, N. (2017). Is variety the spice of life? An experimental investigation into the effects of species richness on self-reported mental well-being. PloS one, 12(1), e0170225. 
Tables

Table 1: List of 8 survey questions and possible responses. Participants were residents in Ottawa who lived within $250 \mathrm{~m}$ of a pre-existing bird point count location of the Ottawa Bird Count (OBC). Participants were recruited door-to-door and through

flyers during summer 2017.

\begin{tabular}{|c|c|c|c|c|c|c|c|c|}
\hline & Question & \multicolumn{7}{|c|}{ Possible Responses } \\
\hline Q1 & $\begin{array}{l}\text { How would you best describe } \\
\text { your disposition? }\end{array}$ & $\begin{array}{l}\text { Extremely } \\
\text { happy }\end{array}$ & $\begin{array}{l}\text { Moderately } \\
\text { happy }\end{array}$ & $\begin{array}{l}\text { Slightly } \\
\text { happy }\end{array}$ & $\begin{array}{l}\text { Neither } \\
\text { happy nor } \\
\text { unhappy }\end{array}$ & $\begin{array}{l}\text { Slightly } \\
\text { unhappy }\end{array}$ & $\begin{array}{l}\text { Moderately } \\
\text { unhappy }\end{array}$ & $\begin{array}{l}\text { Extremely } \\
\text { unhappy }\end{array}$ \\
\hline Q2 & $\begin{array}{l}\text { How would you best describe } \\
\text { your satisfaction with your life as } \\
\text { a whole? }\end{array}$ & $\begin{array}{l}\text { Extremely } \\
\text { satisfied }\end{array}$ & $\begin{array}{l}\text { Moderately } \\
\text { satisfied }\end{array}$ & $\begin{array}{l}\text { Slightly } \\
\text { satisfied }\end{array}$ & $\begin{array}{l}\text { Neither } \\
\text { satisfied } \\
\text { nor } \\
\text { unsatisfied }\end{array}$ & $\begin{array}{l}\text { Slightly } \\
\text { unsatisfied }\end{array}$ & $\begin{array}{l}\text { Moderately } \\
\text { unsatisfied }\end{array}$ & $\begin{array}{l}\text { Extremely } \\
\text { unsatisfied }\end{array}$ \\
\hline Q3 & $\begin{array}{l}\text { How would you best describe } \\
\text { your satisfaction with your } \\
\text { neighbourhood (i.e. the } \\
\text { immediate area surrounding your } \\
\text { residence, usually within a few } \\
\text { hundred metres)? }\end{array}$ & $\begin{array}{l}\text { Extremely } \\
\text { satisfied }\end{array}$ & $\begin{array}{l}\text { Moderately } \\
\text { satisfied }\end{array}$ & $\begin{array}{l}\text { Slightly } \\
\text { satisfied }\end{array}$ & $\begin{array}{l}\text { Neither } \\
\text { satisfied } \\
\text { nor } \\
\text { unsatisfied }\end{array}$ & $\begin{array}{l}\text { Slightly } \\
\text { unsatisfied }\end{array}$ & $\begin{array}{l}\text { Moderately } \\
\text { unsatisfied }\end{array}$ & $\begin{array}{l}\text { Extremely } \\
\text { unsatisfied }\end{array}$ \\
\hline $\mathrm{Q} 4$ & $\begin{array}{l}\text { How would you best describe } \\
\text { your satisfaction with the natural } \\
\text { environment in your } \\
\text { neighbourhood? }\end{array}$ & $\begin{array}{l}\text { Extremely } \\
\text { satisfied }\end{array}$ & $\begin{array}{l}\text { Moderately } \\
\text { satisfied }\end{array}$ & $\begin{array}{l}\text { Slightly } \\
\text { satisfied }\end{array}$ & $\begin{array}{c}\text { Neither } \\
\text { satisfied } \\
\text { nor } \\
\text { unsatisfied }\end{array}$ & $\begin{array}{l}\text { Slightly } \\
\text { unsatisfied }\end{array}$ & $\begin{array}{l}\text { Moderately } \\
\text { unsatisfied }\end{array}$ & $\begin{array}{l}\text { Extremely } \\
\text { unsatisfied }\end{array}$ \\
\hline Q5 & $\begin{array}{l}\text { How would you rate the quality } \\
\text { of your neighbourhood's natural } \\
\text { environment compared to other } \\
\text { areas in Ottawa? }\end{array}$ & $\begin{array}{l}\text { Far above } \\
\text { average }\end{array}$ & $\begin{array}{l}\text { Moderately } \\
\text { above } \\
\text { average }\end{array}$ & $\begin{array}{l}\text { Slightly } \\
\text { above } \\
\text { average }\end{array}$ & Average & $\begin{array}{l}\text { Slightly } \\
\text { below } \\
\text { average }\end{array}$ & $\begin{array}{l}\text { Moderately } \\
\text { below } \\
\text { average }\end{array}$ & $\begin{array}{l}\text { Far below } \\
\text { average }\end{array}$ \\
\hline
\end{tabular}




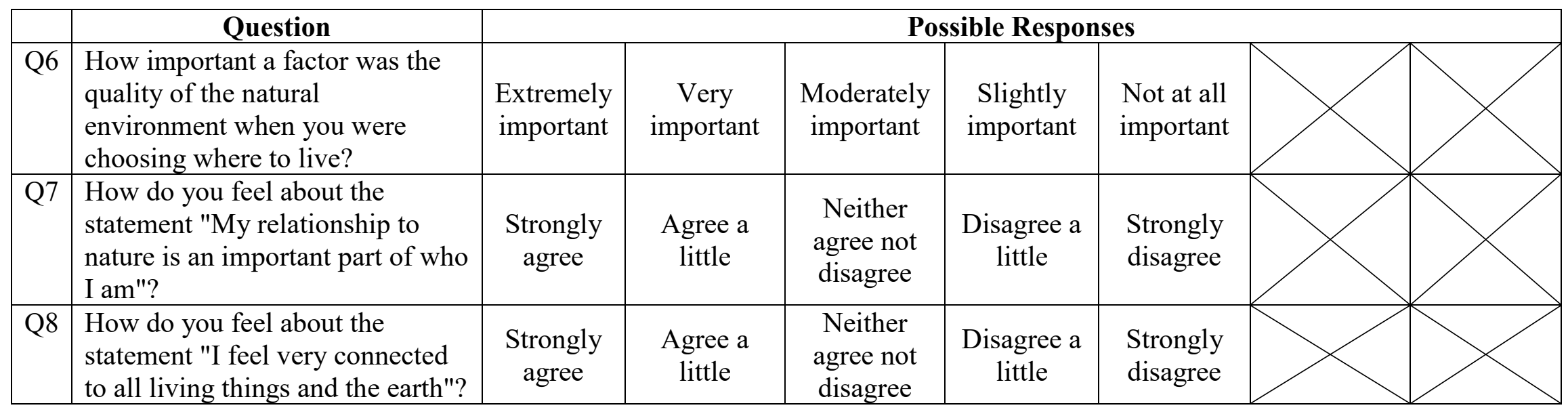


Table 2: Spearman correlation values between the participant responses to each question. There were a total of 1035 participants who were residents in Ottawa who were recruited door-to-door and through flyers during summer 2017. Full questions and possible responses in Table 1.

\begin{tabular}{|l|c|c|c|c|c|c|c|c|}
\hline & $\begin{array}{c}\text { Disposition } \\
(\mathbf{Q 1})\end{array}$ & $\begin{array}{c}\text { Overall } \\
\text { Satisfaction } \\
(\mathbf{Q 2})\end{array}$ & $\begin{array}{c}\text { Neighbourhood } \\
\text { Satisfaction } \\
\mathbf{( Q 3 )}\end{array}$ & $\begin{array}{c}\text { Nature } \\
\text { Satisfaction } \\
\mathbf{( Q 4 )}\end{array}$ & $\begin{array}{c}\text { Nature } \\
\text { Comparison } \\
\mathbf{( Q 5 )}\end{array}$ & $\begin{array}{c}\text { Nature } \\
\text { Importance } \\
\mathbf{( Q 6 )}\end{array}$ & $\begin{array}{c}\text { Nature } \\
\text { Relationship } \\
\text { (Q7) }\end{array}$ & $\begin{array}{c}\text { Nature } \\
\text { Connectivity } \\
\mathbf{( Q 8 )}\end{array}$ \\
\hline Q1 & 1 & 0.574 & 0.288 & 0.219 & 0.185 & 0.084 & 0.130 & 0.143 \\
\hline Q2 & 0.574 & 1 & 0.250 & 0.173 & 0.177 & 0.050 & 0.116 & 0.117 \\
\hline Q3 & 0.288 & 0.250 & 1 & 0.453 & 0.334 & 0.117 & 0.085 & 0.100 \\
\hline Q4 & 0.219 & 0.173 & 0.453 & 1 & 0.517 & 0.245 & 0.137 & 0.142 \\
\hline Q5 & 0.185 & 0.177 & 0.334 & 0.517 & 1 & 0.392 & 0.230 & 0.185 \\
\hline Q6 & 0.084 & 0.050 & 0.117 & 0.245 & 0.392 & 1 & 0.386 & 0.266 \\
\hline Q7 & 0.130 & 0.116 & 0.085 & 0.137 & 0.230 & 0.386 & 1 \\
\hline Q8 & 0.143 & 0.117 & 0.100 & 0.142 & 0.185 & 0.266 & 0.591 & 0.591 \\
\hline
\end{tabular}


Figures

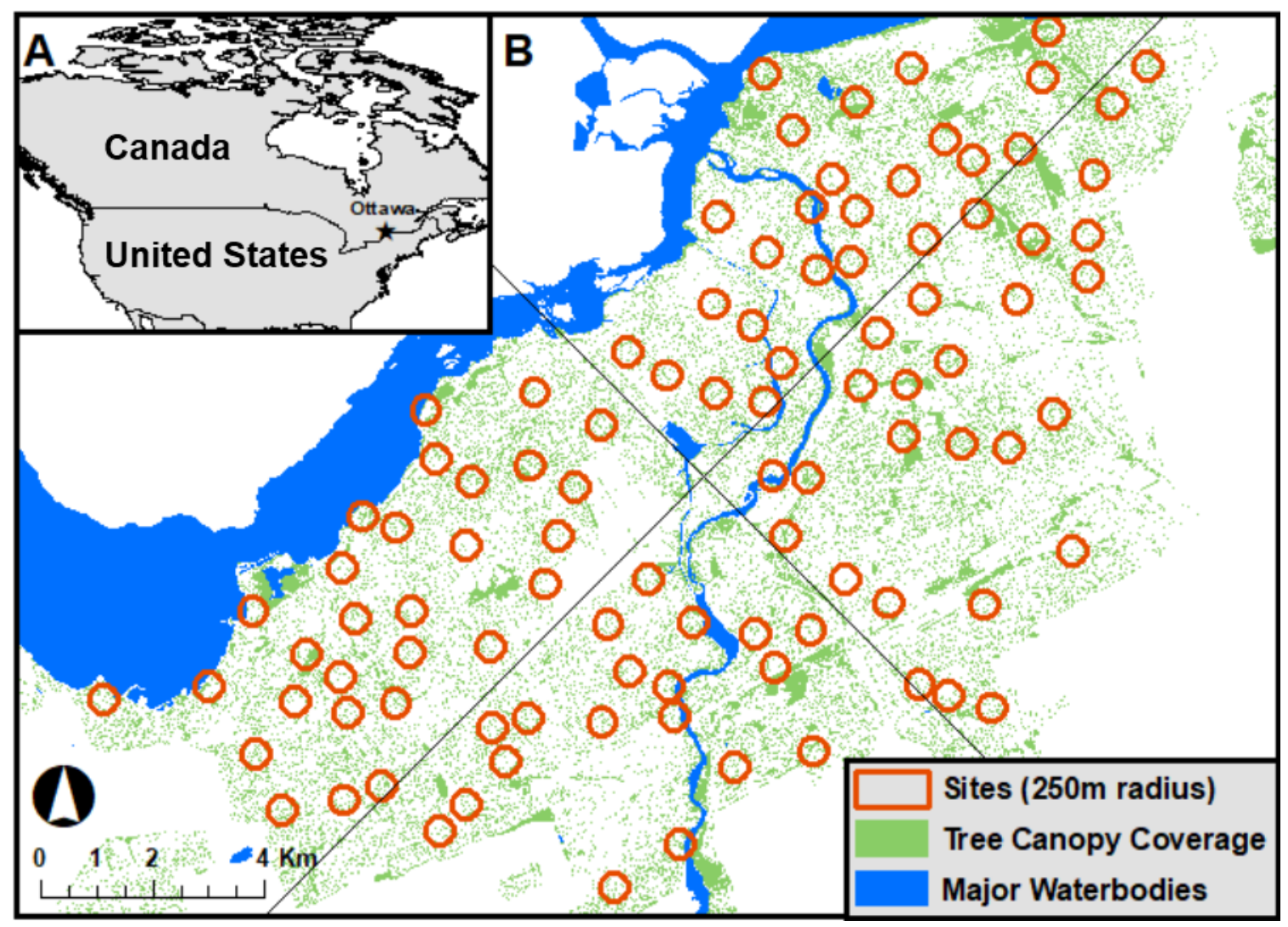

Figure 1: Location of the study region in Ottawa, Canada (A), showing the distribution of 100 study sites across residential Ottawa (B). Sites were centered on pre-existing bird point count locations from the Ottawa Bird Count (OBC) and had a $250 \mathrm{~m}$ radius. Tree canopy cover and water data were provided by the city of Ottawa. Within the sites residents were surveyed door-to-door about their life satisfaction and thoughts about their local environment. The study area was divided into quadrants (straight lines) for sampling. Each day two sites in the same quadrant were visited, with the surveyed quadrant changing every day in a clockwise pattern. 

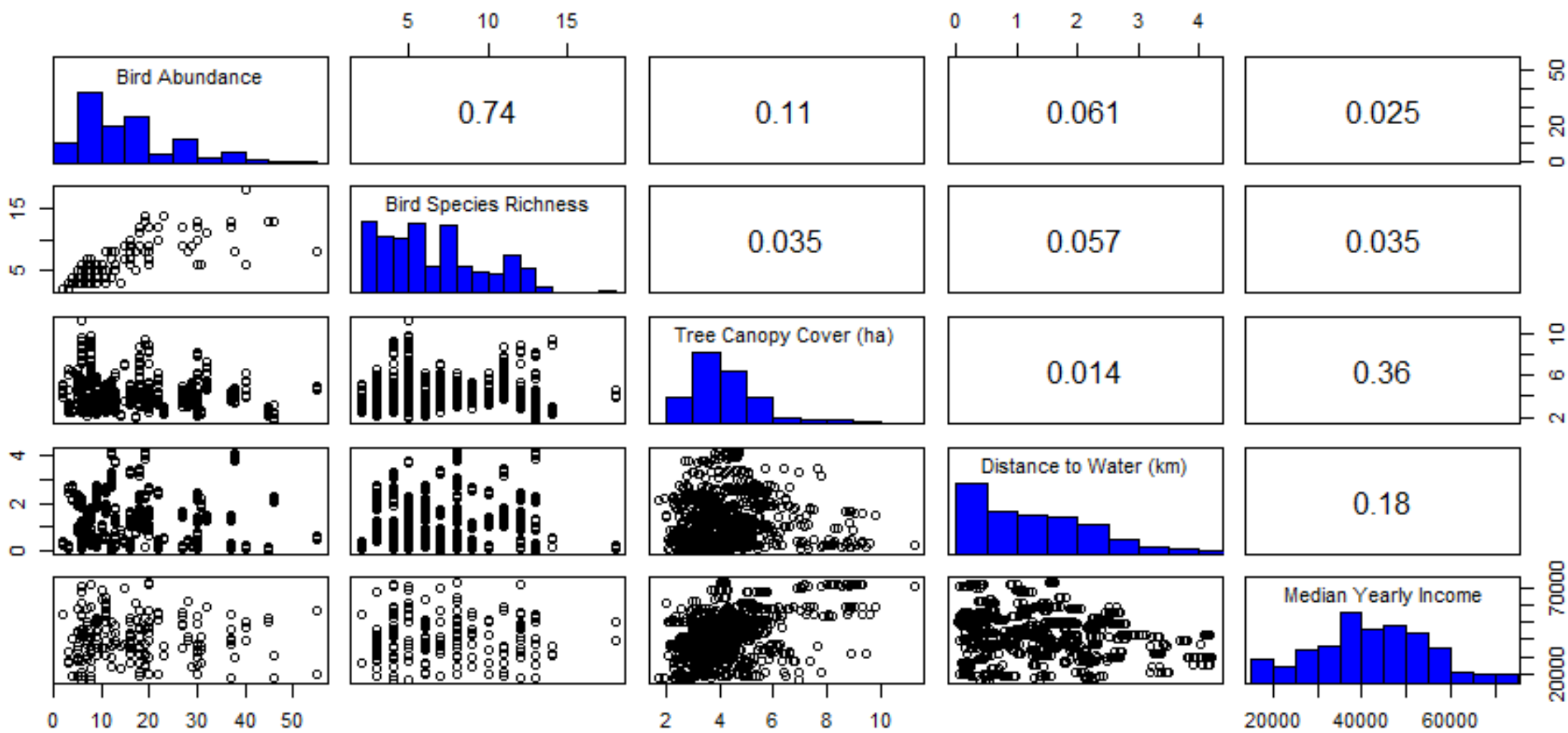

Figure 2: Histograms of predictor measurements for the 1035 door-to-door surveys, with bivariate plots and Pearson correlation values for all pairs of covariates. Variables include bird abundance and species richness (number of bird species) measured at the nearest Ottawa Bird Count (OBC) site to each participant, tree canopy cover in hectares within 250m radius of the participant, Euclidean distance in kilometers between the participant and the nearest body of water, and median individual yearly income in the Canadian Census dissemination area of the participant. 


\section{Q1: Disposition}
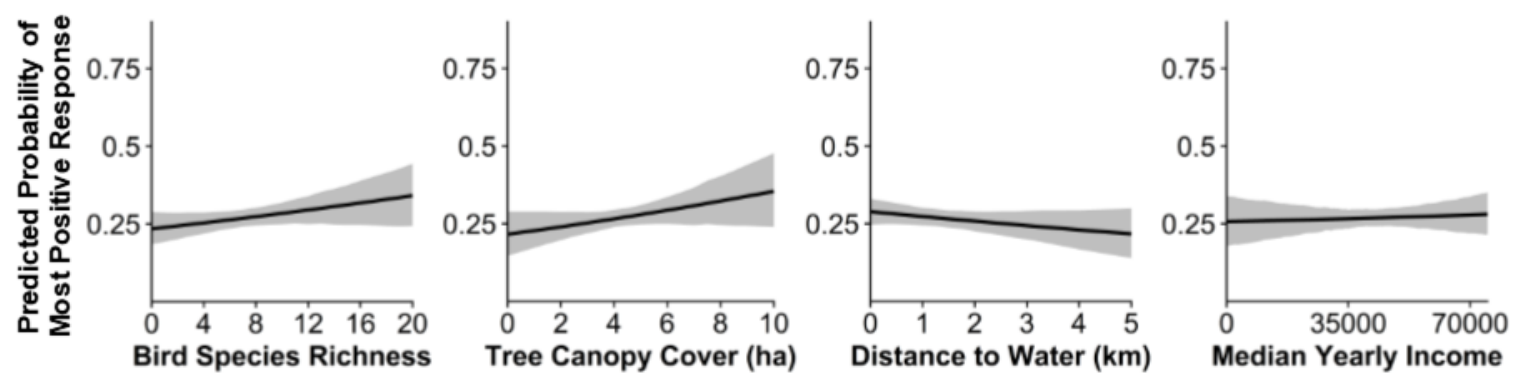

Figure 3: The independent effects of each of four predictor variables, after controlling for the effects of all other variables, on the probability $(+/-95 \%$ credible intervals) of a participant answering the most positive option ("Extremely happy") in response to question 1 ("How would you best describe your disposition?"). The predictor variables in the model include bird species richness, tree canopy cover, distance to water, and median income. Each plot shows the effect of one predictor, while all other predictors are held constant at their means. Effects are plotted in blue if the $95 \%$ credible intervals around their coefficient estimates do not overlap 0. 
Q2: Overall Satisfaction
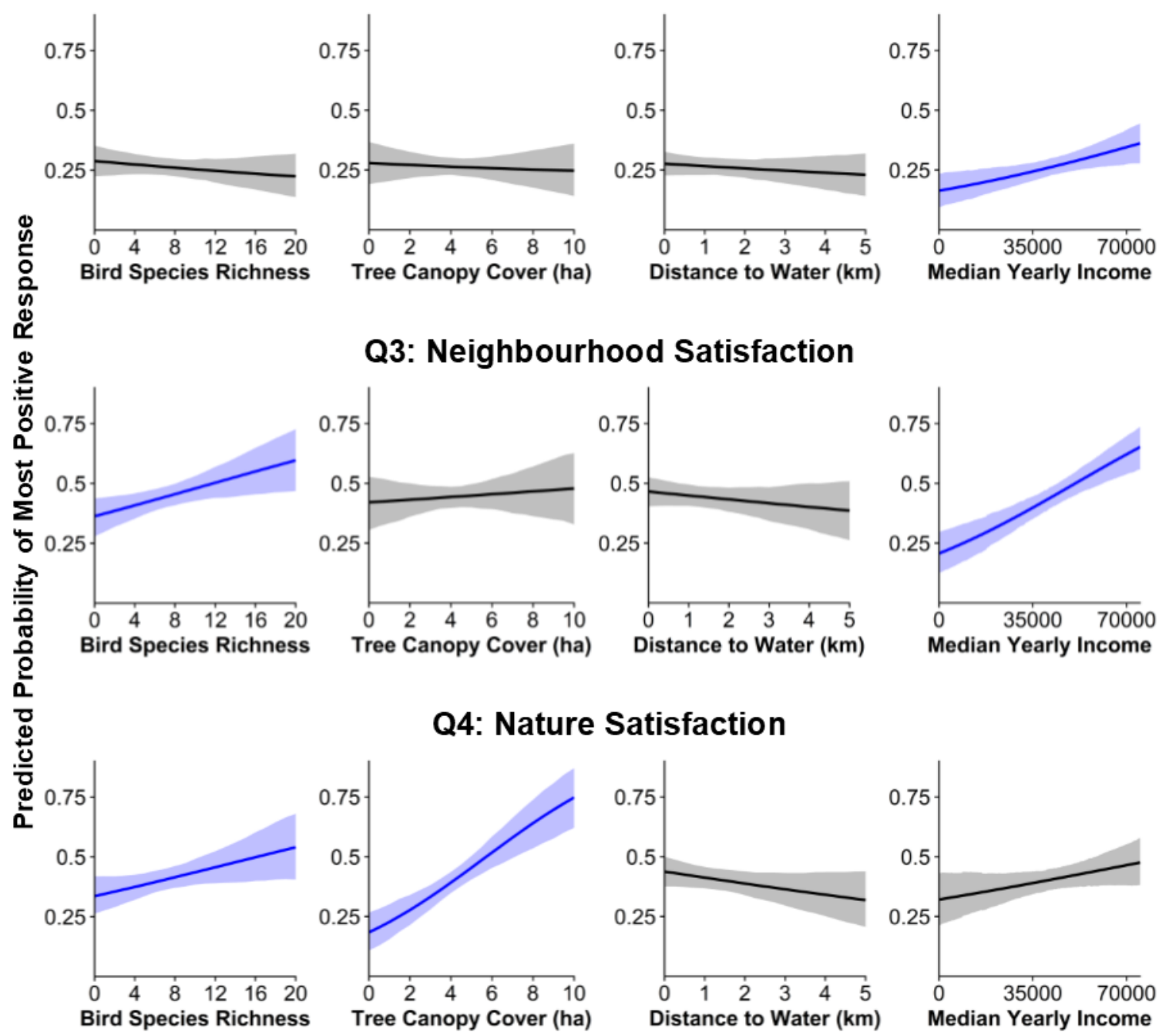

\section{Q3: Neighbourhood Satisfaction}
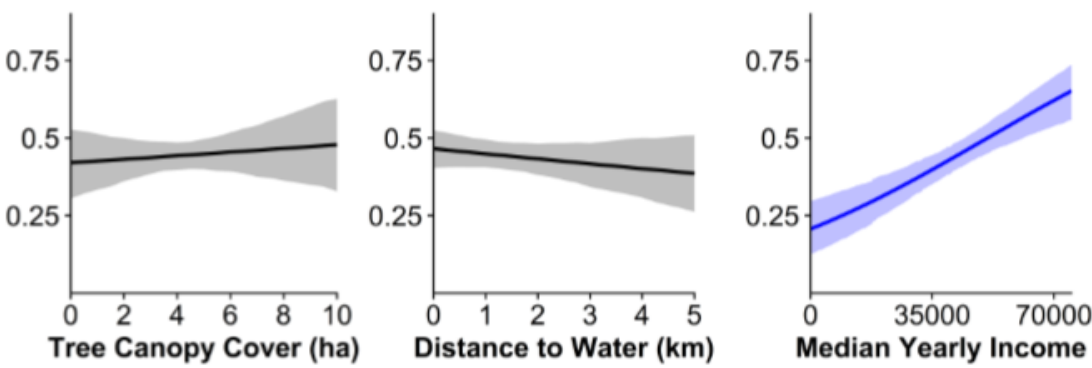

Q4: Nature Satisfaction
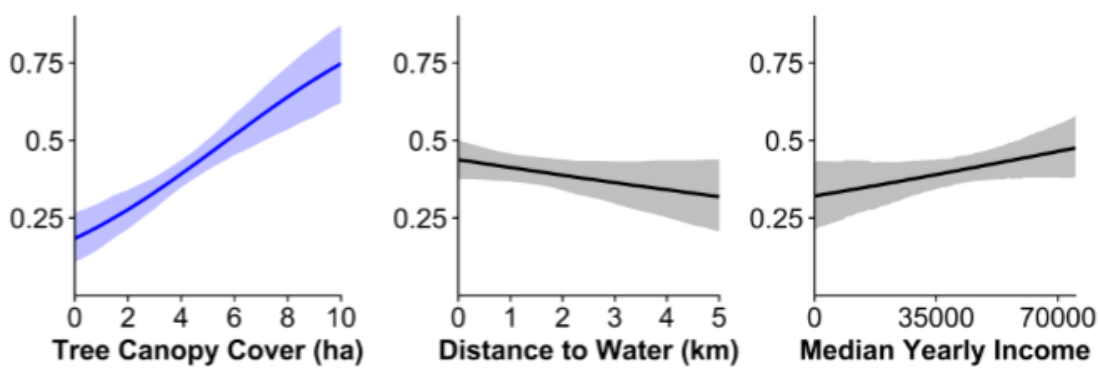

Figure 4: The independent effects of each of four predictor variables, after controlling for the effects of all other variables, on the probability $(+/-95 \%$ credible intervals) of a participant answering the most positive option ("Extremely satisfied") to question 2 ("How would you best describe your satisfaction with your life as a whole?"), question 3 (“How would you best describe your satisfaction with your neighbourhood (i.e. the immediate area surrounding your residence, usually within a few hundred metres)?"), and question 4 (“How would you best describe your satisfaction with the natural environment in your neighbourhood?"). The predictor variables in the model include bird species richness, tree canopy cover, 
distance to water, median income, and disposition (taken from question 1). Each plot shows the effect of one predictor, while all other predictors are held constant at their means (median for disposition). Effects are plotted in blue if the $95 \%$ credible intervals around their coefficient estimates do not overlap 0. 

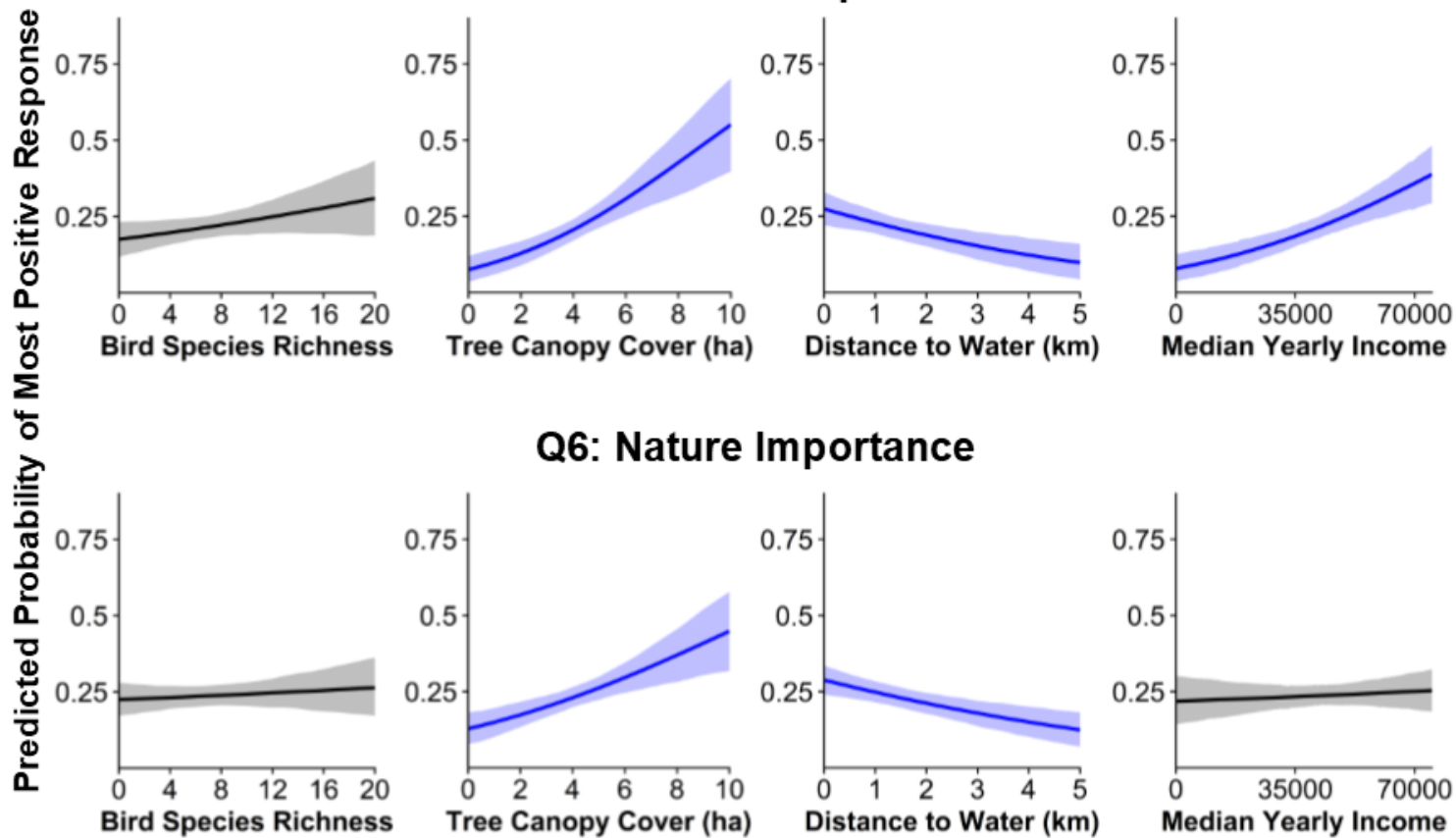

Q6: Nature Importance
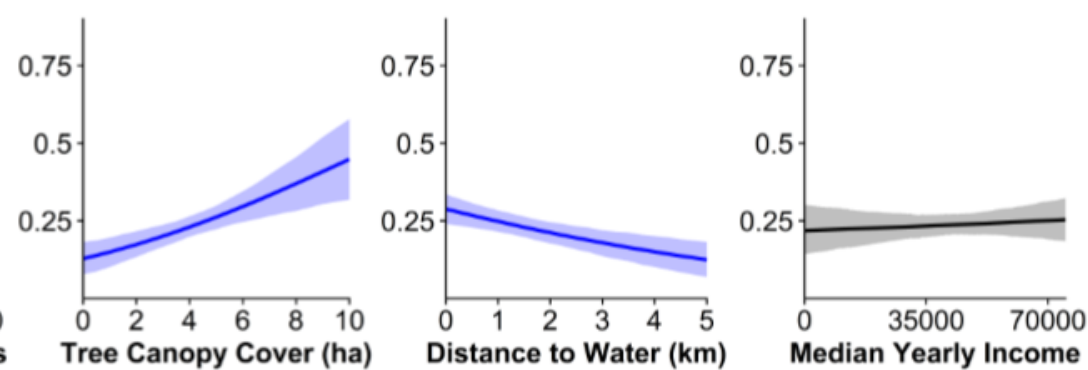

Figure 5: The independent effects of each of four predictor variables, after controlling for the effects of all other variables, on the probability $(+/-95 \%$ credible intervals) of a participant answering the most positive option ("Far above average" or "Extremely important") for question 5 ("How would you rate the quality of your neighbourhood's natural environment compared to other areas in Ottawa?") and question 6 ("How important a factor was the quality of the natural environment when you were choosing where to live?"). The predictor variables in the model include bird species richness, tree canopy cover, distance to water, median income, and disposition (taken from question 1). Each plot shows the effect of one predictor, while all other predictors are held constant at their means (median for disposition). Effects are plotted in blue if the $\mathbf{9 5 \%}$ credible intervals around their coefficient estimates do not overlap 0. 

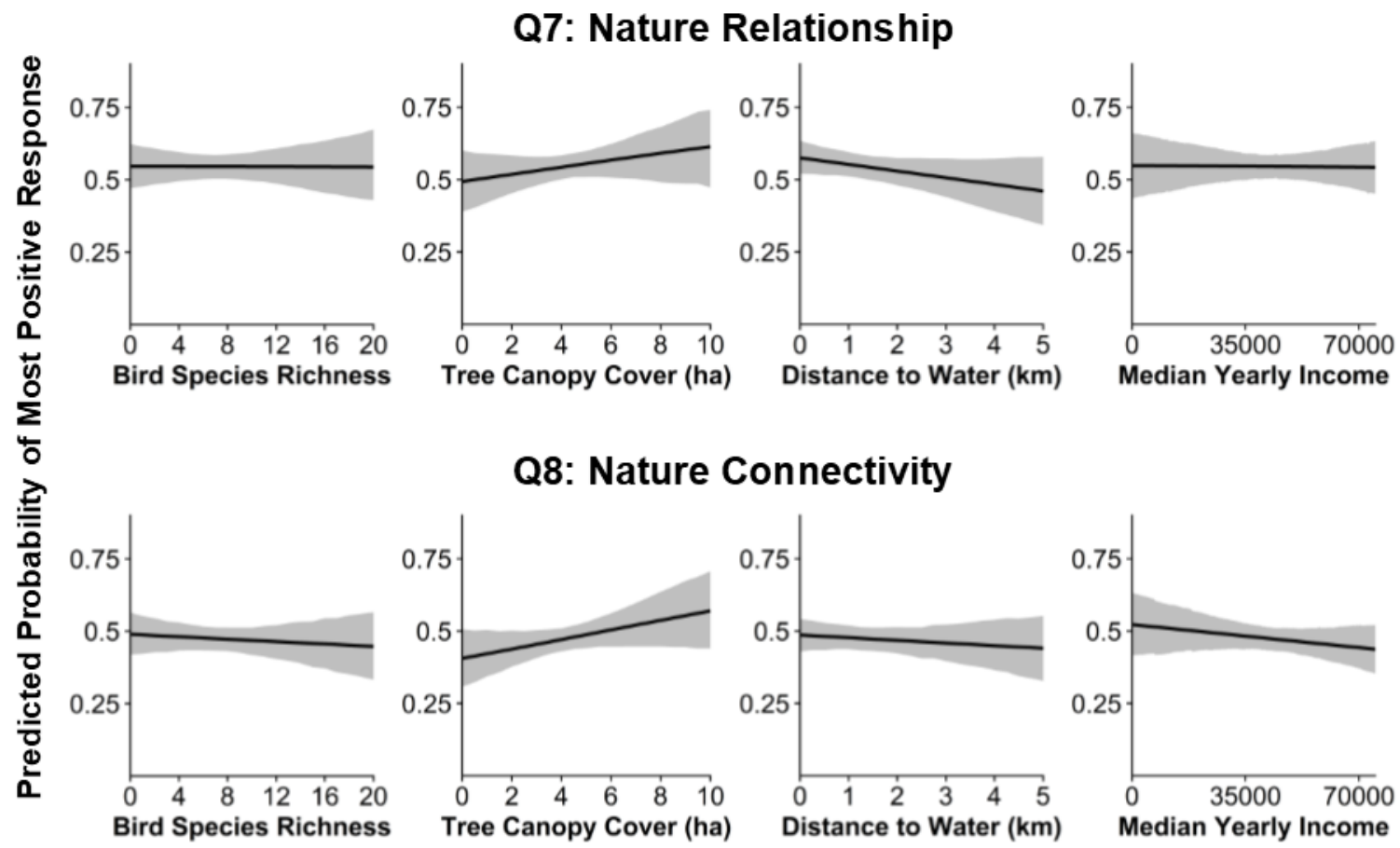

\section{Q8: Nature Connectivity}
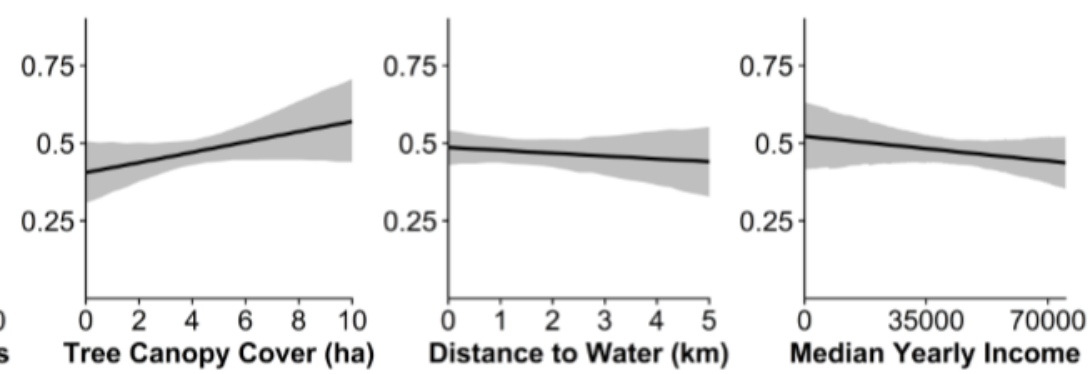

Figure 6: The independent effects of each of four predictor variables, after controlling for the effects of all other variables, on the probability $(+/-95 \%$ credible intervals) of a participant answering the most positive option ("Strongly agree") for question 7 ("How do you feel about the statement "My relationship to nature is an important part of who I am"?") and question 8 ("How do you feel about the statement "I feel very connected to all living things and the earth"?"). The predictor variables in the model include bird species richness, tree canopy cover, distance to water, median income, and disposition (taken from question 1). Each plot shows the effect of one predictor, while all other predictors are held constant at their means (median for disposition). Effects are plotted in blue if the $95 \%$ credible intervals. 


\section{Appendices}
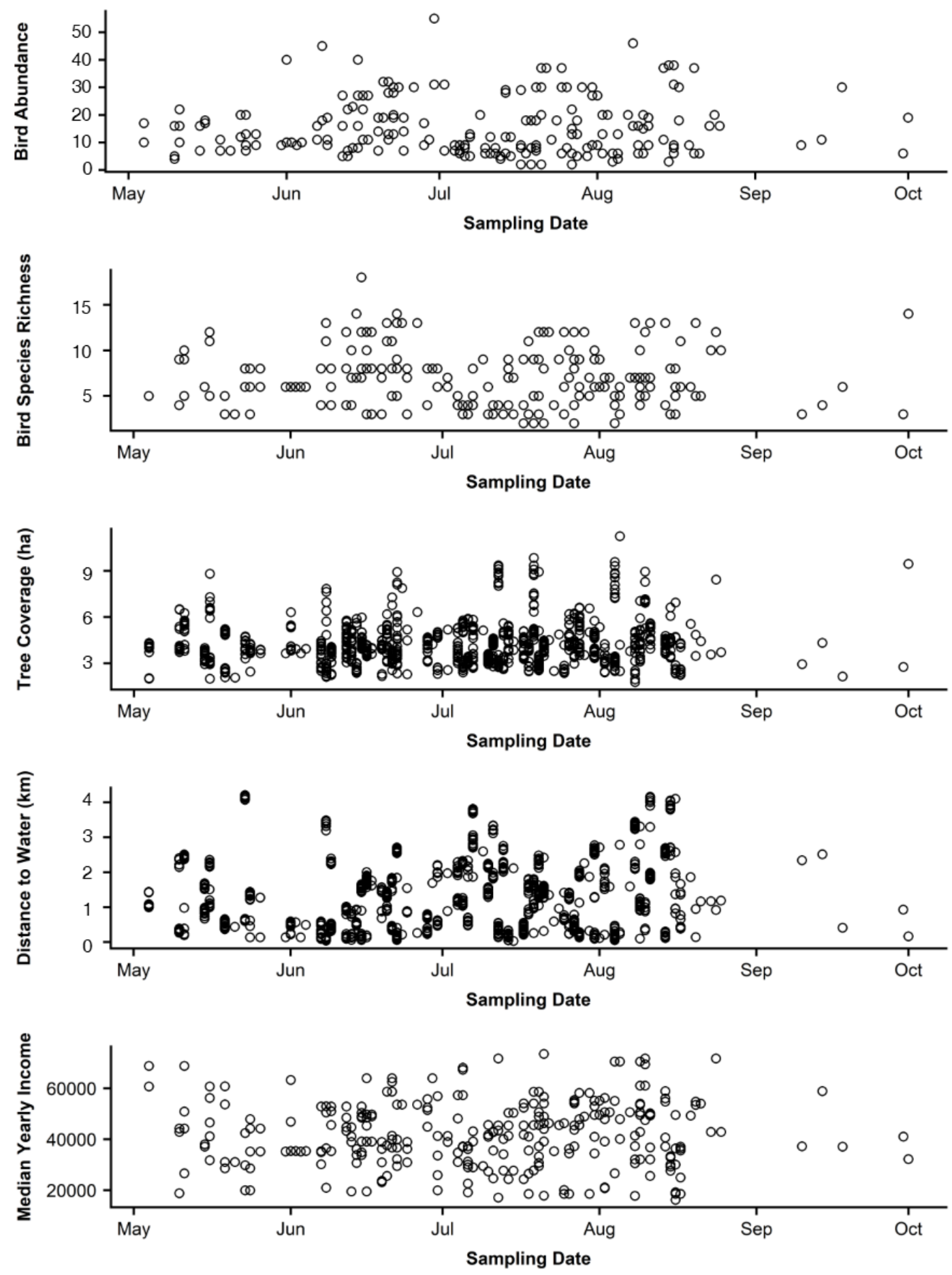

Figure A: In-person surveys were conducted between May 4, 2017 and August 17, 2017. A few on-line surveys were returned after August $17^{\text {th }}$. The sequence of surveys was designed avoid any confounding of sampling date with any of the predictor variables. 
Table A: Survey results recorded during study. A total of 1035 people were surveyed across 100 sites located in Ottawa, Canada (Figure 1). Site corresponds to the site designation used in this study. Easting and Northing are the co-ordinates of the survey site (NAD 83 UTM Zone 18). User ID is a unique identifier for each participant. IDs with four numbers were surveys completed in-person, the first two digits correspond to the site and the second two to the sample number. IDs with a letter prefix were respondents to a flyer. Date is the recorded month and day of the survey submission, all in 2017 . Predictor variables include bird abundance (Abun.) and species richness (Rich.) measured at the nearest Ottawa Bird Count (OBC) point to each participant, tree canopy cover in hectares within $250 \mathrm{~m}$ radius of the participant (Tree), Euclidean distance in kilometers between the participant and the nearest body of water (Water), and median individual yearly income in the dissemination area of the participant (Inc.). Q1-Q8 correspond to the survey questions described in Table 1. Responses are coded so that the least positive answer is 1. Q1-Q5 have a 7-point scale and Q6-Q8 have a 5-point scale.

\begin{tabular}{|c|c|c|c|c|c|c|c|c|c|c|c|c|c|c|c|c|c|}
\hline Site & Easting & Northing & User ID & Date & Abun. & Rich. & Tree & Water & Inc. & Q1 & Q2 & Q3 & Q4 & Q5 & Q6 & Q7 & Q8 \\
\hline 1 & 442406 & 5027902 & 0101 & $05-04$ & 10 & 5 & 3.97 & 0.99 & 68744 & 7 & 7 & 7 & 6 & 7 & 3 & 5 & 4 \\
\hline 1 & 442406 & 5027902 & 0102 & $05-04$ & 10 & 5 & 4.10 & 1.00 & 68744 & 4 & 4 & 6 & 3 & 4 & 1 & 2 & 1 \\
\hline 1 & 442406 & 5027902 & 0103 & $05-04$ & 10 & 5 & 3.97 & 1.00 & 68744 & 6 & 6 & 7 & 7 & 6 & 2 & 4 & 4 \\
\hline 1 & 442406 & 5027902 & 0104 & $05-04$ & 10 & 5 & 3.71 & 1.00 & 68744 & 7 & 6 & 7 & 6 & 6 & 5 & 5 & 5 \\
\hline 1 & 442406 & 5027902 & 0105 & $05-04$ & 10 & 5 & 4.05 & 1.05 & 68744 & 6 & 7 & 7 & 6 & 6 & 5 & 5 & 5 \\
\hline 1 & 442406 & 5027902 & 0106 & $05-04$ & 10 & 5 & 4.12 & 1.02 & 68744 & 5 & 5 & 6 & 6 & 7 & 5 & 4 & 4 \\
\hline 1 & 442406 & 5027902 & 0107 & $05-04$ & 10 & 5 & 4.24 & 1.04 & 68744 & 6 & 6 & 5 & 4 & 4 & 2 & 3 & 4 \\
\hline 1 & 442406 & 5027902 & 0108 & $05-04$ & 10 & 5 & 4.30 & 1.07 & 68744 & 6 & 6 & 7 & 7 & 7 & 1 & 5 & 5 \\
\hline 1 & 442406 & 5027902 & 0109 & $05-04$ & 10 & 5 & 4.29 & 1.08 & 68744 & 5 & 5 & 6 & 7 & 6 & 3 & 5 & 5 \\
\hline 1 & 442406 & 5027902 & 0110 & $05-04$ & 10 & 5 & 4.32 & 1.09 & 68744 & 3 & 3 & 7 & 6 & 5 & 3 & 4 & 4 \\
\hline 1 & 442406 & 5027902 & $\mathrm{~A} 007$ & $05-11$ & 10 & 5 & 3.80 & 0.98 & 68744 & 5 & 6 & 7 & 7 & 4 & 3 & 3 & 3 \\
\hline 2 & 441172 & 5025155 & 0201 & $05-04$ & 17 & 5 & 1.99 & 1.44 & 60685 & 7 & 6 & 7 & 6 & 7 & 5 & 4 & 3 \\
\hline
\end{tabular}




\begin{tabular}{|c|c|c|c|c|c|c|c|c|c|c|c|c|c|c|c|c|c|}
\hline Site & Easting & Northing & User ID & Date & Abun. & Rich. & Tree & Water & Inc. & Q1 & Q2 & Q3 & Q4 & Q5 & Q6 & Q7 & Q8 \\
\hline 2 & 441172 & 5025155 & 0202 & $05-04$ & 17 & 5 & 2.03 & 1.42 & 60685 & 6 & 6 & 7 & 6 & 4 & 2 & 4 & 4 \\
\hline 2 & 441172 & 5025155 & A048 & $05-16$ & 17 & 5 & 1.99 & 1.51 & 60685 & 6 & 6 & 5 & 6 & 2 & 4 & 5 & 4 \\
\hline 3 & 451119 & 5032250 & 0301 & $05-10$ & 4 & 4 & 6.51 & 2.15 & 18800 & 7 & 6 & 6 & 7 & 7 & 5 & 5 & 5 \\
\hline 3 & 451119 & 5032250 & 0302 & $05-10$ & 4 & 4 & 6.47 & 2.22 & 18800 & 7 & 7 & 7 & 7 & 7 & 5 & 5 & 5 \\
\hline 3 & 451119 & 5032250 & 0303 & $05-10$ & 4 & 4 & 6.47 & 2.22 & 18800 & 6 & 6 & 5 & 6 & 5 & 5 & 4 & 4 \\
\hline 3 & 451119 & 5032250 & 0304 & $05-10$ & 4 & 4 & 6.47 & 2.22 & 18800 & 7 & 6 & 7 & 7 & 6 & 5 & 5 & 5 \\
\hline 3 & 451119 & 5032250 & 0305 & $05-10$ & 4 & 4 & 6.47 & 2.22 & 18800 & 7 & 7 & 6 & 6 & 4 & 3 & 4 & 5 \\
\hline 3 & 450985 & 5032248 & 0306 & $05-10$ & 5 & 4 & 5.23 & 2.41 & 18800 & 6 & 6 & 6 & 6 & 5 & 3 & 4 & 4 \\
\hline 3 & 450985 & 5032248 & 0307 & $05-10$ & 5 & 4 & 5.23 & 2.41 & 18800 & 3 & 3 & 6 & 6 & 6 & 5 & 5 & 5 \\
\hline 3 & 450985 & 5032248 & 0309 & $05-10$ & 5 & 4 & 5.37 & 2.36 & 18800 & 5 & 6 & 6 & 6 & 6 & 4 & 5 & 3 \\
\hline 3 & 450985 & 5032248 & 0310 & $05-10$ & 5 & 4 & 5.37 & 2.36 & 18800 & 6 & 2 & 5 & 2 & 2 & 5 & 5 & 5 \\
\hline 4 & 448089 & 5030245 & 0401 & $05-10$ & 16 & 9 & 3.95 & 0.35 & 44228 & 7 & 7 & 7 & 6 & 7 & 5 & 5 & 5 \\
\hline 4 & 448089 & 5030245 & 0402 & $05-10$ & 16 & 9 & 4.04 & 0.38 & 44228 & 6 & 6 & 7 & 4 & 4 & 3 & 4 & 2 \\
\hline 4 & 448089 & 5030245 & 0403 & $05-10$ & 16 & 9 & 3.73 & 0.32 & 44228 & 7 & 7 & 6 & 7 & 7 & 5 & 5 & 5 \\
\hline 4 & 448089 & 5030245 & 0404 & $05-10$ & 16 & 9 & 3.72 & 0.29 & 44228 & 6 & 7 & 7 & 7 & 7 & 5 & 5 & 5 \\
\hline 4 & 448089 & 5030245 & 0405 & $05-10$ & 16 & 9 & 3.73 & 0.26 & 44228 & 6 & 6 & 7 & 7 & 6 & 3 & 5 & 5 \\
\hline 4 & 448089 & 5030245 & 0406 & $05-10$ & 16 & 9 & 3.86 & 0.28 & 44228 & 6 & 7 & 6 & 6 & 6 & 4 & 5 & 5 \\
\hline 4 & 448089 & 5030245 & 0407 & $05-10$ & 16 & 9 & 3.92 & 0.32 & 44228 & 6 & 6 & 7 & 6 & 7 & 4 & 4 & 4 \\
\hline 4 & 448089 & 5030245 & 0408 & $05-10$ & 16 & 9 & 4.03 & 0.35 & 42890 & 7 & 7 & 6 & 6 & 7 & 4 & 5 & 5 \\
\hline 4 & 448089 & 5030245 & 0409 & $05-10$ & 16 & 9 & 4.13 & 0.32 & 42890 & 6 & 5 & 7 & 6 & 4 & 4 & 4 & 5 \\
\hline 4 & 448089 & 5030245 & 0410 & $05-10$ & 16 & 9 & 4.08 & 0.38 & 44228 & 6 & 2 & 5 & 6 & 6 & 4 & 5 & 5 \\
\hline 4 & 448089 & 5030245 & A153 & $05-11$ & 16 & 9 & 3.94 & 0.39 & 44228 & 6 & 7 & 7 & 7 & 7 & 4 & 3 & 3 \\
\hline 5 & 449842 & 5022451 & 0501 & $05-11$ & 16 & 10 & 5.09 & 0.20 & 26602 & 7 & 7 & 6 & 6 & 6 & 3 & 4 & 4 \\
\hline 5 & 449842 & 5022451 & 0502 & $05-11$ & 16 & 10 & 4.19 & 0.23 & 26602 & 4 & 6 & 6 & 6 & 6 & 4 & 5 & 5 \\
\hline 5 & 449842 & 5022451 & 0503 & $05-11$ & 16 & 10 & 5.21 & 0.20 & 26602 & 7 & 6 & 6 & 7 & 6 & 5 & 5 & 5 \\
\hline
\end{tabular}




\begin{tabular}{|c|c|c|c|c|c|c|c|c|c|c|c|c|c|c|c|c|c|}
\hline Site & Easting & Northing & User ID & Date & Abun. & Rich. & Tree & Water & Inc. & Q1 & Q2 & Q3 & Q4 & Q5 & Q6 & Q7 & Q8 \\
\hline 6 & 450063 & 5026986 & 0601 & $05-11$ & 22 & 10 & 5.77 & 2.50 & 50894 & 6 & 5 & 7 & 6 & 6 & 3 & 5 & 4 \\
\hline 6 & 450063 & 5026986 & 0602 & $05-11$ & 22 & 10 & 5.70 & 2.51 & 50894 & 6 & 6 & 7 & 7 & 7 & 4 & 5 & 5 \\
\hline 6 & 450063 & 5026986 & 0603 & $05-11$ & 22 & 10 & 5.43 & 2.49 & 50894 & 6 & 6 & 7 & 6 & 6 & 5 & 5 & 5 \\
\hline 6 & 450063 & 5026986 & 0604 & $05-11$ & 22 & 10 & 5.77 & 2.42 & 50894 & 4 & 4 & 6 & 6 & 5 & 4 & 4 & 4 \\
\hline 6 & 450063 & 5026986 & 0605 & $05-11$ & 22 & 10 & 5.61 & 2.44 & 50894 & 7 & 7 & 5 & 7 & 6 & 4 & 5 & 5 \\
\hline 6 & 450063 & 5026986 & 0606 & $05-11$ & 22 & 10 & 5.54 & 2.45 & 50894 & 6 & 6 & 6 & 7 & 6 & 4 & 5 & 5 \\
\hline 6 & 450063 & 5026986 & 0607 & $05-11$ & 22 & 10 & 5.43 & 2.47 & 50894 & 6 & 6 & 7 & 7 & 7 & 4 & 5 & 5 \\
\hline 6 & 450063 & 5026986 & 0608 & $05-11$ & 22 & 10 & 5.72 & 2.39 & 50894 & 2 & 3 & 4 & 4 & 3 & 2 & 4 & 1 \\
\hline 6 & 450063 & 5026986 & 0609 & $05-11$ & 22 & 10 & 6.25 & 2.37 & 50894 & 4 & 6 & 7 & 6 & 6 & 4 & 4 & 4 \\
\hline 6 & 450063 & 5026986 & 0610 & $05-11$ & 22 & 10 & 5.07 & 2.51 & 50894 & 4 & 4 & 7 & 7 & 7 & 5 & 5 & 5 \\
\hline 6 & 450063 & 5026986 & A212 & $05-11$ & 22 & 10 & 5.21 & 2.49 & 50894 & 6 & 7 & 7 & 5 & 5 & 2 & 3 & 3 \\
\hline 7 & 444111 & 5022896 & 0701 & $05-15$ & 7 & 6 & 3.12 & 0.83 & 37117 & 4 & 7 & 7 & 6 & 4 & 3 & 5 & 5 \\
\hline 7 & 444111 & 5022896 & 0702 & $05-15$ & 7 & 6 & 3.28 & 0.94 & 37117 & 7 & 7 & 7 & 7 & 6 & 3 & 3 & 5 \\
\hline 7 & 444111 & 5022896 & 0703 & $05-15$ & 7 & 6 & 3.30 & 0.90 & 37117 & 6 & 6 & 6 & 6 & 7 & 5 & 5 & 5 \\
\hline 7 & 444111 & 5022896 & 0704 & $05-15$ & 7 & 6 & 3.26 & 0.85 & 37117 & 7 & 7 & 6 & 6 & 6 & 5 & 5 & 4 \\
\hline 7 & 444111 & 5022896 & 0705 & $05-15$ & 7 & 6 & 3.50 & 0.90 & 37117 & 6 & 6 & 5 & 5 & 5 & 4 & 5 & 5 \\
\hline 7 & 444111 & 5022896 & 0706 & $05-15$ & 7 & 6 & 3.27 & 0.81 & 37117 & 4 & 2 & 4 & 5 & 5 & 2 & 5 & 5 \\
\hline 7 & 444111 & 5022896 & 0707 & $05-15$ & 7 & 6 & 3.20 & 0.81 & 37117 & 6 & 6 & 7 & 6 & 6 & 4 & 5 & 4 \\
\hline 7 & 444111 & 5022896 & 0708 & $05-15$ & 7 & 6 & 2.93 & 0.73 & 37117 & 7 & 7 & 7 & 7 & 6 & 3 & 5 & 3 \\
\hline 7 & 444111 & 5022896 & 0709 & $05-15$ & 7 & 6 & 3.64 & 0.98 & 37117 & 6 & 7 & 6 & 7 & 7 & 5 & 5 & 5 \\
\hline 7 & 444111 & 5022896 & 0710 & $05-15$ & 7 & 6 & 3.11 & 0.67 & 37117 & 7 & 6 & 7 & 7 & 6 & 4 & 5 & 5 \\
\hline 8 & 441886 & 5021279 & 0801 & $05-15$ & 16 & 6 & 3.98 & 1.68 & 37965 & 6 & 5 & 6 & 7 & 6 & 4 & 3 & 3 \\
\hline 8 & 441886 & 5021279 & 0802 & $05-15$ & 16 & 6 & 3.70 & 1.65 & 37965 & 6 & 5 & 6 & 5 & 6 & 5 & 4 & 4 \\
\hline 8 & 441886 & 5021279 & 0803 & $05-15$ & 16 & 6 & 3.77 & 1.64 & 37965 & 7 & 6 & 6 & 6 & 4 & 3 & 4 & 4 \\
\hline 8 & 441886 & 5021279 & 0804 & $05-15$ & 16 & 6 & 3.87 & 1.63 & 37965 & 6 & 5 & 6 & 6 & 5 & 4 & 5 & 5 \\
\hline
\end{tabular}




\begin{tabular}{|c|c|c|c|c|c|c|c|c|c|c|c|c|c|c|c|c|c|}
\hline Site & Easting & Northing & User ID & Date & Abun. & Rich. & Tree & Water & Inc. & Q1 & Q2 & Q3 & Q4 & Q5 & Q6 & Q7 & Q8 \\
\hline 8 & 441886 & 5021279 & 0805 & $05-15$ & 16 & 6 & 3.82 & 1.62 & 37965 & 4 & 6 & 7 & 7 & 5 & 3 & 4 & 4 \\
\hline 8 & 441886 & 5021279 & 0806 & $5-15$ & 16 & 6 & 3.73 & 1.51 & 37965 & 5 & 5 & 4 & 6 & 4 & 4 & 4 & 3 \\
\hline 8 & 441886 & 5021279 & 0807 & $5-15$ & 16 & 6 & 3.80 & 1.53 & 37965 & 7 & 7 & 7 & 5 & 5 & 1 & 4 & 5 \\
\hline 8 & 441886 & 5021279 & 0808 & $05-15$ & 16 & 6 & 3.60 & 1.65 & 37965 & 7 & 7 & 7 & 7 & 6 & 5 & 5 & 5 \\
\hline 8 & 441886 & 5021279 & 0809 & $05-15$ & 16 & 6 & 3.68 & 1.62 & 37965 & 6 & 6 & 7 & 6 & 6 & 4 & 4 & 4 \\
\hline 8 & 441886 & 5021279 & 0810 & $05-15$ & 16 & 6 & 3.83 & 1.56 & 37965 & 6 & 6 & 6 & 6 & 6 & 4 & 5 & 5 \\
\hline 9 & 438308 & 5023200 & 0902 & $05-16$ & 18 & 11 & 6.99 & 1.12 & 56223 & 7 & 6 & 6 & 6 & 6 & 5 & 5 & 5 \\
\hline 9 & 438308 & 5023200 & 0903 & $05-16$ & 18 & 11 & 7.29 & 1.10 & 56223 & 6 & 6 & 7 & 6 & 6 & 5 & 5 & 5 \\
\hline 9 & 438308 & 5023200 & 0904 & $05-16$ & 18 & 11 & 8.80 & 1.20 & 56223 & 6 & 7 & 5 & 7 & 6 & 3 & 5 & 5 \\
\hline 9 & 438308 & 5023200 & 0906 & $05-16$ & 18 & 11 & 6.60 & 1.05 & 31790 & 6 & 4 & 7 & 7 & 4 & 1 & 5 & 5 \\
\hline 9 & 438308 & 5023200 & 0907 & $05-16$ & 18 & 11 & 6.50 & 1.04 & 31790 & 6 & 6 & 7 & 7 & 6 & 4 & 5 & 4 \\
\hline 9 & 438308 & 5023200 & 0908 & $05-16$ & 18 & 11 & 6.41 & 1.02 & 31790 & 6 & 5 & 7 & 7 & 7 & 3 & 5 & 5 \\
\hline 9 & 438308 & 5023200 & 0909 & $05-16$ & 18 & 11 & 5.94 & 0.99 & 31790 & 6 & 7 & 6 & 6 & 5 & 4 & 4 & 5 \\
\hline 9 & 438308 & 5023200 & 0910 & $05-16$ & 18 & 11 & 6.41 & 1.04 & 31790 & 6 & 6 & 6 & 7 & 6 & 4 & 4 & 3 \\
\hline 10 & 440163 & 5023246 & 1001 & $05-16$ & 18 & 12 & 3.38 & 2.20 & 41187 & 3 & 3 & 6 & 6 & 3 & 3 & 3 & 4 \\
\hline 10 & 440163 & 5023246 & 1002 & $05-16$ & 18 & 12 & 3.33 & 2.19 & 41187 & 5 & 5 & 7 & 5 & 6 & 4 & 5 & 5 \\
\hline 10 & 440163 & 3246 & 1003 & $05-16$ & 18 & 12 & 3.16 & 2.29 & 41187 & 6 & 0 & 7 & 6 & 7 & 4 & 5 & 5 \\
\hline 10 & 440163 & 5023246 & 1004 & $05-16$ & 18 & 12 & 3.35 & 2.26 & 46544 & 6 & 0 & 6 & 6 & 6 & 4 & 4 & 4 \\
\hline 10 & 440163 & 5023246 & 1005 & $05-16$ & 18 & 12 & 3.11 & 2.16 & 46544 & 7 & 7 & 7 & 6 & 5 & 3 & 3 & 4 \\
\hline 10 & 440163 & 5023246 & 1006 & $05-16$ & 18 & 12 & 3.03 & 2.17 & 46544 & 6 & 6 & 5 & 5 & 6 & 2 & 4 & 3 \\
\hline 10 & 440163 & 5023246 & 1007 & $05-16$ & 18 & 12 & 2.93 & 2.25 & 41187 & 6 & 7 & 7 & 6 & 6 & 5 & 4 & 4 \\
\hline 10 & 440163 & 5023246 & 1008 & $05-16$ & 18 & 12 & 2.97 & 2.28 & 41187 & 6 & 6 & 7 & 7 & 6 & 3 & 4 & 4 \\
\hline 10 & 440163 & 5023246 & 1010 & $05-16$ & 18 & 12 & 3.02 & 2.36 & 41187 & 6 & 6 & 7 & 7 & 5 & 3 & 3 & 3 \\
\hline 10 & 440163 & 5023246 & 1011 & $05-16$ & 18 & 12 & 3.10 & 2.35 & 41187 & 7 & 7 & 7 & 2 & 4 & 1 & 4 & 3 \\
\hline 11 & 445643 & 5027883 & 1101 & 05-19 & 11 & 5 & 4.82 & 0.60 & 60799 & 3 & 7 & 6 & 2 & 3 & 4 & 5 & 5 \\
\hline
\end{tabular}




\begin{tabular}{|c|c|c|c|c|c|c|c|c|c|c|c|c|c|c|c|c|c|}
\hline Site & Easting & Northing & User ID & Date & Abun. & Rich. & Tree & Water & Inc. & Q1 & Q2 & Q3 & Q4 & Q5 & Q6 & Q7 & Q8 \\
\hline 11 & 445643 & 5027883 & 1102 & $05-19$ & 11 & 5 & 5.16 & 0.61 & 60799 & 7 & 7 & 7 & 7 & 7 & 5 & 4 & 4 \\
\hline 11 & 445643 & 5027883 & 1103 & $05-19$ & 11 & 5 & 5.05 & 0.56 & 60799 & 7 & 7 & 7 & 7 & 7 & 5 & 5 & 5 \\
\hline 11 & 445643 & 5027883 & 1104 & 05-19 & 11 & 5 & 4.90 & 0.55 & 60799 & 6 & 6 & 7 & 7 & 7 & 4 & 5 & 4 \\
\hline 11 & 445643 & 5027883 & 1105 & $05-19$ & 11 & 5 & 4.89 & 0.55 & 60799 & 6 & 6 & 7 & 6 & 5 & 4 & 4 & 4 \\
\hline 11 & 445643 & 5027883 & 1106 & $05-19$ & 11 & 5 & 5.22 & 0.63 & 60799 & 7 & 7 & 7 & 7 & 4 & 2 & 3 & 4 \\
\hline 11 & 445643 & 5027883 & 1107 & $05-19$ & 11 & 5 & 5.13 & 0.65 & 53638 & 7 & 7 & 6 & 6 & 6 & 4 & 5 & 4 \\
\hline 11 & 445643 & 5027883 & 1108 & $05-19$ & 11 & 5 & 4.92 & 0.52 & 60799 & 6 & 7 & 7 & 6 & 6 & 2 & 4 & 5 \\
\hline 11 & 445643 & 5027883 & 1109 & $05-19$ & 11 & 5 & 4.84 & 0.52 & 60799 & 6 & 6 & 7 & 7 & 7 & 3 & 5 & 4 \\
\hline 11 & 445643 & 5027883 & 1110 & $05-19$ & 11 & 5 & 5.03 & 0.54 & 60799 & 7 & 7 & 7 & 7 & 6 & 5 & 5 & 5 \\
\hline 11 & 445643 & 5027883 & A326 & $05-19$ & 11 & 5 & 5.12 & 0.61 & 60799 & 2 & 5 & 2 & 6 & 6 & 5 & 3 & 4 \\
\hline 11 & 445643 & 5027883 & A343 & $05-19$ & 11 & 5 & 5.14 & 0.64 & 60799 & 6 & 7 & 7 & 7 & 6 & 3 & 2 & 4 \\
\hline 11 & 445643 & 5027883 & A345 & $05-19$ & 11 & 5 & 5.16 & 0.62 & 53638 & 6 & 7 & 7 & 6 & 5 & 3 & 4 & 5 \\
\hline 12 & 445687 & 5031060 & 1201 & 05-19 & 7 & 3 & 2.38 & 0.40 & 28595 & 7 & 6 & 7 & 7 & 6 & 5 & 4 & 4 \\
\hline 12 & 445687 & 5031060 & 1202 & $05-19$ & 7 & 3 & 2.46 & 0.47 & 28595 & 7 & 7 & 7 & 4 & 3 & 3 & 3 & 5 \\
\hline 12 & 445687 & 5031060 & 1203 & $05-19$ & 7 & 3 & 2.08 & 0.45 & 31103 & 6 & 7 & 6 & 6 & 5 & 4 & 4 & 5 \\
\hline 12 & 445687 & 5031060 & 1204 & $05-19$ & 7 & 3 & 2.08 & 0.46 & 31103 & 6 & 6 & 5 & 6 & 6 & 4 & 4 & 4 \\
\hline 12 & 445687 & 5031060 & 1205 & $05-19$ & 7 & 3 & 2.44 & 0.41 & 28595 & 7 & 7 & 6 & 6 & 7 & 4 & 5 & 4 \\
\hline 12 & 445687 & 5031060 & 1206 & 05-19 & 7 & 3 & 2.44 & 0.42 & 28595 & 6 & 6 & 7 & 6 & 6 & 4 & 4 & 3 \\
\hline 12 & 445687 & 5031060 & 1207 & $05-19$ & 7 & 3 & 2.47 & 0.43 & 28595 & 6 & 6 & 7 & 6 & 6 & 4 & 5 & 5 \\
\hline 12 & 445687 & 5031060 & 1208 & 05-19 & 7 & 3 & 2.48 & 0.45 & 28595 & 6 & 7 & 7 & 7 & 7 & 4 & 4 & 4 \\
\hline 12 & 445687 & 5031060 & 1209 & 05-19 & 7 & 3 & 2.60 & 0.39 & 28595 & 6 & 6 & 6 & 3 & 3 & 3 & 4 & 3 \\
\hline 12 & 445687 & 5031060 & 1210 & 05-19 & 7 & 3 & 2.68 & 0.37 & 28595 & 3 & 4 & 6 & 6 & 5 & 4 & 5 & 5 \\
\hline 12 & 445687 & 5031060 & A379 & $05-24$ & 7 & 3 & 2.45 & 0.46 & 28595 & 5 & 5 & 6 & 3 & 3 & 2 & 4 & 4 \\
\hline 12 & 445687 & 5031060 & A391 & $05-21$ & 7 & 3 & 2.06 & 0.44 & 31103 & 6 & 7 & 6 & 4 & 3 & 1 & 2 & 2 \\
\hline 13 & 448554 & 5028957 & 1301 & $05-23$ & 20 & 6 & 3.30 & 0.61 & 19994 & 7 & 6 & 7 & 6 & 6 & 4 & 5 & 5 \\
\hline
\end{tabular}




\begin{tabular}{|c|c|c|c|c|c|c|c|c|c|c|c|c|c|c|c|c|c|}
\hline Site & Easting & Northing & User ID & Date & Abun. & Rich. & Tree & Water & Inc. & Q1 & Q2 & Q3 & Q4 & Q5 & Q6 & Q7 & Q8 \\
\hline 13 & 448554 & 5028957 & 1302 & $05-23$ & 20 & 6 & 4.27 & 0.63 & 19994 & 6 & 6 & 7 & 6 & 6 & 4 & 5 & 5 \\
\hline 13 & 448554 & 5028957 & 1303 & $05-23$ & 20 & 6 & 3.92 & 0.60 & 19994 & 1 & 7 & 7 & 7 & 7 & 5 & 5 & 5 \\
\hline 13 & 448554 & 5028957 & 1304 & $05-23$ & 20 & 6 & 3.88 & 0.67 & 19994 & 7 & 7 & 7 & 6 & 6 & 4 & 4 & 4 \\
\hline 13 & 448554 & 5028957 & 1305 & $05-23$ & 20 & 6 & 3.59 & 0.64 & 19994 & 5 & 6 & 7 & 6 & 4 & 4 & 3 & 3 \\
\hline 13 & 448554 & 5028957 & A406 & $05-24$ & 20 & 6 & 4.19 & 0.62 & 19994 & 6 & 6 & 7 & 7 & 7 & 3 & 1 & 2 \\
\hline 14 & 452334 & 5029986 & 1401 & $05-23$ & 12 & 8 & 3.84 & 4.13 & 29792 & 5 & 6 & 7 & 6 & 6 & 4 & 5 & 5 \\
\hline 14 & 452334 & 5029986 & 1402 & $05-23$ & 12 & 8 & 3.97 & 4.17 & 29792 & 7 & 5 & 7 & 6 & 7 & 3 & 5 & 5 \\
\hline 14 & 452334 & 5029986 & 1403 & $05-23$ & 12 & 8 & 4.69 & 4.21 & 29792 & 7 & 7 & 7 & 3 & 6 & 2 & 3 & 3 \\
\hline 14 & 452334 & 5029986 & 1404 & $05-23$ & 12 & 8 & 4.74 & 4.21 & 29792 & 6 & 0 & 6 & 5 & 4 & 3 & 5 & 5 \\
\hline 14 & 452334 & 5029986 & 1405 & $05-23$ & 12 & 8 & 4.48 & 4.16 & 42408 & 6 & 6 & 6 & 5 & 3 & 4 & 4 & 5 \\
\hline 14 & 452334 & 5029986 & 1406 & $05-23$ & 12 & 8 & 4.43 & 4.17 & 42408 & 6 & 6 & 7 & 7 & 4 & 5 & 5 & 4 \\
\hline 14 & 452334 & 5029986 & 1407 & $05-23$ & 12 & 8 & 4.48 & 4.12 & 42408 & 6 & 6 & 6 & 6 & 6 & 5 & 5 & 5 \\
\hline 14 & 452334 & 5029986 & 1408 & $05-23$ & 12 & 8 & 4.28 & 4.13 & 42408 & 5 & 5 & 4 & 6 & 5 & 3 & 4 & 4 \\
\hline 14 & 452334 & 5029986 & 1409 & $05-23$ & 12 & 8 & 3.95 & 4.08 & 42408 & 6 & 6 & 7 & 6 & 4 & 4 & 3 & 4 \\
\hline 15 & 444803 & 5022626 & 1501 & $05-24$ & 9 & 6 & 3.63 & 0.14 & 35194 & 6 & 6 & 6 & 7 & 7 & 3 & 5 & 5 \\
\hline 15 & 444803 & 5022626 & 1502 & $05-24$ & 9 & 6 & 3.63 & 0.14 & 35194 & 6 & 6 & 6 & 5 & 4 & 3 & 5 & 5 \\
\hline 15 & 444803 & 5022626 & 1503 & $05-24$ & 9 & 6 & 3.63 & 0.14 & 35194 & 6 & 6 & 7 & 5 & 5 & 4 & 4 & 4 \\
\hline 15 & 444803 & 5022626 & 1504 & $05-24$ & 9 & 6 & 3.63 & 0.14 & 35194 & 6 & 7 & 5 & 7 & 7 & 5 & 5 & 5 \\
\hline 15 & 444803 & 5022626 & 1505 & $05-24$ & 9 & 6 & 3.63 & 0.14 & 35194 & 6 & 6 & 7 & 6 & 6 & 3 & 4 & 5 \\
\hline 15 & 444803 & 5022626 & 1506 & $05-24$ & 9 & 6 & 3.63 & 0.14 & 35194 & 7 & 6 & 6 & 7 & 7 & 5 & 5 & 5 \\
\hline 15 & 444803 & 5022626 & 1507 & $05-24$ & 9 & 6 & 3.63 & 0.14 & 35194 & 6 & 5 & 6 & 6 & 6 & 2 & 4 & 5 \\
\hline 15 & 444803 & 5022626 & 1508 & $05-24$ & 9 & 6 & 3.63 & 0.14 & 35194 & 6 & 6 & 7 & 7 & 4 & 3 & 3 & 2 \\
\hline 15 & 444803 & 5022626 & 1509 & $05-24$ & 9 & 6 & 3.63 & 0.14 & 35194 & 5 & 6 & 3 & 5 & 6 & 4 & 4 & 5 \\
\hline 15 & 444803 & 5022626 & 1510 & $05-24$ & 9 & 6 & 3.63 & 0.14 & 35194 & 6 & 6 & 7 & 3 & 3 & 2 & 4 & 5 \\
\hline 15 & 444803 & 5022626 & A437 & $05-31$ & 9 & 6 & 3.63 & 0.14 & 35194 & 6 & 7 & 6 & 6 & 5 & 2 & 5 & 5 \\
\hline
\end{tabular}




\begin{tabular}{|c|c|c|c|c|c|c|c|c|c|c|c|c|c|c|c|c|c|}
\hline Site & Easting & Northing & User ID & Date & Abun. & Rich. & Tree & Water & Inc. & Q1 & Q2 & Q3 & Q4 & Q5 & Q6 & Q7 & Q8 \\
\hline 15 & 444803 & 5022626 & A463 & $05-24$ & 9 & 6 & 3.63 & 0.14 & 35194 & 5 & 6 & 6 & 6 & 6 & 4 & 5 & 5 \\
\hline 15 & 444803 & 5022626 & A464 & $05-26$ & 9 & 6 & 3.63 & 0.14 & 35194 & 6 & 6 & 6 & 7 & 6 & 4 & 5 & 5 \\
\hline 15 & 444803 & 5022626 & A471 & 06-03 & 9 & 6 & 3.63 & 0.14 & 35194 & 7 & 7 & 7 & 7 & 7 & 5 & 5 & 5 \\
\hline 16 & 447356 & 5023644 & 1601 & $05-24$ & 13 & 8 & 3.75 & 1.36 & 44230 & 6 & 6 & 6 & 6 & 7 & 5 & 5 & 5 \\
\hline 16 & 447356 & 5023644 & 1602 & $05-24$ & 13 & 8 & 3.64 & 1.44 & 44230 & 6 & 5 & 4 & 7 & 3 & 5 & 5 & 5 \\
\hline 16 & 447356 & 5023644 & 1603 & $05-24$ & 13 & 8 & 3.73 & 1.41 & 44230 & 6 & 6 & 7 & 6 & 6 & 5 & 5 & 5 \\
\hline 16 & 447356 & 5023644 & 1604 & $05-24$ & 13 & 8 & 3.79 & 1.37 & 44230 & 7 & 7 & 7 & 7 & 6 & 3 & 4 & 4 \\
\hline 16 & 447356 & 5023644 & 1605 & $05-24$ & 13 & 8 & 3.78 & 1.34 & 44230 & 6 & 6 & 7 & 6 & 6 & 1 & 5 & 5 \\
\hline 16 & 447356 & 5023644 & 1606 & $05-24$ & 13 & 8 & 4.01 & 1.24 & 44230 & 6 & 6 & 7 & 6 & 5 & 2 & 5 & 5 \\
\hline 16 & 447356 & 5023644 & 1607 & $05-24$ & 13 & 8 & 3.88 & 1.32 & 44230 & 6 & 6 & 7 & 7 & 7 & 2 & 2 & 2 \\
\hline 16 & 447356 & 5023644 & 1608 & $05-24$ & 13 & 8 & 3.75 & 1.39 & 47871 & 6 & 7 & 7 & 7 & 6 & 5 & 5 & 5 \\
\hline 16 & 447356 & 5023644 & 1609 & $05-24$ & 13 & 8 & 4.26 & 1.33 & 47871 & 5 & 6 & 7 & 6 & 6 & 5 & 4 & 4 \\
\hline 16 & 447356 & 5023644 & 1610 & 05-24 & 13 & 8 & 4.21 & 1.31 & 47871 & 7 & 7 & 7 & 7 & 6 & 3 & 4 & 3 \\
\hline 16 & 447356 & 5023644 & A495 & $05-26$ & 13 & 8 & 3.89 & 1.27 & 44230 & 6 & 6 & 6 & 6 & 6 & 4 & 5 & 4 \\
\hline 16 & 447356 & 5023644 & A500 & $05-26$ & 13 & 8 & 3.85 & 1.28 & 44230 & 6 & 6 & 7 & 7 & 7 & 3 & 3 & 4 \\
\hline 16 & 447356 & 5023644 & A514 & $05-24$ & 13 & 8 & 4.24 & 1.21 & 44230 & 6 & 6 & 6 & 7 & 6 & 5 & 5 & 5 \\
\hline 17 & 440454 & 5027568 & 1701 & 06-01 & 40 & 6 & 5.40 & 0.23 & 46871 & 6 & 6 & 6 & 6 & 6 & 4 & 4 & 3 \\
\hline 17 & 440454 & 5027568 & 1702 & 06-01 & 40 & 6 & 5.32 & 0.22 & 46871 & 7 & 7 & 5 & 5 & 7 & 5 & 5 & 2 \\
\hline 17 & 440454 & 5027568 & 1703 & 06-01 & 40 & 6 & 6.30 & 0.24 & 46871 & 6 & 6 & 7 & 7 & 6 & 3 & 5 & 5 \\
\hline 17 & 440454 & 5027568 & 1704 & 06-01 & 40 & 6 & 5.41 & 0.24 & 46871 & 6 & 7 & 7 & 6 & 6 & 4 & 4 & 4 \\
\hline 17 & 440454 & 5027568 & 1705 & 06-01 & 40 & 6 & 5.45 & 0.25 & 46871 & 6 & 5 & 7 & 7 & 6 & 4 & 4 & 4 \\
\hline 18 & 439933 & 5025478 & 1801 & 06-01 & 10 & 6 & 3.85 & 0.51 & 35400 & 6 & 5 & 6 & 7 & 6 & 1 & 5 & 4 \\
\hline 18 & 439933 & 5025478 & 1802 & 06-01 & 10 & 6 & 3.92 & 0.53 & 35400 & 7 & 7 & 7 & 7 & 6 & 4 & 5 & 3 \\
\hline 18 & 439933 & 5025478 & 1803 & 06-01 & 10 & 6 & 3.89 & 0.55 & 35400 & 6 & 6 & 6 & 6 & 6 & 5 & 5 & 5 \\
\hline 18 & 439933 & 5025478 & 1804 & 06-01 & 10 & 6 & 3.91 & 0.45 & 35400 & 7 & 7 & 7 & 7 & 7 & 5 & 5 & 4 \\
\hline
\end{tabular}




\begin{tabular}{|c|c|c|c|c|c|c|c|c|c|c|c|c|c|c|c|c|c|}
\hline Site & Easting & Northing & User ID & Date & Abun. & Rich. & Tree & Water & Inc. & Q1 & Q2 & Q3 & Q4 & Q5 & Q6 & Q7 & Q8 \\
\hline 18 & 439933 & 5025478 & 1805 & 06-01 & 10 & 6 & 4.08 & 0.52 & 35400 & 3 & 1 & 7 & 7 & 4 & 5 & 5 & 4 \\
\hline 18 & 439933 & 5025478 & 1806 & 06-01 & 10 & 6 & 4.10 & 0.47 & 35400 & 5 & 6 & 5 & 5 & 6 & 3 & 4 & 3 \\
\hline 18 & 439933 & 5025478 & 1807 & 06-01 & 10 & 6 & 3.81 & 0.59 & 35400 & 6 & 6 & 6 & 6 & 6 & 4 & 4 & 3 \\
\hline 18 & 439933 & 5025478 & 1808 & 06-01 & 10 & 6 & 3.83 & 0.57 & 63224 & 6 & 6 & 7 & 7 & 5 & 3 & 3 & 4 \\
\hline 18 & 439933 & 5025478 & 1809 & 06-01 & 10 & 6 & 3.81 & 0.55 & 63224 & 6 & 7 & 7 & 7 & 6 & 4 & 5 & 4 \\
\hline 18 & 439933 & 5025478 & 1810 & 06-01 & 10 & 6 & 3.81 & 0.53 & 63224 & 4 & 6 & 7 & 4 & 6 & 1 & 5 & 5 \\
\hline 18 & 439933 & 5025478 & A540 & 06-04 & 10 & 6 & 3.93 & 0.49 & 35400 & 4 & 3 & 3 & 7 & 7 & 4 & 4 & 4 \\
\hline 18 & 439933 & 5025478 & A557 & 06-02 & 10 & 6 & 3.92 & 0.57 & 35400 & 6 & 6 & 7 & 7 & 6 & 3 & 4 & 3 \\
\hline 19 & 444081 & 5028637 & 1901 & $06-07$ & 11 & 4 & 3.41 & 0.59 & 30192 & 7 & 7 & 7 & 7 & 7 & 3 & 5 & 5 \\
\hline 19 & 444081 & 5028637 & 1902 & 06-07 & 11 & 4 & 3.02 & 0.54 & 35342 & 6 & 3 & 7 & 7 & 7 & 4 & 5 & 5 \\
\hline 19 & 444081 & 5028637 & 1903 & 06-07 & 11 & 4 & 2.75 & 0.54 & 35342 & 6 & 6 & 7 & 4 & 3 & 3 & 4 & 5 \\
\hline 19 & 444081 & 5028637 & 1904 & $06-07$ & 11 & 4 & 2.50 & 0.59 & 35342 & 6 & 6 & 7 & 5 & 4 & 4 & 5 & 4 \\
\hline 19 & 444081 & 5028637 & 1905 & 06-07 & 11 & 4 & 2.50 & 0.59 & 35342 & 4 & 6 & 4 & 6 & 5 & 5 & 5 & 4 \\
\hline 19 & 444081 & 5028637 & 1906 & 06-07 & 11 & 4 & 2.65 & 0.59 & 35342 & 7 & 7 & 6 & 6 & 2 & 3 & 5 & 5 \\
\hline 19 & 444081 & 5028637 & 1907 & 06-07 & 11 & 4 & 2.67 & 0.59 & 35342 & 6 & 1 & 6 & 6 & 4 & 4 & 5 & 5 \\
\hline 19 & 444081 & 5028637 & 1908 & 06-07 & 11 & 4 & 3.06 & 0.57 & 35342 & 6 & 7 & 7 & 6 & 5 & 4 & 5 & 5 \\
\hline 19 & 444081 & 5028637 & 1909 & 06-07 & 11 & 4 & 3.91 & 0.53 & 30192 & 4 & 6 & 6 & 2 & 4 & 1 & 5 & 5 \\
\hline 19 & 444081 & 5028637 & 1910 & 06-07 & 11 & 4 & 4.07 & 0.47 & 30192 & 7 & 7 & 5 & 3 & 2 & 3 & 5 & 5 \\
\hline 19 & 444081 & 5028637 & A603 & 06-09 & 11 & 4 & 3.04 & 0.53 & 35342 & 7 & 6 & 6 & 5 & 6 & 4 & 4 & 5 \\
\hline 19 & 444081 & 5028637 & A604 & 06-07 & 11 & 4 & 3.00 & 0.53 & 35342 & 7 & 7 & 6 & 6 & 5 & 4 & 4 & 4 \\
\hline 19 & 444081 & 5028637 & A612 & $07-23$ & 11 & 4 & 2.50 & 0.59 & 35342 & 5 & 5 & 6 & 3 & 4 & 2 & 5 & 4 \\
\hline 19 & 444081 & 5028637 & A631 & 06-07 & 11 & 4 & 3.59 & 0.59 & 30192 & 7 & 7 & 6 & 6 & 6 & 2 & 4 & 3 \\
\hline 20 & 447461 & 5030091 & 2001 & 06-07 & 16 & 8 & 4.26 & 0.26 & 34923 & 7 & 7 & 6 & 7 & 7 & 1 & 5 & 5 \\
\hline 20 & 447461 & 5030091 & 2002 & 06-07 & 16 & 8 & 4.43 & 0.23 & 52863 & 4 & 5 & 5 & 5 & 5 & 5 & 5 & 5 \\
\hline 20 & 447461 & 5030091 & 2003 & 06-07 & 16 & 8 & 4.11 & 0.14 & 52863 & 6 & 7 & 6 & 6 & 7 & 4 & 5 & 5 \\
\hline
\end{tabular}




\begin{tabular}{|c|c|c|c|c|c|c|c|c|c|c|c|c|c|c|c|c|c|}
\hline Site & Easting & Northing & User ID & Date & Abun. & Rich. & Tree & Water & Inc. & Q1 & Q2 & Q3 & Q4 & Q5 & Q6 & Q7 & Q8 \\
\hline 20 & 447461 & 5030091 & 2004 & 06-07 & 16 & 8 & 4.31 & 0.33 & 34923 & 5 & 3 & 6 & 6 & 5 & 3 & 4 & 2 \\
\hline 20 & 447461 & 5030091 & 2005 & 06-07 & 16 & 8 & 4.29 & 0.34 & 34923 & 7 & 7 & 6 & 6 & 6 & 4 & 5 & 5 \\
\hline 20 & 447461 & 5030091 & 2006 & 06-07 & 16 & 8 & 4.27 & 0.34 & 34923 & 6 & 6 & 6 & 6 & 6 & 3 & 3 & 5 \\
\hline 20 & 447461 & 5030091 & 2007 & 06-07 & 16 & 8 & 4.07 & 0.12 & 52863 & 6 & 6 & 7 & 6 & 6 & 3 & 2 & 2 \\
\hline 20 & 447461 & 5030091 & 2008 & 06-07 & 16 & 8 & 3.93 & 0.09 & 52863 & 6 & 6 & 6 & 7 & 7 & 4 & 3 & 3 \\
\hline 20 & 447461 & 5030091 & 2009 & 06-07 & 16 & 8 & 3.80 & 0.11 & 52863 & 6 & 7 & 5 & 3 & 3 & 5 & 5 & 5 \\
\hline 20 & 447461 & 5030091 & 2010 & 06-07 & 16 & 8 & 4.26 & 0.34 & 34923 & 7 & 5 & 7 & 7 & 5 & 2 & 3 & 5 \\
\hline 20 & 447461 & 5030091 & A661 & 06-07 & 16 & 8 & 4.44 & 0.22 & 34923 & 6 & 6 & 6 & 7 & 6 & 2 & 4 & 4 \\
\hline 20 & 447461 & 5030091 & A664 & $06-15$ & 16 & 8 & 4.25 & 0.17 & 52863 & 7 & 6 & 7 & 6 & 6 & 5 & 5 & 5 \\
\hline 20 & 447461 & 5030091 & A680 & 06-07 & 16 & 8 & 4.12 & 0.14 & 52863 & 6 & 6 & 6 & 6 & 6 & 4 & 5 & 5 \\
\hline 20 & 447461 & 5030091 & A703 & 06-12 & 16 & 8 & 4.35 & 0.24 & 52863 & 5 & 6 & 4 & 7 & 7 & 3 & 5 & 1 \\
\hline 21 & 451347 & 5030648 & 2101 & 06-08 & 18 & 11 & 6.40 & 3.49 & 20994 & 3 & 2 & 6 & 7 & 4 & 4 & 2 & 1 \\
\hline 21 & 451347 & 5030648 & 2102 & 06-08 & 18 & 11 & 6.96 & 3.32 & 20994 & 7 & 6 & 6 & 6 & 6 & 4 & 4 & 5 \\
\hline 21 & 451347 & 5030648 & 2103 & 06-08 & 18 & 11 & 7.63 & 3.45 & 36440 & 6 & 6 & 1 & 7 & 7 & 5 & 5 & 5 \\
\hline 21 & 451347 & 5030648 & 2104 & 06-08 & 18 & 11 & 6.40 & 3.49 & 20994 & 5 & 5 & 6 & 6 & 6 & 4 & 5 & 5 \\
\hline 21 & 451347 & 5030648 & 2105 & 06-08 & 18 & 11 & 5.71 & 3.47 & 20994 & 7 & 6 & 7 & 7 & 7 & 5 & 5 & 5 \\
\hline 21 & 451347 & 5030648 & 2106 & 06-08 & 18 & 11 & 7.63 & 3.45 & 36440 & 7 & 6 & 7 & 5 & 7 & 5 & 5 & 5 \\
\hline 21 & 451347 & 5030648 & 2107 & 06-08 & 18 & 11 & 7.63 & 3.45 & 36440 & 6 & 7 & 7 & 7 & 7 & 5 & 5 & 4 \\
\hline 21 & 451347 & 5030648 & 2108 & 06-08 & 18 & 11 & 4.84 & 3.39 & 20994 & 6 & 6 & 6 & 5 & 6 & 1 & 3 & 3 \\
\hline 21 & 451347 & 5030648 & 2110 & 06-08 & 18 & 11 & 7.83 & 3.19 & 20994 & 4 & 5 & 7 & 6 & 5 & 1 & 2 & 5 \\
\hline 22 & 446682 & 5026396 & 2201 & 06-08 & 45 & 13 & 2.17 & 0.04 & 50459 & 6 & 7 & 7 & 7 & 7 & 5 & 5 & 5 \\
\hline 22 & 446682 & 5026396 & 2202 & 06-08 & 45 & 13 & 2.62 & 0.08 & 50459 & 6 & 6 & 6 & 6 & 7 & 3 & 4 & 5 \\
\hline 22 & 446682 & 5026396 & 2203 & 06-08 & 45 & 13 & 2.68 & 0.09 & 50459 & 6 & 6 & 6 & 6 & 6 & 4 & 4 & 4 \\
\hline 22 & 446682 & 5026396 & 2204 & 06-08 & 45 & 13 & 2.35 & 0.07 & 50459 & 5 & 5 & 7 & 6 & 5 & 2 & 4 & 3 \\
\hline 22 & 446682 & 5026396 & 2205 & 06-08 & 45 & 13 & 2.80 & 0.13 & 52917 & 6 & 6 & 7 & 7 & 6 & 5 & 4 & 4 \\
\hline
\end{tabular}




\begin{tabular}{|c|c|c|c|c|c|c|c|c|c|c|c|c|c|c|c|c|c|}
\hline Site & Easting & Northing & User ID & Date & Abun. & Rich. & Tree & Water & Inc. & Q1 & Q2 & Q3 & Q4 & Q5 & Q6 & Q7 & Q8 \\
\hline 22 & 446682 & 5026396 & 2206 & 06-08 & 45 & 13 & 2.98 & 0.15 & 52917 & 4 & 6 & 6 & 4 & 5 & 4 & 4 & 4 \\
\hline 22 & 446682 & 5026396 & 2207 & 06-08 & 45 & 13 & 2.94 & 0.16 & 52917 & 6 & 7 & 7 & 7 & 7 & 4 & 5 & 3 \\
\hline 22 & 446682 & 5026396 & 2208 & 06-08 & 45 & 13 & 2.50 & 0.10 & 50459 & 7 & 7 & 7 & 7 & 7 & 2 & 4 & 4 \\
\hline 22 & 446682 & 5026396 & 2209 & 06-08 & 45 & 13 & 2.48 & 0.14 & 50459 & 6 & 7 & 5 & 4 & 6 & 4 & 2 & 3 \\
\hline 22 & 446682 & 5026396 & 2210 & 06-08 & 45 & 13 & 2.10 & 0.09 & 50459 & 6 & 6 & 7 & 7 & 7 & 5 & 4 & 5 \\
\hline 23 & 441644 & 5021884 & 2301 & 06-09 & 19 & 8 & 3.97 & 2.23 & 45611 & 7 & 6 & 7 & 6 & 6 & 3 & 5 & 5 \\
\hline 23 & 441644 & 5021884 & 2302 & 06-09 & 19 & 8 & 4.01 & 2.27 & 52811 & 6 & 6 & 7 & 6 & 5 & 4 & 5 & 4 \\
\hline 23 & 441644 & 5021884 & 2303 & 06-09 & 19 & 8 & 3.85 & 2.32 & 52811 & 6 & 7 & 6 & 7 & 5 & 4 & 4 & 5 \\
\hline 23 & 441644 & 5021884 & 2304 & 06-09 & 19 & 8 & 3.81 & 2.26 & 45611 & 6 & 5 & 7 & 6 & 5 & 5 & 5 & 4 \\
\hline 23 & 441644 & 5021884 & 2305 & 06-09 & 19 & 8 & 3.79 & 2.26 & 45611 & 6 & 7 & 5 & 6 & 5 & 4 & 3 & 4 \\
\hline 23 & 441644 & 5021884 & 2306 & 06-09 & 19 & 8 & 3.62 & 2.31 & 45611 & 4 & 6 & 7 & 6 & 7 & 2 & 5 & 5 \\
\hline 23 & 441644 & 5021884 & 2307 & 06-09 & 19 & 8 & 3.69 & 2.31 & 45611 & 5 & 5 & 6 & 7 & 6 & 3 & 3 & 3 \\
\hline 23 & 441644 & 5021884 & 2308 & 06-09 & 19 & 8 & 3.78 & 2.23 & 45611 & 5 & 5 & 6 & 5 & 4 & 4 & 4 & 4 \\
\hline 23 & 441644 & 5021884 & 2309 & 06-09 & 19 & 8 & 4.04 & 2.24 & 52811 & 6 & 7 & 6 & 6 & 7 & 4 & 4 & 3 \\
\hline 23 & 441644 & 5021884 & 2310 & 06-09 & 19 & 8 & 3.72 & 2.39 & 45611 & 5 & 6 & 6 & 6 & 6 & 3 & 4 & 4 \\
\hline 24 & 444432 & 5024561 & 2401 & 06-09 & 9 & 6 & 3.93 & 0.36 & 50991 & 6 & 5 & 6 & 7 & 7 & 5 & 2 & 3 \\
\hline 24 & 444432 & 5024561 & 2402 & 06-09 & 9 & 6 & 3.63 & 0.40 & 50991 & 7 & 6 & 7 & 6 & 7 & 4 & 4 & 3 \\
\hline 24 & 444432 & 5024561 & 2403 & 06-09 & 9 & 6 & 3.41 & 0.47 & 50991 & 6 & 6 & 7 & 7 & 5 & 3 & 4 & 4 \\
\hline 24 & 444432 & 5024561 & 2404 & 06-09 & 9 & 6 & 3.44 & 0.52 & 50991 & 5 & 4 & 5 & 6 & 5 & 5 & 5 & 4 \\
\hline 24 & 444432 & 5024561 & 2405 & 06-09 & 9 & 6 & 3.06 & 0.49 & 50991 & 5 & 6 & 7 & 6 & 5 & 3 & 2 & 4 \\
\hline 24 & 444432 & 5024561 & 2406 & 06-09 & 9 & 6 & 4.06 & 0.33 & 50991 & 5 & 5 & 6 & 7 & 5 & 4 & 4 & 5 \\
\hline 24 & 444432 & 5024561 & 2407 & 06-09 & 9 & 6 & 2.23 & 0.45 & 50991 & 6 & 6 & 6 & 6 & 6 & 4 & 4 & 3 \\
\hline 24 & 444432 & 5024561 & 2408 & 06-09 & 9 & 6 & 2.23 & 0.45 & 50991 & 5 & 6 & 5 & 6 & 6 & 4 & 4 & 3 \\
\hline 24 & 444432 & 5024561 & 2409 & 06-09 & 9 & 6 & 2.32 & 0.47 & 50991 & 6 & 6 & 3 & 3 & 3 & 3 & 4 & 5 \\
\hline 24 & 444432 & 5024561 & 2410 & 06-09 & 9 & 6 & 3.99 & 0.31 & 50991 & 6 & 5 & 6 & 6 & 6 & 4 & 4 & 5 \\
\hline
\end{tabular}




\begin{tabular}{|c|c|c|c|c|c|c|c|c|c|c|c|c|c|c|c|c|c|}
\hline Site & Easting & Northing & User ID & Date & Abun. & Rich. & Tree & Water & Inc. & Q1 & Q2 & Q3 & Q4 & Q5 & Q6 & Q7 & Q8 \\
\hline 24 & 444432 & 5024561 & A883 & 06-09 & 9 & 6 & 4.03 & 0.36 & 50991 & 7 & 7 & 6 & 7 & 6 & 5 & 5 & 5 \\
\hline 24 & 444432 & 5024561 & A888 & 06-09 & 9 & 6 & 3.74 & 0.41 & 50991 & 6 & 6 & 5 & 5 & 6 & 3 & 5 & 4 \\
\hline 25 & 436569 & 5022642 & 2501 & $06-12$ & 27 & 12 & 4.14 & 0.12 & 48461 & 4 & 5 & 5 & 6 & 5 & 3 & 4 & 4 \\
\hline 25 & 436569 & 5022642 & 2502 & 06-12 & 27 & 12 & 3.63 & 0.09 & 48461 & 6 & 6 & 6 & 2 & 6 & 4 & 5 & 4 \\
\hline 25 & 436569 & 5022642 & 2503 & 06-12 & 27 & 12 & 3.58 & 0.09 & 48461 & 7 & 7 & 6 & 7 & 6 & 5 & 4 & 3 \\
\hline 25 & 436569 & 5022642 & 2504 & 06-12 & 27 & 12 & 4.04 & 0.13 & 48461 & 6 & 5 & 6 & 7 & 5 & 3 & 4 & 4 \\
\hline 25 & 436569 & 5022642 & 2505 & 06-12 & 27 & 12 & 3.64 & 0.15 & 48461 & 7 & 7 & 7 & 6 & 5 & 3 & 5 & 5 \\
\hline 25 & 436569 & 5022642 & 2506 & $06-12$ & 27 & 12 & 3.97 & 0.14 & 48461 & 6 & 6 & 7 & 7 & 7 & 5 & 5 & 4 \\
\hline 25 & 436569 & 5022642 & 2507 & 06-12 & 27 & 12 & 3.92 & 0.13 & 48461 & 7 & 7 & 6 & 7 & 7 & 5 & 5 & 5 \\
\hline 25 & 436569 & 5022642 & 2508 & $06-12$ & 27 & 12 & 4.59 & 0.17 & 48461 & 6 & 6 & 6 & 6 & 7 & 5 & 5 & 5 \\
\hline 25 & 436569 & 5022642 & 2509 & 06-12 & 27 & 12 & 4.62 & 0.17 & 48461 & 6 & 6 & 7 & 7 & 6 & 5 & 5 & 5 \\
\hline 25 & 436569 & 5022642 & 2510 & $06-12$ & 27 & 12 & 3.05 & 0.11 & 48461 & 6 & 6 & 7 & 7 & 7 & 5 & 5 & 5 \\
\hline 25 & 436569 & 5022642 & A899 & 06-15 & 27 & 12 & 4.33 & 0.15 & 48461 & 5 & 6 & 7 & 7 & 7 & 5 & 5 & 4 \\
\hline 25 & 436569 & 5022642 & A902 & 06-16 & 27 & 12 & 4.19 & 0.13 & 48461 & 7 & 7 & 7 & 7 & 7 & 5 & 5 & 5 \\
\hline 25 & 436569 & 5022642 & A917 & 06-12 & 27 & 12 & 3.35 & 0.11 & 48461 & 5 & 6 & 7 & 7 & 6 & 4 & 4 & 5 \\
\hline 25 & 436569 & 5022642 & A921 & 06-12 & 27 & 12 & 3.41 & 0.13 & 48461 & 7 & 7 & 7 & 7 & 7 & 3 & 2 & 2 \\
\hline 25 & 436569 & 5022642 & A934 & $06-12$ & 27 & 12 & 3.32 & 0.14 & 48461 & 6 & 7 & 7 & 7 & 7 & 4 & 5 & 5 \\
\hline 26 & 437883 & 5020404 & 2601 & $06-12$ & 5 & 4 & 5.66 & 0.98 & 43235 & 7 & 7 & 7 & 7 & 7 & 5 & 5 & 5 \\
\hline 26 & 437883 & 5020404 & 2602 & $06-12$ & 5 & 4 & 4.72 & 0.90 & 43235 & 6 & 7 & 6 & 7 & 7 & 4 & 5 & 5 \\
\hline 26 & 437883 & 5020404 & 2603 & $06-12$ & 5 & 4 & 4.42 & 0.89 & 43235 & 7 & 7 & 7 & 6 & 6 & 2 & 5 & 5 \\
\hline 26 & 437883 & 5020404 & 2604 & $06-12$ & 5 & 4 & 4.72 & 0.97 & 43235 & 6 & 6 & 7 & 6 & 6 & 4 & 5 & 4 \\
\hline 26 & 437883 & 5020404 & 2605 & 06-12 & 5 & 4 & 4.96 & 0.99 & 43235 & 6 & 6 & 6 & 6 & 7 & 4 & 4 & 4 \\
\hline 26 & 437883 & 5020404 & 2606 & $06-12$ & 5 & 4 & 5.27 & 1.02 & 43235 & 6 & 6 & 6 & 6 & 7 & 5 & 5 & 4 \\
\hline 26 & 437883 & 5020404 & 2607 & 06-12 & 5 & 4 & 5.69 & 0.95 & 43235 & 6 & 7 & 7 & 7 & 7 & 5 & 5 & 5 \\
\hline 26 & 437883 & 5020404 & 2608 & 06-12 & 5 & 4 & 5.38 & 0.92 & 43235 & 7 & 7 & 7 & 6 & 7 & 2 & 5 & 5 \\
\hline
\end{tabular}




\begin{tabular}{|c|c|c|c|c|c|c|c|c|c|c|c|c|c|c|c|c|c|}
\hline Site & Easting & Northing & User ID & Date & Abun. & Rich. & Tree & Water & Inc. & Q1 & Q2 & Q3 & Q4 & Q5 & Q6 & Q7 & Q8 \\
\hline 26 & 437883 & 5020404 & 2609 & 06-12 & 5 & 4 & 5.78 & 0.92 & 44716 & 7 & 6 & 7 & 6 & 5 & 4 & 4 & 4 \\
\hline 26 & 437883 & 5020404 & 2610 & 06-12 & 5 & 4 & 4.85 & 0.80 & 44716 & 6 & 7 & 7 & 6 & 6 & 2 & 2 & 3 \\
\hline 26 & 437883 & 5020404 & A942 & 06-12 & 5 & 4 & 5.19 & 0.94 & 43235 & 7 & 7 & 7 & 7 & 6 & 3 & 3 & 3 \\
\hline 26 & 437883 & 5020404 & A961 & 06-13 & 5 & 4 & 5.14 & 0.89 & 44716 & 6 & 6 & 7 & 7 & 7 & 4 & 4 & 3 \\
\hline 27 & 447380 & 5031209 & 2702 & 06-13 & 22 & 10 & 3.10 & 0.06 & 19534 & 6 & 6 & 5 & 7 & 6 & 5 & 4 & 4 \\
\hline 27 & 447380 & 5031209 & 2703 & 06-13 & 22 & 10 & 3.50 & 0.13 & 19534 & 6 & 6 & 6 & 6 & 6 & 4 & 5 & 4 \\
\hline 27 & 447380 & 5031209 & 2704 & 06-13 & 22 & 10 & 3.20 & 0.12 & 19534 & 5 & 5 & 2 & 3 & 3 & 3 & 5 & 5 \\
\hline 27 & 447380 & 5031209 & 2705 & 06-13 & 22 & 10 & 3.23 & 0.16 & 19534 & 7 & 7 & 7 & 7 & 6 & 3 & 4 & 4 \\
\hline 27 & 447380 & 5031209 & 2706 & 06-13 & 22 & 10 & 3.77 & 0.23 & 19534 & 7 & 6 & 6 & 6 & 6 & 5 & 5 & 5 \\
\hline 27 & 447380 & 5031209 & B004 & 06-16 & 22 & 10 & 3.44 & 0.19 & 19534 & 6 & 6 & 6 & 6 & 5 & 3 & 4 & 4 \\
\hline 27 & 447380 & 5031209 & B011 & 06-13 & 22 & 10 & 3.81 & 0.22 & 19534 & 6 & 6 & 7 & 7 & 6 & 4 & 5 & 4 \\
\hline 27 & 447380 & 5031209 & B012 & 06-13 & 22 & 10 & 3.70 & 0.23 & 19534 & 7 & 7 & 6 & 7 & 5 & 3 & 3 & 4 \\
\hline 28 & 449163 & 5033707 & 2801 & 06-13 & 7 & 7 & 5.06 & 0.82 & 38950 & 5 & 6 & 4 & 7 & 5 & 3 & 5 & 3 \\
\hline 28 & 449163 & 5033707 & 2802 & 06-13 & 7 & 7 & 4.98 & 0.81 & 38950 & 6 & 7 & 7 & 7 & 7 & 5 & 5 & 5 \\
\hline 28 & 449163 & 5033707 & 2803 & 06-13 & 7 & 7 & 5.18 & 0.89 & 38950 & 7 & 6 & 6 & 7 & 6 & 4 & 5 & 5 \\
\hline 28 & 449163 & 5033707 & 2804 & 06-13 & 7 & 7 & 5.18 & 0.89 & 38950 & 6 & 6 & 5 & 6 & 6 & 5 & 5 & 4 \\
\hline 28 & 449163 & 5033707 & 2805 & 06-13 & 7 & 7 & 5.18 & 0.89 & 38950 & 6 & 6 & 6 & 7 & 6 & 3 & 4 & 4 \\
\hline 28 & 449163 & 5033707 & 2807 & 06-13 & 7 & 7 & 5.18 & 0.89 & 38950 & 6 & 6 & 7 & 7 & 7 & 5 & 4 & 3 \\
\hline 28 & 449163 & 5033707 & 2808 & 06-13 & 7 & 7 & 4.65 & 0.80 & 38950 & 5 & 6 & 7 & 7 & 7 & 5 & 5 & 5 \\
\hline 28 & 449163 & 5033707 & 2809 & 06-13 & 7 & 7 & 3.94 & 0.73 & 41094 & 7 & 7 & 7 & 7 & 7 & 4 & 5 & 4 \\
\hline 28 & 449163 & 5033707 & 2810 & 06-13 & 7 & 7 & 4.47 & 0.80 & 41094 & 7 & 7 & 7 & 7 & 7 & 5 & 5 & 5 \\
\hline 28 & 449163 & 5033707 & B035 & 06-13 & 7 & 7 & 4.36 & 0.81 & 38950 & 6 & 7 & 7 & 7 & 7 & 4 & 5 & 5 \\
\hline 28 & 449163 & 5033707 & B038 & 06-13 & 7 & 7 & 5.18 & 0.89 & 38950 & 3 & 6 & 7 & 7 & 6 & 4 & 5 & 5 \\
\hline 28 & 449163 & 5033707 & B074 & $07-02$ & 7 & 7 & 5.18 & 0.89 & 38950 & 6 & 6 & 6 & 7 & 5 & 4 & 4 & 3 \\
\hline 28 & 449163 & 5033707 & B076 & $06-24$ & 7 & 7 & 5.18 & 0.89 & 38950 & 5 & 5 & 6 & 7 & 7 & 5 & 5 & 5 \\
\hline
\end{tabular}




\begin{tabular}{|c|c|c|c|c|c|c|c|c|c|c|c|c|c|c|c|c|c|}
\hline Site & Easting & Northing & User ID & Date & Abun. & Rich. & Tree & Water & Inc. & Q1 & Q2 & Q3 & Q4 & Q5 & Q6 & Q7 & Q8 \\
\hline 28 & 449163 & 5033707 & B087 & 06-19 & 7 & 7 & 5.18 & 0.89 & 38950 & 6 & 6 & 6 & 7 & 5 & 4 & 5 & 4 \\
\hline 29 & 446891 & 5025317 & 2901 & 06-14 & 8 & 7 & 5.63 & 0.92 & 33820 & 7 & 6 & 7 & 6 & 4 & 5 & 5 & 5 \\
\hline 29 & 446891 & 5025317 & 2902 & 06-14 & 8 & 7 & 5.45 & 0.93 & 33820 & 5 & 6 & 7 & 6 & 5 & 5 & 4 & 3 \\
\hline 29 & 446891 & 5025317 & 2903 & 06-14 & 8 & 7 & 5.87 & 0.91 & 33820 & 5 & 5 & 6 & 5 & 2 & 2 & 3 & 3 \\
\hline 29 & 446891 & 5025317 & B153 & $06-15$ & 8 & 7 & 5.98 & 0.90 & 33820 & 6 & 6 & 6 & 6 & 5 & 4 & 5 & 5 \\
\hline 30 & 449309 & 5022651 & 3001 & 06-14 & 23 & 14 & 2.40 & 0.50 & 36158 & 7 & 7 & 7 & 6 & 4 & 3 & 3 & 4 \\
\hline 30 & 449309 & 5022651 & 3002 & 06-14 & 23 & 14 & 2.45 & 0.50 & 36158 & 6 & 5 & 6 & 6 & 4 & 1 & 4 & 4 \\
\hline 30 & 449309 & 5022651 & 3003 & 06-14 & 23 & 14 & 2.50 & 0.50 & 36158 & 6 & 7 & 7 & 6 & 6 & 4 & 5 & 5 \\
\hline 30 & 449309 & 5022651 & 3004 & 06-14 & 23 & 14 & 2.54 & 0.51 & 36158 & 6 & 6 & 6 & 6 & 6 & 4 & 5 & 4 \\
\hline 30 & 449309 & 5022651 & 3005 & 06-14 & 23 & 14 & 2.55 & 0.51 & 36158 & 7 & 7 & 6 & 6 & 4 & 4 & 4 & 4 \\
\hline 30 & 449309 & 5022651 & 3006 & 06-14 & 23 & 14 & 2.58 & 0.51 & 36158 & 6 & 6 & 6 & 6 & 4 & 4 & 5 & 5 \\
\hline 30 & 449309 & 5022651 & 3007 & 06-14 & 23 & 14 & 2.60 & 0.52 & 36158 & 6 & 6 & 7 & 6 & 6 & 1 & 3 & 1 \\
\hline 30 & 449309 & 5022651 & 3008 & 06-14 & 23 & 14 & 2.75 & 0.55 & 36158 & 1 & 2 & 7 & 6 & 6 & 4 & 4 & 2 \\
\hline 30 & 449309 & 5022651 & 3009 & 06-14 & 23 & 14 & 3.02 & 0.57 & 36158 & 6 & 6 & 7 & 6 & 6 & 4 & 5 & 3 \\
\hline 30 & 449309 & 5022651 & 3010 & 06-14 & 23 & 14 & 2.96 & 0.56 & 36158 & 6 & 7 & 7 & 7 & 5 & 3 & 5 & 4 \\
\hline 30 & 449309 & 5022651 & B165 & 06-14 & 23 & 14 & 2.37 & 0.47 & 30673 & 7 & 6 & 6 & 6 & 5 & 5 & 5 & 5 \\
\hline 31 & 447412 & 5021470 & 3101 & $06-15$ & 27 & 12 & 4.36 & 1.52 & 48973 & 7 & 6 & 6 & 7 & 7 & 5 & 5 & 5 \\
\hline 31 & 447412 & 5021470 & 3102 & 06-15 & 27 & 12 & 4.18 & 1.54 & 48973 & 5 & 6 & 6 & 6 & 6 & 4 & 5 & 5 \\
\hline 31 & 447412 & 5021470 & 3103 & $06-15$ & 27 & 12 & 4.12 & 1.56 & 48973 & 6 & 6 & 5 & 6 & 6 & 4 & 4 & 4 \\
\hline 31 & 447412 & 5021470 & 3104 & 06-15 & 27 & 12 & 3.92 & 1.62 & 48973 & 7 & 7 & 7 & 6 & 3 & 3 & 5 & 4 \\
\hline 31 & 447412 & 5021470 & 3105 & $06-15$ & 27 & 12 & 3.92 & 1.66 & 48973 & 7 & 6 & 7 & 6 & 6 & 2 & 5 & 5 \\
\hline 31 & 447412 & 5021470 & 3106 & $06-15$ & 27 & 12 & 4.70 & 1.47 & 48973 & 6 & 6 & 6 & 7 & 7 & 5 & 5 & 5 \\
\hline 31 & 447412 & 5021470 & 3107 & $06-15$ & 27 & 12 & 4.44 & 1.57 & 34904 & 7 & 7 & 7 & 6 & 6 & 4 & 5 & 5 \\
\hline 31 & 447412 & 5021470 & 3108 & 06-15 & 27 & 12 & 5.01 & 1.44 & 48973 & 6 & 6 & 5 & 5 & 4 & 3 & 4 & 3 \\
\hline 31 & 447412 & 5021470 & 3109 & 06-15 & 27 & 12 & 5.01 & 1.44 & 48973 & 6 & 6 & 6 & 6 & 6 & 4 & 5 & 5 \\
\hline
\end{tabular}




\begin{tabular}{|c|c|c|c|c|c|c|c|c|c|c|c|c|c|c|c|c|c|}
\hline Site & Easting & Northing & User ID & Date & Abun. & Rich. & Tree & Water & Inc. & Q1 & Q2 & Q3 & Q4 & Q5 & Q6 & Q7 & Q8 \\
\hline 31 & 447412 & 5021470 & 3110 & $06-15$ & 27 & 12 & 5.02 & 1.43 & 48973 & 6 & 6 & 6 & 7 & 6 & 5 & 4 & 4 \\
\hline 31 & 447412 & 5021470 & B192 & $06-15$ & 27 & 12 & 4.05 & 1.58 & 48973 & 6 & 6 & 5 & 5 & 5 & 3 & 3 & 3 \\
\hline 31 & 447412 & 5021470 & B197 & $06-15$ & 27 & 12 & 3.93 & 1.61 & 48973 & 5 & 5 & 6 & 6 & 4 & 2 & 2 & 2 \\
\hline 31 & 447412 & 5021470 & B198 & 06-17 & 27 & 12 & 3.94 & 1.62 & 48973 & 6 & 6 & 5 & 3 & 4 & 2 & 4 & 4 \\
\hline 32 & 444906 & 5022100 & 3201 & $06-15$ & 40 & 18 & 3.98 & 0.09 & 50388 & 6 & 7 & 7 & 6 & 7 & 4 & 3 & 3 \\
\hline 32 & 444906 & 5022100 & 3202 & 06-15 & 40 & 18 & 4.13 & 0.06 & 39111 & 1 & 6 & 6 & 6 & 5 & 4 & 3 & 3 \\
\hline 32 & 444906 & 5022100 & 3203 & $06-15$ & 40 & 18 & 4.04 & 0.06 & 39111 & 6 & 7 & 4 & 5 & 4 & 1 & 4 & 4 \\
\hline 32 & 444906 & 5022100 & 3204 & 06-15 & 40 & 18 & 4.60 & 0.24 & 39111 & 5 & 6 & 7 & 6 & 6 & 5 & 5 & 5 \\
\hline 32 & 444906 & 5022100 & 3205 & $06-15$ & 40 & 18 & 3.98 & 0.19 & 39111 & 7 & 7 & 6 & 6 & 4 & 3 & 3 & 2 \\
\hline 33 & 440186 & 5023966 & 3301 & 06-16 & 11 & 8 & 3.98 & 1.73 & 49716 & 7 & 7 & 7 & 7 & 6 & 1 & 5 & 5 \\
\hline 33 & 440186 & 5023966 & 3302 & $06-16$ & 11 & 8 & 3.46 & 1.81 & 49716 & 7 & 6 & 6 & 6 & 6 & 2 & 3 & 4 \\
\hline 33 & 440186 & 5023966 & 3303 & 06-16 & 11 & 8 & 3.68 & 1.77 & 49716 & 7 & 7 & 7 & 6 & 5 & 1 & 4 & 4 \\
\hline 33 & 440186 & 5023966 & 3304 & $06-16$ & 11 & 8 & 3.98 & 1.69 & 49716 & 7 & 7 & 7 & 6 & 6 & 5 & 5 & 5 \\
\hline 33 & 440186 & 5023966 & 3305 & 06-16 & 11 & 8 & 3.96 & 1.66 & 49716 & 6 & 6 & 7 & 7 & 6 & 5 & 5 & 5 \\
\hline 33 & 440186 & 5023966 & 3306 & 06-16 & 11 & 8 & 3.98 & 1.63 & 49716 & 7 & 7 & 7 & 6 & 7 & 5 & 5 & 5 \\
\hline 33 & 440186 & 5023966 & 3307 & $06-16$ & 11 & 8 & 3.97 & 1.80 & 63916 & 6 & 6 & 6 & 6 & 7 & 4 & 5 & 5 \\
\hline 33 & 440186 & 5023966 & 3308 & 06-16 & 11 & 8 & 3.96 & 1.82 & 63916 & 6 & 6 & 6 & 6 & 6 & 3 & 4 & 5 \\
\hline 33 & 440186 & 5023966 & 3309 & $06-16$ & 11 & 8 & 4.16 & 1.73 & 63916 & 5 & 5 & 6 & 6 & 5 & 4 & 5 & 5 \\
\hline 33 & 440186 & 5023966 & 3310 & 06-16 & 11 & 8 & 4.13 & 1.57 & 49716 & 6 & 7 & 7 & 7 & 7 & 5 & 3 & 3 \\
\hline 33 & 440186 & 5023966 & B319 & 06-17 & 11 & 8 & 4.00 & 1.62 & 49716 & 6 & 7 & 5 & 6 & 4 & 4 & 3 & 3 \\
\hline 33 & 440186 & 5023966 & B341 & $06-21$ & 11 & 8 & 4.21 & 1.71 & 63916 & 6 & 7 & 5 & 3 & 2 & 3 & 4 & 3 \\
\hline 33 & 440186 & 5023966 & B342 & $06-29$ & 11 & 8 & 4.23 & 1.69 & 63916 & 4 & 6 & 7 & 7 & 6 & 4 & 4 & 4 \\
\hline 34 & 438997 & 5020593 & 3401 & 06-16 & 11 & 3 & 3.58 & 1.74 & 39059 & 6 & 6 & 6 & 7 & 5 & 5 & 2 & 4 \\
\hline 34 & 438997 & 5020593 & 3402 & 06-16 & 11 & 3 & 3.56 & 1.81 & 39059 & 6 & 6 & 7 & 7 & 6 & 2 & 4 & 5 \\
\hline 34 & 438997 & 5020593 & 3403 & $06-16$ & 11 & 3 & 3.62 & 1.87 & 39059 & 5 & 7 & 6 & 6 & 5 & 2 & 3 & 4 \\
\hline
\end{tabular}




\begin{tabular}{|c|c|c|c|c|c|c|c|c|c|c|c|c|c|c|c|c|c|}
\hline Site & Easting & Northing & User ID & Date & Abun. & Rich. & Tree & Water & Inc. & Q1 & Q2 & Q3 & Q4 & Q5 & Q6 & Q7 & Q8 \\
\hline 34 & 438997 & 5020593 & 3404 & 06-16 & 11 & 3 & 3.65 & 1.91 & 39059 & 6 & 6 & 7 & 7 & 7 & 4 & 4 & 5 \\
\hline 34 & 438997 & 5020593 & 3405 & 06-16 & 11 & 3 & 3.69 & 1.85 & 39059 & 6 & 6 & 5 & 5 & 5 & 4 & 3 & 4 \\
\hline 34 & 438997 & 5020593 & 3406 & $06-16$ & 11 & 3 & 3.55 & 1.85 & 39059 & 4 & 5 & 5 & 4 & 4 & 3 & 5 & 5 \\
\hline 34 & 438997 & 5020593 & 3407 & $06-16$ & 11 & 3 & 3.56 & 1.85 & 39059 & 4 & 6 & 7 & 7 & 6 & 5 & 5 & 5 \\
\hline 34 & 438997 & 5020593 & 3408 & 06-16 & 11 & 3 & 3.77 & 1.80 & 45365 & 5 & 6 & 6 & 6 & 6 & 4 & 5 & 5 \\
\hline 34 & 438997 & 5020593 & 3409 & 06-16 & 11 & 3 & 3.84 & 1.79 & 45365 & 6 & 6 & 5 & 6 & 5 & 3 & 4 & 4 \\
\hline 34 & 438997 & 5020593 & 3410 & $06-16$ & 11 & 3 & 3.81 & 1.78 & 45365 & 7 & 7 & 7 & 7 & 6 & 4 & 4 & 4 \\
\hline 34 & 438997 & 5020593 & B348 & 06-17 & 11 & 3 & 3.60 & 1.76 & 39059 & 7 & 7 & 7 & 7 & 6 & 4 & 5 & 5 \\
\hline 34 & 438997 & 5020593 & B362 & $06-16$ & 11 & 3 & 3.70 & 2.00 & 39059 & 6 & 7 & 7 & 7 & 6 & 4 & 5 & 5 \\
\hline 35 & 449037 & 5031682 & 3501 & 06-19 & 19 & 8 & 4.22 & 1.43 & 23734 & 1 & 7 & 1 & 5 & 3 & 3 & 5 & 5 \\
\hline 35 & 449037 & 5031682 & 3502 & 06-19 & 19 & 8 & 4.49 & 1.49 & 30977 & 6 & 5 & 7 & 7 & 7 & 2 & 5 & 5 \\
\hline 35 & 449037 & 5031682 & 3503 & 06-19 & 19 & 8 & 4.44 & 1.50 & 30977 & 7 & 7 & 6 & 6 & 5 & 1 & 4 & 5 \\
\hline 35 & 449037 & 5031682 & 3504 & 06-19 & 19 & 8 & 4.49 & 1.50 & 30977 & 7 & 6 & 6 & 6 & 6 & 4 & 5 & 5 \\
\hline 35 & 449037 & 5031682 & 3505 & 06-19 & 19 & 8 & 4.19 & 1.48 & 30977 & 4 & 4 & 7 & 7 & 6 & 3 & 3 & 3 \\
\hline 35 & 449037 & 5031682 & 3506 & 06-19 & 19 & 8 & 4.00 & 1.48 & 30977 & 6 & 6 & 6 & 5 & 4 & 3 & 4 & 4 \\
\hline 35 & 449037 & 5031682 & 3507 & 06-19 & 19 & 8 & 3.89 & 1.48 & 30977 & 6 & 4 & 6 & 6 & 5 & 1 & 5 & 5 \\
\hline 35 & 449037 & 5031682 & 3508 & 06-19 & 19 & 8 & 4.16 & 1.57 & 30977 & 6 & 7 & 6 & 6 & 6 & 5 & 5 & 5 \\
\hline 35 & 449037 & 5031682 & 3509 & 06-19 & 19 & 8 & 4.10 & 1.56 & 30977 & 7 & 7 & 6 & 6 & 7 & 1 & 4 & 4 \\
\hline 35 & 449037 & 5031682 & 3510 & 06-19 & 19 & 8 & 3.93 & 1.56 & 30977 & 6 & 6 & 7 & 7 & 6 & 4 & 5 & 5 \\
\hline 35 & 449037 & 5031682 & B392 & $06-24$ & 19 & 8 & 4.48 & 1.55 & 30977 & 6 & 6 & 6 & 7 & 5 & 1 & 4 & 4 \\
\hline 36 & 445624 & 5029485 & 3601 & 06-19 & 14 & 3 & 2.30 & 0.68 & 23151 & 6 & 7 & 4 & 6 & 5 & 2 & 5 & 5 \\
\hline 36 & 445624 & 5029485 & 3602 & 06-19 & 14 & 3 & 2.16 & 0.88 & 36220 & 6 & 6 & 6 & 6 & 5 & 3 & 5 & 5 \\
\hline 36 & 445624 & 5029485 & B455 & $06-24$ & 14 & 3 & 2.28 & 0.85 & 36220 & 4 & 5 & 6 & 2 & 2 & 2 & 5 & 5 \\
\hline 37 & 450594 & 5022241 & 3701 & $06-20$ & 19 & 13 & 3.19 & 1.27 & 37587 & 6 & 6 & 5 & 6 & 6 & 4 & 4 & 5 \\
\hline 37 & 450594 & 5022241 & 3702 & $06-20$ & 19 & 13 & 3.09 & 1.32 & 25645 & 6 & 6 & 7 & 6 & 6 & 5 & 5 & 5 \\
\hline
\end{tabular}




\begin{tabular}{|c|c|c|c|c|c|c|c|c|c|c|c|c|c|c|c|c|c|}
\hline Site & Easting & Northing & User ID & Date & Abun. & Rich. & Tree & Water & Inc. & Q1 & Q2 & Q3 & Q4 & Q5 & Q6 & Q7 & Q8 \\
\hline 37 & 450594 & 5022241 & 3703 & $06-20$ & 19 & 13 & 3.13 & 1.28 & 25645 & 5 & 4 & 5 & 5 & 6 & 4 & 3 & 4 \\
\hline 37 & 450594 & 5022241 & 3704 & $06-20$ & 19 & 13 & 3.13 & 1.28 & 25645 & 7 & 6 & 7 & 7 & 6 & 5 & 5 & 4 \\
\hline 37 & 450594 & 5022241 & 3705 & $06-20$ & 19 & 13 & 3.63 & 1.03 & 37587 & 6 & 7 & 6 & 6 & 7 & 3 & 4 & 3 \\
\hline 37 & 450594 & 5022241 & 3706 & $06-20$ & 19 & 13 & 3.89 & 0.96 & 37587 & 6 & 7 & 6 & 6 & 6 & 4 & 5 & 4 \\
\hline 37 & 450594 & 5022241 & 3707 & $06-20$ & 19 & 13 & 4.01 & 0.92 & 37587 & 7 & 7 & 6 & 6 & 3 & 4 & 5 & 4 \\
\hline 37 & 450594 & 5022241 & 3708 & $06-20$ & 19 & 13 & 4.12 & 0.89 & 37587 & 7 & 7 & 6 & 5 & 5 & 3 & 5 & 5 \\
\hline 37 & 450594 & 5022241 & 3709 & $06-20$ & 19 & 13 & 3.08 & 1.26 & 25645 & 5 & 3 & 2 & 6 & 4 & 1 & 5 & 3 \\
\hline 37 & 450594 & 5022241 & 3710 & $06-20$ & 19 & 13 & 3.08 & 1.26 & 25645 & 6 & 5 & 6 & 7 & 5 & 4 & 5 & 4 \\
\hline 38 & 449032 & 5027102 & 3801 & $06-20$ & 32 & 11 & 4.64 & 1.35 & 58680 & 6 & 6 & 6 & 6 & 7 & 5 & 5 & 5 \\
\hline 38 & 449032 & 5027102 & 3802 & $06-20$ & 32 & 11 & 5.50 & 1.43 & 58680 & 6 & 6 & 7 & 7 & 6 & 5 & 4 & 4 \\
\hline 38 & 449032 & 5027102 & 3803 & $06-20$ & 32 & 11 & 5.23 & 1.35 & 58680 & 7 & 7 & 6 & 7 & 7 & 3 & 5 & 5 \\
\hline 38 & 449032 & 5027102 & 3804 & $06-20$ & 32 & 11 & 5.13 & 1.33 & 58680 & 6 & 6 & 7 & 7 & 6 & 3 & 4 & 5 \\
\hline 38 & 449032 & 5027102 & 3805 & $06-20$ & 32 & 11 & 4.66 & 1.28 & 58680 & 6 & 6 & 6 & 7 & 6 & 4 & 5 & 5 \\
\hline 38 & 449032 & 5027102 & 3806 & $06-20$ & 32 & 11 & 4.94 & 1.35 & 58680 & 6 & 6 & 6 & 6 & 6 & 5 & 5 & 4 \\
\hline 38 & 449032 & 5027102 & 3807 & $06-20$ & 32 & 11 & 4.87 & 1.37 & 58680 & 5 & 6 & 6 & 7 & 7 & 3 & 5 & 5 \\
\hline 38 & 449032 & 5027102 & 3808 & $06-20$ & 32 & 11 & 6.18 & 1.45 & 58680 & 5 & 7 & 7 & 7 & 7 & 4 & 5 & 4 \\
\hline 38 & 449032 & 5027102 & 3809 & $06-20$ & 32 & 11 & 5.40 & 1.43 & 58680 & 5 & 6 & 7 & 7 & 6 & 3 & 2 & 4 \\
\hline 38 & 449032 & 5027102 & 3810 & $06-20$ & 32 & 11 & 4.95 & 1.40 & 58680 & 5 & 3 & 7 & 4 & 5 & 1 & 4 & 4 \\
\hline 38 & 449032 & 5027102 & B580 & $06-21$ & 32 & 11 & 7.27 & 1.52 & 58680 & 6 & 7 & 7 & 6 & 7 & 4 & 5 & 5 \\
\hline 38 & 449032 & 5027102 & B601 & $06-21$ & 32 & 11 & 6.77 & 1.46 & 58680 & 6 & 6 & 6 & 7 & 6 & 3 & 4 & 4 \\
\hline 39 & 446374 & 5023581 & 3901 & $06-21$ & 28 & 8 & 3.30 & 0.33 & 41353 & 7 & 7 & 6 & 7 & 6 & 5 & 5 & 5 \\
\hline 39 & 446374 & 5023581 & 3902 & $06-21$ & 28 & 8 & 3.30 & 0.33 & 41353 & 6 & 6 & 7 & 7 & 7 & 5 & 5 & 5 \\
\hline 39 & 446374 & 5023581 & 3903 & $06-21$ & 28 & 8 & 3.34 & 0.35 & 41353 & 7 & 4 & 7 & 4 & 5 & 5 & 3 & 3 \\
\hline 39 & 446374 & 5023581 & 3904 & $06-21$ & 28 & 8 & 2.97 & 0.35 & 62487 & 6 & 6 & 7 & 7 & 7 & 5 & 5 & 5 \\
\hline 39 & 446374 & 5023581 & 3905 & $06-21$ & 28 & 8 & 2.97 & 0.35 & 62487 & 6 & 7 & 5 & 6 & 6 & 4 & 5 & 5 \\
\hline
\end{tabular}




\begin{tabular}{|c|c|c|c|c|c|c|c|c|c|c|c|c|c|c|c|c|c|}
\hline Site & Easting & Northing & User ID & Date & Abun. & Rich. & Tree & Water & Inc. & Q1 & Q2 & Q3 & Q4 & Q5 & Q6 & Q7 & Q8 \\
\hline 39 & 446374 & 5023581 & 3906 & $06-21$ & 28 & 8 & 3.02 & 0.38 & 62487 & 5 & 6 & 6 & 6 & 5 & 3 & 4 & 3 \\
\hline 39 & 446374 & 5023581 & 3907 & $06-21$ & 28 & 8 & 3.16 & 0.42 & 62487 & 6 & 6 & 7 & 7 & 7 & 5 & 5 & 5 \\
\hline 39 & 446374 & 5023581 & 3908 & $06-21$ & 28 & 8 & 3.71 & 0.44 & 39909 & 7 & 7 & 6 & 7 & 6 & 5 & 5 & 5 \\
\hline 39 & 446374 & 5023581 & 3909 & $06-21$ & 28 & 8 & 3.74 & 0.44 & 39909 & 6 & 6 & 7 & 7 & 6 & 4 & 4 & 4 \\
\hline 39 & 446374 & 5023581 & 3910 & $06-21$ & 28 & 8 & 3.48 & 0.47 & 39909 & 6 & 6 & 7 & 7 & 7 & 5 & 5 & 5 \\
\hline 39 & 446374 & 5023581 & B620 & $07-14$ & 28 & 8 & 3.30 & 0.33 & 41353 & 6 & 6 & 6 & 7 & 6 & 4 & 3 & 4 \\
\hline 39 & 446374 & 5023581 & B655 & $06-22$ & 28 & 8 & 3.58 & 0.41 & 39909 & 5 & 3 & 7 & 7 & 6 & 3 & 4 & 4 \\
\hline 40 & 441189 & 5020508 & 4001 & $06-21$ & 13 & 5 & 3.85 & 1.72 & 36702 & 5 & 6 & 4 & 6 & 6 & 3 & 4 & 4 \\
\hline 40 & 441189 & 5020508 & 4002 & $06-21$ & 13 & 5 & 3.61 & 1.75 & 36702 & 6 & 6 & 6 & 6 & 7 & 4 & 5 & 5 \\
\hline 40 & 441189 & 5020508 & 4003 & $06-21$ & 13 & 5 & 3.60 & 1.77 & 36702 & 6 & 6 & 6 & 6 & 6 & 3 & 5 & 5 \\
\hline 40 & 441189 & 5020508 & 4004 & $06-21$ & 13 & 5 & 3.49 & 1.77 & 36702 & 6 & 5 & 6 & 6 & 7 & 2 & 4 & 3 \\
\hline 40 & 441189 & 5020508 & 4005 & $06-21$ & 13 & 5 & 3.29 & 1.80 & 36702 & 6 & 7 & 7 & 6 & 5 & 4 & 5 & 5 \\
\hline 40 & 441189 & 5020508 & 4006 & $06-21$ & 13 & 5 & 3.22 & 1.83 & 36702 & 7 & 7 & 6 & 6 & 6 & 4 & 4 & 4 \\
\hline 40 & 441189 & 5020508 & 4007 & $06-21$ & 13 & 5 & 2.55 & 1.84 & 36702 & 7 & 7 & 7 & 7 & 6 & 4 & 5 & 5 \\
\hline 40 & 441189 & 5020508 & 4008 & $06-21$ & 13 & 5 & 3.27 & 1.78 & 36702 & 6 & 6 & 6 & 6 & 6 & 3 & 4 & 5 \\
\hline 40 & 441189 & 5020508 & 4009 & $06-21$ & 13 & 5 & 3.21 & 1.77 & 36702 & 1 & 6 & 7 & 2 & 5 & 4 & 5 & 5 \\
\hline 40 & 441189 & 5020508 & 4010 & $06-21$ & 13 & 5 & 3.47 & 1.73 & 36702 & 6 & 3 & 6 & 5 & 2 & 2 & 4 & 3 \\
\hline 40 & 441189 & 5020508 & 4011 & $06-21$ & 13 & 5 & 3.50 & 1.73 & 36702 & 4 & 1 & 1 & 3 & 4 & 5 & 5 & 5 \\
\hline 40 & 441189 & 5020508 & B671 & $06-21$ & 13 & 5 & 3.45 & 1.77 & 36702 & 6 & 6 & 5 & 5 & 4 & 3 & 5 & 5 \\
\hline 40 & 441189 & 5020508 & B682 & $06-22$ & 13 & 5 & 2.93 & 1.84 & 36702 & 2 & 2 & 4 & 6 & 6 & 4 & 4 & 4 \\
\hline 41 & 437351 & 5023988 & 4101 & $06-22$ & 30 & 13 & 2.34 & 0.06 & 53589 & 7 & 7 & 7 & 7 & 7 & 4 & 5 & 5 \\
\hline 41 & 437351 & 5023988 & 4102 & $06-22$ & 30 & 13 & 4.10 & 0.07 & 53589 & 6 & 4 & 6 & 7 & 6 & 3 & 3 & 4 \\
\hline 41 & 437351 & 5023988 & 4103 & $06-22$ & 30 & 13 & 3.75 & 0.09 & 53589 & 6 & 7 & 7 & 7 & 7 & 5 & 5 & 5 \\
\hline 41 & 437351 & 5023988 & 4104 & $06-22$ & 30 & 13 & 2.99 & 0.11 & 53589 & 6 & 6 & 6 & 6 & 7 & 5 & 5 & 5 \\
\hline 41 & 437351 & 5023988 & 4105 & $06-22$ & 30 & 13 & 6.00 & 0.28 & 53589 & 7 & 7 & 7 & 7 & 7 & 5 & 5 & 4 \\
\hline
\end{tabular}




\begin{tabular}{|c|c|c|c|c|c|c|c|c|c|c|c|c|c|c|c|c|c|}
\hline Site & Easting & Northing & User ID & Date & Abun. & Rich. & Tree & Water & Inc. & Q1 & Q2 & Q3 & Q4 & Q5 & Q6 & Q7 & Q8 \\
\hline 41 & 437351 & 5023988 & 4106 & $06-22$ & 30 & 13 & 6.12 & 0.27 & 53589 & 6 & 7 & 7 & 7 & 7 & 5 & 5 & 5 \\
\hline 41 & 437351 & 5023988 & 4107 & $06-22$ & 30 & 13 & 5.68 & 0.13 & 53589 & 7 & 6 & 6 & 5 & 7 & 4 & 5 & 5 \\
\hline 41 & 437351 & 5023988 & 4108 & $06-22$ & 30 & 13 & 8.10 & 0.21 & 53589 & 7 & 7 & 7 & 7 & 7 & 5 & 5 & 5 \\
\hline 41 & 437351 & 5023988 & 4109 & $06-22$ & 30 & 13 & 8.24 & 0.20 & 53589 & 7 & 7 & 6 & 7 & 7 & 4 & 4 & 5 \\
\hline 41 & 437700 & 5024115 & 4110 & $06-22$ & 19 & 14 & 8.92 & 0.17 & 32199 & 7 & 7 & 7 & 7 & 7 & 4 & 4 & 4 \\
\hline 41 & 437351 & 5023988 & B721 & $06-26$ & 30 & 13 & 6.32 & 0.26 & 53589 & 6 & 7 & 7 & 7 & 7 & 5 & 5 & 5 \\
\hline 41 & 437351 & 5023988 & B733 & $06-23$ & 30 & 13 & 7.88 & 0.21 & 53589 & 6 & 6 & 7 & 7 & 7 & 3 & 5 & 5 \\
\hline 41 & 437700 & 5024115 & B744 & $10-01$ & 19 & 14 & 9.44 & 0.16 & 32199 & 6 & 6 & 7 & 7 & 7 & 5 & 4 & 5 \\
\hline 42 & 439912 & 5022331 & 4201 & $06-22$ & 20 & 9 & 5.30 & 2.58 & 29502 & 6 & 6 & 6 & 6 & 7 & 1 & 4 & 4 \\
\hline 42 & 439912 & 5022331 & 4202 & $06-22$ & 20 & 9 & 4.63 & 2.64 & 29502 & 7 & 7 & 7 & 6 & 4 & 5 & 5 & 5 \\
\hline 42 & 439912 & 5022331 & 4203 & $06-22$ & 20 & 9 & 2.86 & 2.71 & 29502 & 6 & 7 & 7 & 6 & 4 & 2 & 5 & 5 \\
\hline 42 & 439912 & 5022331 & 4204 & $06-22$ & 20 & 9 & 3.46 & 2.59 & 29502 & 6 & 5 & 7 & 7 & 6 & 5 & 5 & 4 \\
\hline 42 & 439912 & 5022331 & 4205 & $06-22$ & 20 & 9 & 3.31 & 2.68 & 29502 & 5 & 4 & 7 & 7 & 6 & 1 & 4 & 5 \\
\hline 42 & 439912 & 5022331 & 4206 & $06-22$ & 20 & 9 & 3.88 & 2.60 & 29502 & 6 & 6 & 7 & 7 & 6 & 4 & 5 & 4 \\
\hline 42 & 439912 & 5022331 & 4207 & $06-22$ & 20 & 9 & 4.53 & 2.54 & 29502 & 6 & 6 & 7 & 7 & 6 & 5 & 5 & 5 \\
\hline 42 & 439912 & 5022331 & 4208 & $06-22$ & 20 & 9 & 4.79 & 2.58 & 29502 & 6 & 7 & 7 & 6 & 6 & 5 & 4 & 5 \\
\hline 42 & 439912 & 5022331 & 4209 & $06-22$ & 20 & 9 & 3.63 & 2.67 & 29502 & 7 & 6 & 4 & 7 & 7 & 5 & 5 & 5 \\
\hline 42 & 439912 & 5022331 & 4210 & $06-22$ & 20 & 9 & 3.53 & 2.69 & 29502 & 7 & 7 & 5 & 6 & 6 & 1 & 5 & 5 \\
\hline 42 & 439912 & 5022331 & B757 & 07-09 & 20 & 9 & 5.13 & 2.60 & 29502 & 3 & 3 & 4 & 5 & 5 & 1 & 2 & 2 \\
\hline 43 & 446520 & 5027733 & 4301 & $06-28$ & 9 & 4 & 3.16 & 0.40 & 44891 & 7 & 7 & 7 & 7 & 7 & 5 & 4 & 5 \\
\hline 43 & 446520 & 5027733 & 4302 & $06-28$ & 9 & 4 & 3.21 & 0.40 & 44891 & 7 & 7 & 7 & 7 & 6 & 3 & 4 & 5 \\
\hline 43 & 446520 & 5027733 & 4303 & $06-28$ & 9 & 4 & 3.09 & 0.33 & 44891 & 6 & 6 & 7 & 6 & 6 & 4 & 4 & 4 \\
\hline 43 & 446520 & 5027733 & 4304 & 06-28 & 9 & 4 & 3.09 & 0.33 & 44891 & 7 & 6 & 7 & 6 & 7 & 5 & 4 & 4 \\
\hline 43 & 446520 & 5027733 & 4305 & $06-28$ & 9 & 4 & 3.19 & 0.31 & 44891 & 6 & 5 & 6 & 3 & 5 & 1 & 5 & 5 \\
\hline 43 & 446520 & 5027733 & 4306 & $06-28$ & 9 & 4 & 3.93 & 0.28 & 44891 & 7 & 7 & 7 & 6 & 7 & 4 & 5 & 5 \\
\hline
\end{tabular}




\begin{tabular}{|c|c|c|c|c|c|c|c|c|c|c|c|c|c|c|c|c|c|}
\hline Site & Easting & Northing & User ID & Date & Abun. & Rich. & Tree & Water & Inc. & Q1 & Q2 & Q3 & Q4 & Q5 & Q6 & Q7 & Q8 \\
\hline 43 & 446520 & 5027733 & 4307 & $06-28$ & 9 & 4 & 4.21 & 0.27 & 44891 & 5 & 5 & 4 & 5 & 3 & 4 & 4 & 3 \\
\hline 43 & 446520 & 5027733 & 4308 & $06-28$ & 9 & 4 & 4.13 & 0.23 & 52421 & 4 & 6 & 7 & 5 & 5 & 3 & 3 & 4 \\
\hline 43 & 446520 & 5027733 & 4309 & $06-28$ & 9 & 4 & 3.97 & 0.23 & 52421 & 6 & 6 & 7 & 7 & 7 & 5 & 5 & 4 \\
\hline 43 & 446520 & 5027733 & 4310 & $06-28$ & 9 & 4 & 3.73 & 0.23 & 52421 & 6 & 6 & 2 & 2 & 2 & 4 & 3 & 3 \\
\hline 43 & 446520 & 5027733 & B807 & $07-17$ & 9 & 4 & 3.95 & 0.23 & 52421 & 6 & 6 & 7 & 7 & 6 & 4 & 5 & 5 \\
\hline 44 & 447025 & 5032594 & 4401 & $06-28$ & 17 & 8 & 4.68 & 0.69 & 51452 & 7 & 7 & 7 & 7 & 6 & 4 & 5 & 5 \\
\hline 44 & 447025 & 5032594 & 4402 & $06-28$ & 17 & 8 & 4.40 & 0.78 & 51452 & 5 & 6 & 7 & 7 & 7 & 5 & 5 & 5 \\
\hline 44 & 447025 & 5032594 & 4403 & $06-28$ & 17 & 8 & 4.39 & 0.80 & 51452 & 6 & 7 & 7 & 7 & 7 & 3 & 4 & 3 \\
\hline 44 & 447025 & 5032594 & 4404 & $06-28$ & 17 & 8 & 4.40 & 0.77 & 51452 & 6 & 6 & 7 & 7 & 7 & 4 & 4 & 4 \\
\hline 44 & 447025 & 5032594 & 4405 & $06-28$ & 17 & 8 & 4.48 & 0.73 & 51452 & 6 & 6 & 7 & 7 & 6 & 5 & 5 & 5 \\
\hline 44 & 447025 & 5032594 & 4406 & $06-28$ & 17 & 8 & 4.48 & 0.67 & 51452 & 5 & 6 & 6 & 6 & 6 & 4 & 3 & 3 \\
\hline 44 & 447025 & 5032594 & 4407 & $06-28$ & 17 & 8 & 4.61 & 0.68 & 51452 & 4 & 6 & 7 & 6 & 6 & 3 & 4 & 2 \\
\hline 44 & 447025 & 5032594 & 4408 & $06-28$ & 17 & 8 & 4.55 & 0.70 & 55787 & 6 & 6 & 7 & 7 & 7 & 5 & 5 & 5 \\
\hline 44 & 447025 & 5032594 & 4409 & $06-28$ & 17 & 8 & 4.51 & 0.69 & 51452 & 6 & 6 & 7 & 7 & 5 & 3 & 3 & 4 \\
\hline 44 & 447025 & 5032594 & 4410 & $06-28$ & 17 & 8 & 4.64 & 0.74 & 51452 & 6 & 6 & 7 & 6 & 6 & 2 & 5 & 5 \\
\hline 44 & 447025 & 5032594 & B816 & $06-28$ & 17 & 8 & 4.40 & 0.78 & 51452 & 7 & 7 & 7 & 7 & 6 & 5 & 5 & 5 \\
\hline 45 & 448260 & 5028018 & 4501 & $06-30$ & 55 & 8 & 5.02 & 0.62 & 56880 & 6 & 6 & 4 & 5 & 6 & 3 & 5 & 5 \\
\hline 45 & 448260 & 5028018 & 4502 & $06-30$ & 55 & 8 & 4.99 & 0.58 & 56880 & 7 & 6 & 6 & 5 & 5 & 4 & 5 & 4 \\
\hline 45 & 448260 & 5028018 & 4503 & $06-30$ & 55 & 8 & 4.75 & 0.51 & 19994 & 6 & 6 & 7 & 7 & 6 & 5 & 5 & 5 \\
\hline 45 & 448260 & 5028018 & 4504 & $06-30$ & 55 & 8 & 4.86 & 0.49 & 19994 & 5 & 5 & 5 & 3 & 6 & 4 & 5 & 5 \\
\hline 45 & 448260 & 5028018 & 4505 & $06-30$ & 55 & 8 & 4.64 & 0.46 & 19994 & 7 & 7 & 7 & 7 & 7 & 5 & 5 & 4 \\
\hline 45 & 448260 & 5028018 & 4506 & $06-30$ & 55 & 8 & 4.99 & 0.50 & 19994 & 7 & 7 & 6 & 7 & 6 & 5 & 5 & 5 \\
\hline 45 & 448260 & 5028018 & 4507 & $06-30$ & 55 & 8 & 4.87 & 0.51 & 19994 & 7 & 6 & 7 & 7 & 6 & 4 & 5 & 4 \\
\hline 45 & 448260 & 5028018 & 4508 & $06-30$ & 55 & 8 & 4.99 & 0.63 & 56880 & 6 & 6 & 7 & 6 & 6 & 3 & 5 & 5 \\
\hline 46 & 447983 & 5024559 & 4601 & $06-30$ & 31 & 6 & 2.73 & 1.97 & 41284 & 7 & 7 & 7 & 6 & 4 & 3 & 4 & 3 \\
\hline
\end{tabular}




\begin{tabular}{|c|c|c|c|c|c|c|c|c|c|c|c|c|c|c|c|c|c|}
\hline Site & Easting & Northing & User ID & Date & Abun. & Rich. & Tree & Water & Inc. & Q1 & Q2 & Q3 & Q4 & Q5 & Q6 & Q7 & Q8 \\
\hline 46 & 447983 & 5024559 & 4602 & $06-30$ & 31 & 6 & 2.69 & 2.00 & 41284 & 6 & 6 & 6 & 6 & 6 & 1 & 3 & 3 \\
\hline 46 & 447983 & 5024559 & 4603 & $06-30$ & 31 & 6 & 2.73 & 2.00 & 41284 & 6 & 6 & 7 & 6 & 4 & 2 & 5 & 5 \\
\hline 46 & 447983 & 5024559 & 4604 & $06-30$ & 31 & 6 & 2.30 & 2.18 & 25949 & 6 & 6 & 7 & 7 & 6 & 4 & 5 & 5 \\
\hline 46 & 447983 & 5024559 & 4605 & $06-30$ & 31 & 6 & 2.30 & 2.21 & 25949 & 6 & 6 & 7 & 6 & 6 & 4 & 5 & 5 \\
\hline 46 & 447983 & 5024559 & 4606 & $08-16$ & 31 & 6 & 2.37 & 1.86 & 36401 & 6 & 6 & 7 & 6 & 5 & 3 & 3 & 4 \\
\hline 46 & 447983 & 5024559 & 4607 & $08-16$ & 31 & 6 & 2.32 & 1.97 & 36401 & 7 & 7 & 7 & 7 & 6 & 3 & 5 & 5 \\
\hline 46 & 447983 & 5024559 & B905 & $06-30$ & 31 & 6 & 2.55 & 1.86 & 33634 & 4 & 6 & 6 & 6 & 4 & 3 & 4 & 3 \\
\hline 46 & 447983 & 5024559 & B913 & $07-02$ & 31 & 6 & 2.56 & 1.97 & 41284 & 6 & 6 & 5 & 6 & 4 & 1 & 3 & 1 \\
\hline 47 & 443843 & 5019020 & 4701 & $07-04$ & 7 & 4 & 5.25 & 1.26 & 57267 & 6 & 6 & 6 & 6 & 6 & 5 & 5 & 4 \\
\hline 47 & 443843 & 5019020 & 4702 & $07-04$ & 7 & 4 & 4.34 & 1.22 & 57267 & 7 & 7 & 6 & 7 & 6 & 4 & 5 & 5 \\
\hline 47 & 443843 & 5019020 & 4703 & $07-04$ & 7 & 4 & 4.34 & 1.06 & 57267 & 6 & 6 & 6 & 7 & 7 & 5 & 5 & 5 \\
\hline 47 & 443843 & 5019020 & 4704 & $07-04$ & 7 & 4 & 3.62 & 1.21 & 57267 & 7 & 7 & 7 & 7 & 7 & 4 & 5 & 4 \\
\hline 47 & 443843 & 5019020 & 4705 & $07-04$ & 7 & 4 & 3.34 & 1.21 & 57267 & 6 & 6 & 5 & 6 & 7 & 5 & 5 & 5 \\
\hline 47 & 443843 & 5019020 & 4706 & $07-04$ & 7 & 4 & 3.46 & 1.15 & 57267 & 6 & 6 & 5 & 5 & 6 & 3 & 4 & 4 \\
\hline 47 & 443843 & 5019020 & 4707 & $07-04$ & 7 & 4 & 2.99 & 1.19 & 57267 & 6 & 6 & 6 & 5 & 7 & 4 & 3 & 4 \\
\hline 47 & 443843 & 5019020 & 4708 & $07-04$ & 7 & 4 & 4.98 & 1.18 & 48135 & 6 & 7 & 6 & 7 & 4 & 3 & 4 & 4 \\
\hline 47 & 443843 & 5019020 & 4708 & $07-04$ & 7 & 4 & 4.98 & 1.18 & 48135 & 6 & 6 & 6 & 6 & 6 & 5 & 5 & 4 \\
\hline 47 & 443843 & 5019020 & 4710 & $07-04$ & 7 & 4 & 5.30 & 1.22 & 48135 & 4 & 2 & 6 & 7 & 6 & 3 & 4 & 2 \\
\hline 47 & 443843 & 5019020 & B950 & $07-05$ & 7 & 4 & 2.55 & 1.12 & 57267 & 6 & 6 & 6 & 7 & 7 & 4 & 5 & 4 \\
\hline 47 & 443843 & 5019020 & B957 & $07-04$ & 7 & 4 & 3.15 & 1.18 & 57267 & 6 & 6 & 7 & 7 & 7 & 5 & 5 & 5 \\
\hline 48 & 440704 & 5020030 & 4801 & $07-04$ & 9 & 5 & 3.59 & 2.12 & 31070 & 5 & 6 & 7 & 7 & 5 & 5 & 5 & 5 \\
\hline 48 & 440704 & 5020030 & 4802 & $07-04$ & 9 & 5 & 3.13 & 2.29 & 31070 & 6 & 6 & 6 & 5 & 4 & 1 & 2 & 1 \\
\hline 48 & 440704 & 5020030 & 4802 & $07-04$ & 9 & 5 & 3.13 & 2.29 & 31070 & 5 & 5 & 6 & 6 & 5 & 3 & 5 & 5 \\
\hline 48 & 440704 & 5020030 & 4804 & $07-04$ & 9 & 5 & 3.42 & 2.18 & 31070 & 6 & 6 & 7 & 7 & 7 & 4 & 4 & 4 \\
\hline 48 & 440704 & 5020030 & 4805 & $07-04$ & 9 & 5 & 3.77 & 2.12 & 31070 & 6 & 6 & 7 & 7 & 6 & 4 & 3 & 3 \\
\hline
\end{tabular}




\begin{tabular}{|c|c|c|c|c|c|c|c|c|c|c|c|c|c|c|c|c|c|}
\hline Site & Easting & Northing & User ID & Date & Abun. & Rich. & Tree & Water & Inc. & Q1 & Q2 & Q3 & Q4 & Q5 & Q6 & Q7 & Q8 \\
\hline 48 & 440704 & 5020030 & 4806 & $07-04$ & 9 & 5 & 3.95 & 2.04 & 31070 & 7 & 7 & 7 & 6 & 5 & 2 & 3 & 4 \\
\hline 48 & 440704 & 5020030 & 4807 & $07-04$ & 9 & 5 & 3.94 & 2.00 & 31070 & 6 & 6 & 5 & 6 & 6 & 3 & 4 & 4 \\
\hline 48 & 440704 & 5020030 & 4808 & $07-04$ & 9 & 5 & 3.92 & 1.91 & 34761 & 6 & 7 & 6 & 5 & 5 & 2 & 3 & 4 \\
\hline 48 & 440704 & 5020030 & 4809 & $07-04$ & 9 & 5 & 4.12 & 1.97 & 34761 & 7 & 7 & 1 & 4 & 7 & 4 & 5 & 2 \\
\hline 48 & 440704 & 5020030 & 4810 & $07-04$ & 9 & 5 & 4.09 & 2.01 & 34761 & 6 & 7 & 6 & 6 & 5 & 3 & 3 & 2 \\
\hline 49 & 443593 & 5027323 & 4901 & $07-05$ & 6 & 3 & 5.38 & 1.11 & 68044 & 6 & 6 & 7 & 5 & 6 & 3 & 5 & 5 \\
\hline 49 & 443593 & 5027323 & 4902 & $07-05$ & 6 & 3 & 5.64 & 1.07 & 68044 & 6 & 7 & 6 & 6 & 7 & 3 & 4 & 5 \\
\hline 49 & 443593 & 5027323 & 4903 & $07-05$ & 6 & 3 & 5.53 & 1.13 & 68044 & 5 & 2 & 6 & 3 & 6 & 4 & 5 & 3 \\
\hline 49 & 443593 & 5027323 & 4904 & $07-05$ & 6 & 3 & 5.78 & 1.07 & 68044 & 6 & 6 & 7 & 7 & 6 & 5 & 5 & 5 \\
\hline 49 & 443593 & 5027323 & 4905 & $07-05$ & 6 & 3 & 5.64 & 1.04 & 67218 & 6 & 6 & 7 & 7 & 7 & 5 & 5 & 5 \\
\hline 49 & 443593 & 5027323 & 4906 & $07-05$ & 6 & 3 & 5.58 & 1.13 & 68044 & 6 & 6 & 7 & 7 & 7 & 5 & 5 & 5 \\
\hline 49 & 443593 & 5027323 & 4907 & $07-05$ & 6 & 3 & 5.39 & 1.20 & 68044 & 7 & 6 & 7 & 6 & 6 & 4 & 4 & 4 \\
\hline 49 & 443593 & 5027323 & 4908 & $07-05$ & 6 & 3 & 5.34 & 1.19 & 68044 & 6 & 6 & 3 & 6 & 5 & 4 & 4 & 3 \\
\hline 49 & 443593 & 5027323 & 4909 & $07-05$ & 6 & 3 & 5.00 & 1.26 & 68044 & 6 & 6 & 6 & 6 & 6 & 4 & 5 & 5 \\
\hline 49 & 443593 & 5027323 & 4910 & $07-05$ & 6 & 3 & 5.09 & 1.18 & 68044 & 6 & 7 & 7 & 7 & 6 & 1 & 3 & 4 \\
\hline 49 & 443593 & 5027323 & $\mathrm{C} 035$ & $07-05$ & 6 & 3 & 5.55 & 1.06 & 68044 & 4 & 6 & 6 & 6 & 6 & 2 & 5 & 3 \\
\hline 49 & 443593 & 5027323 & $\mathrm{C} 055$ & $07-05$ & 6 & 3 & 5.68 & 1.04 & 67218 & 6 & 6 & 7 & 7 & 6 & 4 & 4 & 4 \\
\hline 50 & 442600 & 5024465 & 5001 & $07-05$ & 9 & 3 & 2.79 & 2.26 & 37211 & 5 & 4 & 6 & 7 & 7 & 5 & 5 & 4 \\
\hline 50 & 442600 & 5024465 & 5002 & $07-05$ & 9 & 3 & 2.40 & 2.22 & 37211 & 7 & 7 & 7 & 7 & 7 & 5 & 5 & 5 \\
\hline 50 & 442600 & 5024465 & 5003 & $07-05$ & 9 & 3 & 2.69 & 2.26 & 37211 & 6 & 7 & 6 & 6 & 5 & 3 & 3 & 4 \\
\hline 50 & 442600 & 5024465 & 5004 & $07-05$ & 9 & 3 & 2.77 & 2.27 & 37211 & 6 & 4 & 7 & 6 & 3 & 3 & 4 & 5 \\
\hline 50 & 442600 & 5024465 & 5005 & $07-05$ & 9 & 3 & 3.02 & 2.32 & 37211 & 6 & 7 & 6 & 5 & 4 & 3 & 5 & 4 \\
\hline 50 & 442600 & 5024465 & 5006 & $07-05$ & 9 & 3 & 3.16 & 2.31 & 36947 & 7 & 7 & 6 & 6 & 6 & 3 & 4 & 4 \\
\hline 50 & 442600 & 5024465 & 5007 & $07-05$ & 9 & 3 & 3.14 & 2.31 & 36947 & 5 & 6 & 6 & 6 & 6 & 5 & 4 & 4 \\
\hline 50 & 442600 & 5024465 & 5008 & $07-05$ & 9 & 3 & 2.78 & 2.33 & 37211 & 6 & 6 & 6 & 6 & 3 & 4 & 5 & 4 \\
\hline
\end{tabular}




\begin{tabular}{|c|c|c|c|c|c|c|c|c|c|c|c|c|c|c|c|c|c|}
\hline Site & Easting & Northing & User ID & Date & Abun. & Rich. & Tree & Water & Inc. & Q1 & Q2 & Q3 & Q4 & Q5 & Q6 & Q7 & Q8 \\
\hline 50 & 442600 & 5024465 & 5009 & $07-05$ & 9 & 3 & 2.78 & 2.33 & 37211 & 6 & 7 & 6 & 5 & 5 & 3 & 4 & 4 \\
\hline 50 & 442600 & 5024465 & 5010 & $07-05$ & 9 & 3 & 2.77 & 2.32 & 37211 & 7 & 7 & 6 & 6 & 5 & 3 & 5 & 5 \\
\hline 50 & 442600 & 5024465 & C094 & $07-20$ & 9 & 3 & 2.59 & 2.24 & 37211 & 5 & 5 & 7 & 7 & 4 & 3 & 4 & 3 \\
\hline 50 & 442600 & 5024465 & C099 & $07-05$ & 9 & 3 & 2.91 & 2.31 & 37211 & 6 & 5 & 6 & 5 & 4 & 3 & 4 & 4 \\
\hline 50 & 442600 & 5024465 & C102 & $07-06$ & 9 & 3 & 2.94 & 2.34 & 37211 & 6 & 6 & 7 & 7 & 7 & 3 & 5 & 5 \\
\hline 50 & 442600 & 5024465 & C104 & 09-10 & 9 & 3 & 2.94 & 2.34 & 37211 & 7 & 7 & 6 & 6 & 6 & 4 & 4 & 2 \\
\hline 51 & 449761 & 5032427 & 5101 & $07-06$ & 5 & 4 & 5.82 & 1.87 & 28986 & 6 & 7 & 6 & 7 & 7 & 4 & 5 & 5 \\
\hline 51 & 449761 & 5032427 & 5102 & $07-06$ & 5 & 4 & 5.82 & 1.87 & 28986 & 4 & 4 & 1 & 1 & 4 & 4 & 5 & 5 \\
\hline 51 & 449761 & 5032427 & 5103 & $07-06$ & 5 & 4 & 5.82 & 1.87 & 28986 & 7 & 6 & 5 & 2 & 4 & 4 & 3 & 2 \\
\hline 51 & 449761 & 5032427 & 5104 & $07-06$ & 5 & 4 & 5.82 & 1.87 & 28986 & 6 & 6 & 7 & 6 & 6 & 5 & 5 & 5 \\
\hline 51 & 449761 & 5032427 & 5105 & $07-06$ & 5 & 4 & 5.89 & 2.06 & 36156 & 6 & 5 & 4 & 6 & 6 & 3 & 4 & 4 \\
\hline 51 & 449761 & 5032427 & 5106 & 07-06 & 5 & 4 & 3.09 & 2.15 & 30059 & 3 & 5 & 5 & 6 & 5 & 2 & 5 & 5 \\
\hline 51 & 449761 & 5032427 & 5107 & 07-06 & 5 & 4 & 3.16 & 2.17 & 30059 & 4 & 3 & 6 & 6 & 4 & 1 & 2 & 3 \\
\hline 51 & 449761 & 5032427 & C145 & $07-07$ & 5 & 4 & 5.82 & 1.87 & 28986 & 6 & 6 & 3 & 7 & 6 & 3 & 5 & 5 \\
\hline 52 & 446561 & 5030410 & 5201 & $07-06$ & 8 & 3 & 3.32 & 0.58 & 22628 & 5 & 6 & 5 & 6 & 5 & 3 & 3 & 4 \\
\hline 52 & 446561 & 5030410 & 5202 & $07-06$ & 8 & 3 & 3.00 & 0.50 & 19133 & 6 & 6 & 7 & 7 & 6 & 4 & 5 & 5 \\
\hline 52 & 446561 & 5030410 & 5203 & $07-06$ & 8 & 3 & 3.00 & 0.50 & 19133 & 6 & 5 & 7 & 6 & 4 & 3 & 3 & 3 \\
\hline 52 & 446561 & 5030410 & 5204 & $07-06$ & 8 & 3 & 3.00 & 0.50 & 19133 & 2 & 6 & 5 & 6 & 6 & 5 & 5 & 5 \\
\hline 52 & 446561 & 5030410 & 5205 & $07-06$ & 8 & 3 & 3.00 & 0.50 & 19133 & 5 & 5 & 5 & 3 & 4 & 3 & 5 & 5 \\
\hline 52 & 446561 & 5030410 & 5206 & $07-06$ & 8 & 3 & 3.31 & 0.62 & 22628 & 7 & 7 & 7 & 7 & 7 & 1 & 5 & 5 \\
\hline 52 & 446561 & 5030410 & 5207 & $07-06$ & 8 & 3 & 3.21 & 0.59 & 22628 & 4 & 6 & 6 & 6 & 6 & 3 & 4 & 3 \\
\hline 52 & 446561 & 5030410 & 5208 & $07-06$ & 8 & 3 & 3.19 & 0.60 & 22628 & 6 & 7 & 5 & 5 & 6 & 3 & 4 & 5 \\
\hline 52 & 446561 & 5030410 & 5209 & $07-06$ & 8 & 3 & 3.43 & 0.70 & 31235 & 6 & 6 & 5 & 5 & 6 & 5 & 5 & 3 \\
\hline 52 & 446561 & 5030410 & 5210 & $07-06$ & 8 & 3 & 3.39 & 0.69 & 31235 & 6 & 5 & 7 & 6 & 5 & 4 & 2 & 4 \\
\hline 52 & 446561 & 5030410 & C188 & $07-06$ & 8 & 3 & 3.38 & 0.58 & 22628 & 5 & 6 & 5 & 5 & 5 & 1 & 3 & 3 \\
\hline
\end{tabular}




\begin{tabular}{|c|c|c|c|c|c|c|c|c|c|c|c|c|c|c|c|c|c|}
\hline Site & Easting & Northing & User ID & Date & Abun. & Rich. & Tree & Water & Inc. & Q1 & Q2 & Q3 & Q4 & Q5 & Q6 & Q7 & Q8 \\
\hline 52 & 446561 & 5030410 & C194 & $07-06$ & 8 & 3 & 3.16 & 0.47 & 19133 & 5 & 3 & 6 & 6 & 6 & 2 & 5 & 5 \\
\hline 52 & 446561 & 5030410 & C238 & $07-06$ & 8 & 3 & 3.43 & 0.58 & 19133 & 6 & 6 & 6 & 6 & 5 & 3 & 5 & 5 \\
\hline 53 & 452062 & 5025064 & 5301 & $07-07$ & 13 & 5 & 2.69 & 3.82 & 39132 & 5 & 4 & 3 & 5 & 2 & 4 & 5 & 5 \\
\hline 53 & 452062 & 5025064 & 5302 & $07-07$ & 13 & 5 & 2.74 & 3.79 & 39132 & 6 & 6 & 6 & 6 & 6 & 4 & 3 & 3 \\
\hline 53 & 452062 & 5025064 & 5303 & $07-07$ & 13 & 5 & 2.83 & 3.77 & 39132 & 6 & 6 & 7 & 7 & 7 & 3 & 5 & 5 \\
\hline 53 & 452062 & 5025064 & 5304 & $07-07$ & 13 & 5 & 3.21 & 3.73 & 39132 & 6 & 6 & 6 & 6 & 6 & 5 & 5 & 4 \\
\hline 53 & 452062 & 5025064 & 5307 & $07-07$ & 13 & 5 & 3.37 & 3.80 & 39132 & 1 & 7 & 4 & 6 & 7 & 4 & 5 & 5 \\
\hline 53 & 452062 & 5025064 & 5308 & $07-07$ & 13 & 5 & 3.36 & 3.79 & 39132 & 6 & 7 & 5 & 7 & 7 & 5 & 5 & 5 \\
\hline 53 & 452062 & 5025064 & 5309 & $07-07$ & 13 & 5 & 3.58 & 3.74 & 39132 & 6 & 6 & 6 & 7 & 7 & 4 & 4 & 5 \\
\hline 53 & 452062 & 5025064 & 5310 & $07-07$ & 13 & 5 & 3.61 & 3.68 & 39132 & 7 & 7 & 2 & 7 & 6 & 4 & 5 & 5 \\
\hline 54 & 452445 & 5031780 & 5401 & $07-07$ & 12 & 8 & 5.13 & 2.92 & 43099 & 6 & 6 & 7 & 6 & 5 & 2 & 4 & 2 \\
\hline 54 & 452445 & 5031780 & 5402 & $07-07$ & 12 & 8 & 4.81 & 2.95 & 43099 & 7 & 7 & 6 & 7 & 7 & 4 & 5 & 5 \\
\hline 54 & 452445 & 5031780 & 5403 & $07-07$ & 12 & 8 & 4.63 & 3.00 & 43099 & 4 & 5 & 7 & 6 & 7 & 4 & 5 & 5 \\
\hline 54 & 452445 & 5031780 & 5404 & $07-07$ & 12 & 8 & 3.99 & 3.06 & 43099 & 5 & 6 & 5 & 5 & 6 & 5 & 5 & 4 \\
\hline 54 & 452445 & 5031780 & 5405 & $07-07$ & 12 & 8 & 5.29 & 2.82 & 43099 & 6 & 6 & 5 & 5 & 4 & 4 & 5 & 4 \\
\hline 54 & 452445 & 5031780 & 5405 & $07-07$ & 12 & 8 & 5.29 & 2.82 & 43099 & 6 & 6 & 6 & 5 & 6 & 5 & 5 & 4 \\
\hline 54 & 452445 & 5031780 & 5406 & $07-07$ & 12 & 8 & 5.34 & 2.76 & 43099 & 7 & 6 & 6 & 6 & 5 & 3 & 3 & 4 \\
\hline 54 & 452445 & 5031780 & 5406 & $07-07$ & 12 & 8 & 5.34 & 2.76 & 43099 & 7 & 7 & 7 & 6 & 6 & 5 & 5 & 5 \\
\hline 54 & 452445 & 5031780 & 5407 & $07-07$ & 12 & 8 & 5.40 & 2.74 & 43099 & 6 & 6 & 5 & 6 & 4 & 3 & 4 & 5 \\
\hline 54 & 452445 & 5031780 & 5408 & $07-07$ & 12 & 8 & 5.25 & 2.77 & 43099 & 7 & 7 & 6 & 7 & 4 & 1 & 5 & 5 \\
\hline 54 & 452445 & 5031780 & 5409 & $07-07$ & 12 & 8 & 5.20 & 2.76 & 43099 & 6 & 6 & 6 & 7 & 5 & 1 & 4 & 4 \\
\hline 54 & 452445 & 5031780 & 5410 & $07-07$ & 12 & 8 & 5.38 & 2.70 & 43099 & 6 & 6 & 6 & 5 & 5 & 4 & 5 & 5 \\
\hline 55 & 443717 & 5023735 & 5501 & $07-10$ & 8 & 6 & 3.04 & 1.57 & 40983 & 7 & 7 & 7 & 7 & 6 & 4 & 4 & 5 \\
\hline 55 & 443717 & 5023735 & 5502 & $07-10$ & 8 & 6 & 3.08 & 1.50 & 40983 & 7 & 7 & 7 & 7 & 6 & 5 & 5 & 3 \\
\hline 55 & 443717 & 5023735 & 5503 & $07-10$ & 8 & 6 & 3.14 & 1.43 & 40983 & 6 & 6 & 6 & 6 & 7 & 4 & 5 & 5 \\
\hline
\end{tabular}




\begin{tabular}{|c|c|c|c|c|c|c|c|c|c|c|c|c|c|c|c|c|c|}
\hline Site & Easting & Northing & User ID & Date & Abun. & Rich. & Tree & Water & Inc. & Q1 & Q2 & Q3 & Q4 & Q5 & Q6 & Q7 & Q8 \\
\hline 55 & 443717 & 5023735 & 5504 & $07-10$ & 8 & 6 & 3.12 & 1.51 & 40983 & 7 & 7 & 6 & 6 & 5 & 3 & 5 & 3 \\
\hline 55 & 443717 & 5023735 & 5505 & $07-10$ & 8 & 6 & 3.11 & 1.53 & 40983 & 7 & 7 & 7 & 7 & 6 & 5 & 5 & 5 \\
\hline 55 & 443717 & 5023735 & 5506 & $07-10$ & 8 & 6 & 3.09 & 1.39 & 41738 & 6 & 6 & 7 & 7 & 6 & 5 & 5 & 5 \\
\hline 55 & 443717 & 5023735 & 5507 & $07-10$ & 8 & 6 & 3.09 & 1.37 & 41738 & 6 & 6 & 5 & 7 & 6 & 1 & 5 & 5 \\
\hline 55 & 443717 & 5023735 & 5508 & $07-10$ & 8 & 6 & 3.20 & 1.29 & 41738 & 6 & 6 & 5 & 6 & 5 & 1 & 5 & 4 \\
\hline 55 & 443717 & 5023735 & 5509 & $07-10$ & 8 & 6 & 3.25 & 1.34 & 40983 & 5 & 5 & 3 & 6 & 4 & 4 & 5 & 5 \\
\hline 55 & 443717 & 5023735 & 5509 & $07-10$ & 8 & 6 & 3.25 & 1.34 & 40983 & 6 & 6 & 6 & 6 & 6 & 3 & 3 & 3 \\
\hline 55 & 443717 & 5023735 & 5510 & $07-10$ & 8 & 6 & 3.35 & 1.35 & 40983 & 5 & 3 & 3 & 6 & 6 & 4 & 5 & 5 \\
\hline 56 & 442299 & 5022060 & 5601 & $07-10$ & 6 & 3 & 2.94 & 2.16 & 27413 & 5 & 7 & 6 & 6 & 6 & 4 & 5 & 5 \\
\hline 56 & 442299 & 5022060 & 5602 & $07-10$ & 6 & 3 & 3.39 & 2.15 & 27413 & 2 & 6 & 5 & 5 & 7 & 1 & 2 & 1 \\
\hline 56 & 442299 & 5022060 & 5603 & $07-10$ & 6 & 3 & 3.61 & 2.13 & 27413 & 6 & 7 & 6 & 7 & 4 & 3 & 5 & 5 \\
\hline 56 & 442299 & 5022060 & 5604 & $07-10$ & 6 & 3 & 3.48 & 2.12 & 27413 & 6 & 7 & 6 & 6 & 5 & 3 & 4 & 4 \\
\hline 56 & 442299 & 5022060 & 5605 & 07-10 & 6 & 3 & 3.46 & 2.19 & 45611 & 6 & 6 & 7 & 7 & 6 & 3 & 4 & 5 \\
\hline 56 & 442299 & 5022060 & 5606 & $07-10$ & 6 & 3 & 3.47 & 2.19 & 45611 & 6 & 5 & 6 & 6 & 4 & 5 & 5 & 4 \\
\hline 56 & 442299 & 5022060 & 5607 & $07-10$ & 6 & 3 & 3.59 & 2.20 & 45611 & 5 & 6 & 5 & 6 & 4 & 5 & 1 & 2 \\
\hline 56 & 442299 & 5022060 & 5608 & $07-10$ & 6 & 3 & 3.51 & 2.21 & 45611 & 6 & 6 & 5 & 6 & 5 & 3 & 4 & 4 \\
\hline 56 & 442299 & 5022060 & 5609 & $07-10$ & 6 & 3 & 3.34 & 2.24 & 45611 & 7 & 7 & 6 & 5 & 4 & 4 & 5 & 4 \\
\hline 56 & 442299 & 5022060 & 5610 & $07-10$ & 6 & 3 & 3.49 & 2.24 & 45611 & 6 & 6 & 6 & 5 & 4 & 3 & 4 & 2 \\
\hline 57 & 441622 & 5023337 & 5701 & $07-11$ & 12 & 4 & 3.23 & 3.22 & 24644 & 7 & 7 & 7 & 6 & 6 & 4 & 5 & 5 \\
\hline 57 & 441622 & 5023337 & 5702 & $07-11$ & 12 & 4 & 3.45 & 3.12 & 42830 & 7 & 7 & 7 & 7 & 7 & 4 & 5 & 5 \\
\hline 57 & 441622 & 5023337 & 5703 & $07-11$ & 12 & 4 & 2.78 & 3.19 & 35603 & 5 & 7 & 4 & 5 & 5 & 4 & 4 & 5 \\
\hline 57 & 441622 & 5023337 & 5704 & $07-11$ & 12 & 4 & 2.78 & 3.19 & 35603 & 5 & 5 & 7 & 7 & 7 & 4 & 5 & 5 \\
\hline 57 & 441622 & 5023337 & 5705 & $07-11$ & 12 & 4 & 2.99 & 3.33 & 24644 & 6 & 7 & 7 & 5 & 3 & 1 & 5 & 4 \\
\hline 57 & 441622 & 5023337 & 5706 & $07-11$ & 12 & 4 & 2.78 & 3.19 & 35603 & 7 & 7 & 5 & 7 & 6 & 4 & 4 & 5 \\
\hline 57 & 441622 & 5023337 & 5707 & $07-11$ & 12 & 4 & 2.78 & 3.19 & 35603 & 6 & 7 & 7 & 6 & 6 & 3 & 4 & 4 \\
\hline
\end{tabular}




\begin{tabular}{|c|c|c|c|c|c|c|c|c|c|c|c|c|c|c|c|c|c|}
\hline Site & Easting & Northing & User ID & Date & Abun. & Rich. & Tree & Water & Inc. & Q1 & Q2 & Q3 & Q4 & Q5 & Q6 & Q7 & Q8 \\
\hline 57 & 441622 & 5023337 & 5708 & $07-11$ & 12 & 4 & 3.29 & 3.21 & 24644 & 6 & 7 & 7 & 7 & 6 & 4 & 5 & 4 \\
\hline 57 & 441622 & 5023337 & 5709 & $07-11$ & 12 & 4 & 3.30 & 3.23 & 24644 & 6 & 7 & 5 & 4 & 4 & 2 & 5 & 5 \\
\hline 57 & 441622 & 5023337 & 5710 & $07-11$ & 12 & 4 & 3.05 & 3.34 & 24644 & 7 & 6 & 6 & 6 & 4 & 4 & 5 & 5 \\
\hline 58 & 443123 & 5026198 & 5801 & $07-11$ & 6 & 3 & 4.21 & 1.85 & 43026 & 6 & 7 & 6 & 5 & 2 & 1 & 3 & 3 \\
\hline 58 & 443123 & 5026198 & 5802 & $07-11$ & 6 & 3 & 4.36 & 1.87 & 43026 & 7 & 7 & 7 & 7 & 6 & 1 & 5 & 5 \\
\hline 58 & 443123 & 5026198 & 5803 & $07-11$ & 6 & 3 & 4.34 & 1.86 & 43026 & 2 & 1 & 7 & 7 & 5 & 4 & 5 & 3 \\
\hline 58 & 443123 & 5026198 & 5804 & $07-11$ & 6 & 3 & 4.12 & 1.82 & 42730 & 7 & 7 & 7 & 6 & 6 & 4 & 5 & 5 \\
\hline 58 & 443123 & 5026198 & 5805 & $07-11$ & 6 & 3 & 4.44 & 1.87 & 42730 & 7 & 7 & 7 & 7 & 4 & 3 & 5 & 5 \\
\hline 58 & 443123 & 5026198 & 5806 & $07-11$ & 6 & 3 & 4.62 & 1.89 & 43026 & 1 & 7 & 7 & 7 & 6 & 3 & 4 & 5 \\
\hline 58 & 443123 & 5026198 & 5807 & $07-11$ & 6 & 3 & 4.60 & 1.90 & 43026 & 6 & 6 & 6 & 7 & 6 & 3 & 5 & 4 \\
\hline 58 & 443123 & 5026198 & 5809 & $07-11$ & 6 & 3 & 4.46 & 1.91 & 43026 & 6 & 6 & 6 & 7 & 6 & 4 & 4 & 5 \\
\hline 58 & 443123 & 5026198 & 5810 & $07-11$ & 6 & 3 & 4.54 & 1.98 & 43026 & 6 & 6 & 7 & 7 & 6 & 5 & 5 & 5 \\
\hline 58 & 443123 & 5026198 & C464 & $07-11$ & 6 & 3 & 4.25 & 1.86 & 43026 & 6 & 6 & 6 & 6 & 5 & 4 & 5 & 5 \\
\hline 59 & 447730 & 5031727 & 5901 & $07-12$ & 6 & 4 & 2.99 & 0.36 & 45400 & 6 & 7 & 6 & 6 & 6 & 5 & 5 & 5 \\
\hline 59 & 447730 & 5031727 & 5902 & $07-12$ & 6 & 4 & 3.12 & 0.25 & 45400 & 6 & 5 & 7 & 7 & 6 & 5 & 5 & 5 \\
\hline 59 & 447730 & 5031727 & 5903 & $07-12$ & 6 & 4 & 2.97 & 0.37 & 45400 & 6 & 7 & 7 & 5 & 3 & 3 & 5 & 5 \\
\hline 59 & 447730 & 5031727 & 5904 & $07-12$ & 6 & 4 & 2.95 & 0.54 & 17133 & 6 & 5 & 6 & 3 & 3 & 3 & 5 & 5 \\
\hline 59 & 447730 & 5031727 & 5905 & $07-12$ & 6 & 4 & 2.80 & 0.55 & 17133 & 6 & 6 & 6 & 5 & 3 & 3 & 4 & 4 \\
\hline 59 & 447730 & 5031727 & 5906 & $07-12$ & 6 & 4 & 2.74 & 0.47 & 17133 & 6 & 6 & 5 & 5 & 4 & 3 & 5 & 5 \\
\hline 59 & 447730 & 5031727 & 5907 & $07-12$ & 6 & 4 & 2.85 & 0.39 & 17133 & 7 & 6 & 4 & 4 & 3 & 3 & 5 & 3 \\
\hline 59 & 447730 & 5031727 & 5908 & $07-12$ & 6 & 4 & 3.53 & 0.16 & 43444 & 6 & 6 & 7 & 6 & 6 & 5 & 5 & 4 \\
\hline 59 & 447730 & 5031727 & 5909 & $07-12$ & 6 & 4 & 3.54 & 0.16 & 43444 & 6 & 7 & 6 & 7 & 6 & 5 & 5 & 4 \\
\hline 59 & 447730 & 5031727 & 5910 & $07-12$ & 6 & 4 & 3.20 & 0.13 & 43444 & 6 & 6 & 6 & 6 & 7 & 5 & 5 & 5 \\
\hline 59 & 447730 & 5031727 & C522 & $07-14$ & 6 & 4 & 3.03 & 0.32 & 45400 & 6 & 7 & 6 & 6 & 5 & 4 & 4 & 4 \\
\hline 59 & 447730 & 5031727 & C543 & $07-27$ & 6 & 4 & 2.97 & 0.36 & 45400 & 6 & 6 & 6 & 6 & 6 & 4 & 4 & 4 \\
\hline
\end{tabular}




\begin{tabular}{|c|c|c|c|c|c|c|c|c|c|c|c|c|c|c|c|c|c|}
\hline Site & Easting & Northing & User ID & Date & Abun. & Rich. & Tree & Water & Inc. & Q1 & Q2 & Q3 & Q4 & Q5 & Q6 & Q7 & Q8 \\
\hline 60 & 451620 & 5034379 & 6001 & $07-12$ & 8 & 4 & 8.90 & 0.44 & 71658 & 6 & 7 & 7 & 7 & 6 & 3 & 5 & 5 \\
\hline 60 & 451620 & 5034379 & 6002 & $07-12$ & 8 & 4 & 9.35 & 0.40 & 71658 & 7 & 7 & 7 & 7 & 7 & 4 & 5 & 5 \\
\hline 60 & 451620 & 5034379 & 6003 & $07-12$ & 8 & 4 & 8.25 & 0.41 & 71658 & 7 & 7 & 6 & 5 & 7 & 5 & 4 & 4 \\
\hline 60 & 451620 & 5034379 & 6004 & $07-12$ & 8 & 4 & 8.02 & 0.22 & 71658 & 6 & 7 & 7 & 7 & 6 & 3 & 5 & 5 \\
\hline 60 & 451620 & 5034379 & 6005 & $07-12$ & 8 & 4 & 8.18 & 0.25 & 71658 & 6 & 6 & 7 & 6 & 6 & 4 & 5 & 5 \\
\hline 60 & 451620 & 5034379 & 6006 & $07-12$ & 8 & 4 & 8.23 & 0.32 & 71658 & 4 & 4 & 6 & 6 & 7 & 3 & 3 & 1 \\
\hline 60 & 451620 & 5034379 & 6007 & $07-12$ & 8 & 4 & 8.67 & 0.24 & 71658 & 6 & 6 & 6 & 7 & 7 & 5 & 5 & 4 \\
\hline 60 & 451620 & 5034379 & 6008 & $07-12$ & 8 & 4 & 8.75 & 0.32 & 71658 & 6 & 6 & 7 & 7 & 6 & 3 & 4 & 4 \\
\hline 60 & 451620 & 5034379 & 6009 & $07-12$ & 8 & 4 & 9.27 & 0.34 & 71658 & 7 & 7 & 7 & 7 & 7 & 4 & 5 & 5 \\
\hline 60 & 451620 & 5034379 & 6010 & $07-12$ & 8 & 4 & 9.10 & 0.24 & 71658 & 6 & 6 & 6 & 6 & 7 & 4 & 5 & 5 \\
\hline 61 & 450469 & 5024097 & 6101 & $07-13$ & 5 & 3 & 3.40 & 2.09 & 27727 & 6 & 6 & 6 & 6 & 4 & 5 & 5 & 5 \\
\hline 61 & 450469 & 5024097 & 6102 & $07-13$ & 5 & 3 & 3.35 & 2.08 & 27727 & 6 & 6 & 5 & 6 & 7 & 5 & 5 & 5 \\
\hline 61 & 450469 & 5024097 & 6103 & 07-13 & 5 & 3 & 3.23 & 2.02 & 27727 & 6 & 6 & 6 & 7 & 7 & 4 & 5 & 5 \\
\hline 61 & 450469 & 5024097 & 6104 & $07-13$ & 5 & 3 & 3.21 & 2.01 & 27727 & 7 & 6 & 7 & 3 & 6 & 4 & 5 & 5 \\
\hline 61 & 450469 & 5024097 & 6105 & $07-13$ & 5 & 3 & 5.00 & 2.09 & 27727 & 7 & 7 & 7 & 6 & 6 & 4 & 5 & 4 \\
\hline 61 & 450469 & 5024097 & 6106 & $07-13$ & 5 & 3 & 4.94 & 2.24 & 27727 & 7 & 6 & 6 & 6 & 6 & 4 & 4 & 5 \\
\hline 61 & 450469 & 5024097 & 6107 & $07-13$ & 5 & 3 & 5.05 & 2.30 & 27727 & 6 & 2 & 5 & 5 & 4 & 1 & 4 & 4 \\
\hline 61 & 450469 & 5024097 & 6108 & $07-13$ & 5 & 3 & 5.60 & 2.25 & 27727 & 5 & 6 & 6 & 7 & 6 & 4 & 5 & 5 \\
\hline 61 & 450469 & 5024097 & 6109 & $07-13$ & 5 & 3 & 3.36 & 2.12 & 34107 & 6 & 7 & 6 & 3 & 2 & 2 & 4 & 4 \\
\hline 61 & 450469 & 5024097 & 6110 & $07-13$ & 5 & 3 & 3.39 & 2.15 & 34107 & 6 & 7 & 3 & 3 & 4 & 1 & 5 & 4 \\
\hline 61 & 450469 & 5024097 & C645 & $07-15$ & 5 & 3 & 3.86 & 2.12 & 27727 & 6 & 6 & 4 & 6 & 6 & 4 & 5 & 5 \\
\hline 61 & 450469 & 5024097 & C690 & $07-13$ & 5 & 3 & 4.80 & 2.26 & 27727 & 6 & 6 & 5 & 7 & 6 & 4 & 4 & 2 \\
\hline 62 & 451062 & 5029559 & 6201 & $07-13$ & 4 & 3 & 2.61 & 2.63 & 40111 & 5 & 6 & 3 & 3 & 3 & 4 & 4 & 3 \\
\hline 62 & 451062 & 5029559 & 6202 & $07-13$ & 4 & 3 & 2.64 & 2.68 & 40111 & 7 & 6 & 7 & 7 & 4 & 1 & 5 & 5 \\
\hline 62 & 451062 & 5029559 & 6203 & $07-13$ & 4 & 3 & 2.66 & 2.67 & 40111 & 7 & 7 & 7 & 6 & 7 & 4 & 5 & 4 \\
\hline
\end{tabular}




\begin{tabular}{|c|c|c|c|c|c|c|c|c|c|c|c|c|c|c|c|c|c|}
\hline Site & Easting & Northing & User ID & Date & Abun. & Rich. & Tree & Water & Inc. & Q1 & Q2 & Q3 & Q4 & Q5 & Q6 & Q7 & Q8 \\
\hline 62 & 451062 & 5029559 & 6204 & $07-13$ & 4 & 3 & 2.77 & 2.75 & 40111 & 6 & 6 & 6 & 5 & 5 & 1 & 4 & 2 \\
\hline 62 & 451062 & 5029559 & C778 & $08-05$ & 4 & 3 & 2.49 & 2.79 & 40111 & 1 & 2 & 5 & 7 & 7 & 3 & 4 & 4 \\
\hline 63 & 445016 & 5019793 & 6301 & $07-14$ & 12 & 7 & 4.37 & 0.05 & 50388 & 6 & 7 & 6 & 6 & 6 & 1 & 5 & 4 \\
\hline 63 & 445016 & 5019793 & 6302 & $07-14$ & 12 & 7 & 3.93 & 0.06 & 50388 & 4 & 4 & 4 & 4 & 6 & 5 & 5 & 5 \\
\hline 63 & 445016 & 5019793 & 6303 & $07-14$ & 12 & 7 & 4.89 & 0.05 & 50388 & 7 & 7 & 7 & 7 & 7 & 5 & 5 & 4 \\
\hline 63 & 445016 & 5019793 & 6304 & $07-14$ & 12 & 7 & 5.44 & 0.05 & 50388 & 7 & 7 & 7 & 7 & 7 & 4 & 5 & 5 \\
\hline 63 & 445016 & 5019793 & 6305 & $07-14$ & 12 & 7 & 5.01 & 0.15 & 50388 & 6 & 6 & 4 & 6 & 6 & 4 & 5 & 4 \\
\hline 63 & 445016 & 5019793 & 6306 & $07-14$ & 12 & 7 & 5.12 & 0.21 & 50388 & 7 & 7 & 7 & 6 & 6 & 4 & 5 & 5 \\
\hline 63 & 445016 & 5019793 & C793 & $07-15$ & 12 & 7 & 4.41 & 0.03 & 50388 & 7 & 7 & 7 & 7 & 7 & 5 & 5 & 5 \\
\hline 64 & 445255 & 5023779 & 6401 & $07-14$ & 29 & 9 & 3.76 & 0.21 & 24333 & 5 & 5 & 7 & 7 & 7 & 4 & 5 & 5 \\
\hline 64 & 445255 & 5023779 & 6402 & $07-14$ & 29 & 9 & 3.93 & 0.19 & 24333 & 6 & 6 & 6 & 7 & 7 & 5 & 5 & 5 \\
\hline 64 & 445255 & 5023779 & 6403 & $07-14$ & 29 & 9 & 3.85 & 0.16 & 24333 & 6 & 6 & 5 & 7 & 6 & 5 & 5 & 5 \\
\hline 64 & 445255 & 5023779 & 6404 & $07-14$ & 29 & 9 & 4.82 & 0.12 & 24333 & 6 & 3 & 4 & 7 & 4 & 5 & 5 & 5 \\
\hline 64 & 445255 & 5023779 & 6405 & $07-14$ & 29 & 9 & 5.35 & 0.20 & 24333 & 6 & 6 & 6 & 7 & 6 & 4 & 4 & 5 \\
\hline 64 & 445255 & 5023779 & 6406 & $07-14$ & 29 & 9 & 4.93 & 0.25 & 24333 & 7 & 7 & 6 & 7 & 6 & 4 & 5 & 4 \\
\hline 64 & 445255 & 5023779 & 6407 & $07-14$ & 29 & 9 & 5.01 & 0.23 & 24333 & 6 & 6 & 5 & 6 & 7 & 4 & 4 & 4 \\
\hline 64 & 445255 & 5023779 & 6408 & $07-14$ & 29 & 9 & 5.06 & 0.19 & 24333 & 7 & 7 & 7 & 7 & 6 & 3 & 5 & 3 \\
\hline 64 & 445255 & 5023779 & 6409 & $07-14$ & 29 & 9 & 4.84 & 0.14 & 24333 & 6 & 2 & 7 & 7 & 6 & 3 & 5 & 5 \\
\hline 64 & 445255 & 5023779 & 6410 & $07-14$ & 29 & 9 & 4.48 & 0.17 & 24333 & 6 & 6 & 6 & 6 & 7 & 5 & 5 & 5 \\
\hline 64 & 445255 & 5023779 & C839 & $07-17$ & 29 & 9 & 5.08 & 0.21 & 24333 & 6 & 6 & 6 & 7 & 7 & 4 & 5 & 4 \\
\hline 65 & 440627 & 5026701 & 6501 & $07-17$ & 2 & 2 & 3.86 & 0.38 & 54062 & 7 & 4 & 5 & 4 & 4 & 1 & 2 & 4 \\
\hline 65 & 440627 & 5026701 & 6502 & $07-17$ & 2 & 2 & 4.60 & 0.30 & 54062 & 5 & 6 & 5 & 6 & 6 & 4 & 5 & 4 \\
\hline 65 & 440627 & 5026701 & 6503 & $07-17$ & 2 & 2 & 4.70 & 0.30 & 54062 & 6 & 6 & 6 & 5 & 5 & 4 & 5 & 4 \\
\hline 65 & 440627 & 5026701 & 6504 & $07-17$ & 2 & 2 & 4.28 & 0.34 & 54062 & 7 & 7 & 7 & 6 & 6 & 3 & 4 & 5 \\
\hline 65 & 440627 & 5026701 & 6505 & $07-17$ & 2 & 2 & 4.42 & 0.33 & 54062 & 7 & 7 & 7 & 7 & 7 & 4 & 5 & 4 \\
\hline
\end{tabular}




\begin{tabular}{|c|c|c|c|c|c|c|c|c|c|c|c|c|c|c|c|c|c|}
\hline Site & Easting & Northing & User ID & Date & Abun. & Rich. & Tree & Water & Inc. & Q1 & Q2 & Q3 & Q4 & Q5 & Q6 & Q7 & Q8 \\
\hline 65 & 440627 & 5026701 & 6506 & $07-17$ & 2 & 2 & 4.48 & 0.30 & 54062 & 6 & 6 & 6 & 6 & 6 & 4 & 4 & 4 \\
\hline 65 & 440627 & 5026701 & 6507 & $07-17$ & 2 & 2 & 4.67 & 0.28 & 54062 & 6 & 6 & 6 & 7 & 7 & 4 & 5 & 5 \\
\hline 65 & 440627 & 5026701 & 6508 & $07-17$ & 2 & 2 & 5.06 & 0.24 & 54062 & 7 & 7 & 7 & 6 & 7 & 5 & 5 & 4 \\
\hline 65 & 440627 & 5026701 & 6509 & $07-17$ & 2 & 2 & 4.58 & 0.27 & 54062 & 7 & 7 & 6 & 7 & 5 & 4 & 4 & 5 \\
\hline 65 & 440627 & 5026701 & 6510 & $07-17$ & 2 & 2 & 4.66 & 0.26 & 54062 & 6 & 6 & 6 & 3 & 6 & 5 & 5 & 5 \\
\hline 65 & 440627 & 5026701 & C851 & $07-27$ & 2 & 2 & 4.35 & 0.32 & 54062 & 6 & 7 & 6 & 5 & 5 & 4 & 5 & 5 \\
\hline 65 & 440627 & 5026701 & C904 & $07-19$ & 2 & 2 & 5.21 & 0.26 & 54062 & 6 & 6 & 7 & 7 & 7 & 5 & 5 & 4 \\
\hline 65 & 440627 & 5026701 & C984 & $07-17$ & 2 & 2 & 4.48 & 0.32 & 54062 & 6 & 6 & 7 & 7 & 7 & 5 & 5 & 5 \\
\hline 66 & 438960 & 5024758 & 6601 & $07-17$ & 8 & 4 & 3.27 & 0.45 & 45431 & 7 & 5 & 6 & 7 & 7 & 5 & 5 & 5 \\
\hline 66 & 438960 & 5024758 & 6602 & $07-17$ & 8 & 4 & 3.28 & 0.43 & 45431 & 7 & 7 & 7 & 6 & 6 & 4 & 4 & 4 \\
\hline 66 & 438960 & 5024758 & 6603 & $07-17$ & 8 & 4 & 3.35 & 0.43 & 41825 & 7 & 6 & 7 & 6 & 6 & 5 & 5 & 5 \\
\hline 66 & 438960 & 5024758 & 6604 & $07-17$ & 8 & 4 & 3.46 & 0.54 & 45431 & 7 & 6 & 7 & 6 & 6 & 5 & 5 & 4 \\
\hline 66 & 438960 & 5024758 & 6605 & 07-17 & 8 & 4 & 3.40 & 0.55 & 45431 & 6 & 7 & 7 & 7 & 7 & 3 & 5 & 5 \\
\hline 66 & 438960 & 5024758 & 6606 & $07-17$ & 8 & 4 & 3.52 & 0.49 & 45431 & 7 & 7 & 6 & 6 & 3 & 3 & 5 & 5 \\
\hline 66 & 438960 & 5024758 & 6607 & $07-17$ & 8 & 4 & 3.41 & 0.48 & 45431 & 5 & 6 & 6 & 6 & 5 & 4 & 4 & 4 \\
\hline 66 & 438960 & 5024758 & 6608 & $07-18$ & 8 & 4 & 3.30 & 0.46 & 45431 & 7 & 7 & 7 & 7 & 4 & 2 & 5 & 4 \\
\hline 67 & 449385 & 5030658 & 6701 & $07-18$ & 18 & 11 & 4.05 & 1.56 & 18602 & 4 & 6 & 5 & 6 & 4 & 3 & 5 & 2 \\
\hline 67 & 449385 & 5030658 & 6702 & $07-18$ & 18 & 11 & 4.24 & 1.46 & 18602 & 4 & 4 & 6 & 4 & 4 & 3 & 5 & 5 \\
\hline 67 & 449385 & 5030658 & 6703 & $07-18$ & 18 & 11 & 4.02 & 1.54 & 35561 & 6 & 6 & 6 & 7 & 6 & 4 & 5 & 5 \\
\hline 67 & 449385 & 5030658 & 6704 & $07-18$ & 18 & 11 & 3.96 & 1.59 & 35561 & 6 & 7 & 5 & 3 & 1 & 2 & 5 & 5 \\
\hline 67 & 449385 & 5030658 & 6705 & $07-18$ & 18 & 11 & 3.85 & 1.59 & 35561 & 7 & 7 & 7 & 6 & 7 & 4 & 5 & 5 \\
\hline 67 & 449385 & 5030658 & 6706 & $07-18$ & 18 & 11 & 3.90 & 1.78 & 26481 & 6 & 6 & 6 & 5 & 4 & 4 & 4 & 5 \\
\hline 67 & 449385 & 5030658 & 6707 & $07-18$ & 18 & 11 & 4.22 & 1.40 & 18602 & 6 & 5 & 2 & 4 & 2 & 1 & 4 & 4 \\
\hline 67 & 449385 & 5030658 & 6708 & 08-17 & 18 & 11 & 4.04 & 1.67 & 35561 & 7 & 7 & 7 & 7 & 4 & 3 & 5 & 5 \\
\hline 67 & 449385 & 5030658 & 6708 & 08-17 & 18 & 11 & 4.04 & 1.67 & 35561 & 7 & 6 & 7 & 7 & 6 & 1 & 5 & 4 \\
\hline
\end{tabular}




\begin{tabular}{|c|c|c|c|c|c|c|c|c|c|c|c|c|c|c|c|c|c|}
\hline Site & Easting & Northing & User ID & Date & Abun. & Rich. & Tree & Water & Inc. & Q1 & Q2 & Q3 & Q4 & Q5 & Q6 & Q7 & Q8 \\
\hline 67 & 449385 & 5030658 & 6709 & 08-17 & 18 & 11 & 4.31 & 1.36 & 18602 & 4 & 3 & 1 & 1 & 1 & 1 & 4 & 4 \\
\hline 67 & 449385 & 5030658 & 6710 & $07-18$ & 18 & 11 & 4.23 & 1.42 & 18602 & 3 & 3 & 7 & 7 & 6 & 4 & 5 & 5 \\
\hline 67 & 449385 & 5030658 & C980 & $07-21$ & 18 & 11 & 4.00 & 1.62 & 35561 & 7 & 6 & 7 & 7 & 5 & 3 & 4 & 5 \\
\hline 67 & 449385 & 5030658 & D019 & $07-18$ & 18 & 11 & 3.78 & 1.81 & 26481 & 6 & 7 & 6 & 3 & 2 & 3 & 4 & 3 \\
\hline 68 & 444771 & 5028207 & 6801 & $07-18$ & 6 & 3 & 3.10 & 0.94 & 41047 & 4 & 5 & 5 & 3 & 2 & 2 & 2 & 3 \\
\hline 68 & 444771 & 5028207 & 6802 & $07-18$ & 6 & 3 & 2.77 & 0.81 & 41047 & 6 & 6 & 1 & 6 & 4 & 4 & 5 & 5 \\
\hline 68 & 444771 & 5028207 & 6803 & $07-18$ & 6 & 3 & 2.79 & 0.81 & 18592 & 5 & 7 & 5 & 6 & 5 & 4 & 4 & 3 \\
\hline 68 & 444771 & 5028207 & 6804 & $07-18$ & 6 & 3 & 2.80 & 0.79 & 18592 & 6 & 6 & 6 & 5 & 5 & 3 & 4 & 4 \\
\hline 68 & 444771 & 5028207 & 6805 & $07-18$ & 6 & 3 & 2.51 & 0.86 & 18592 & 7 & 7 & 5 & 6 & 4 & 2 & 4 & 4 \\
\hline 68 & 444771 & 5028207 & 6806 & $08-16$ & 6 & 3 & 2.46 & 0.87 & 18592 & 1 & 7 & 2 & 4 & 3 & 2 & 4 & 4 \\
\hline 68 & 444771 & 5028207 & 6807 & $08-16$ & 6 & 3 & 2.53 & 0.95 & 19228 & 6 & 7 & 7 & 5 & 4 & 3 & 3 & 4 \\
\hline 68 & 444771 & 5028207 & 6808 & $08-16$ & 6 & 3 & 2.65 & 0.97 & 19228 & 3 & 1 & 4 & 4 & 6 & 5 & 5 & 5 \\
\hline 68 & 444771 & 5028207 & 6809 & $08-16$ & 6 & 3 & 2.87 & 0.82 & 18592 & 7 & 7 & 7 & 6 & 6 & 3 & 5 & 5 \\
\hline 68 & 444771 & 5028207 & 6810 & $07-18$ & 6 & 3 & 2.87 & 0.82 & 18592 & 6 & 6 & 6 & 6 & 4 & 1 & 4 & 3 \\
\hline 68 & 444771 & 5028207 & D093 & $07-25$ & 6 & 3 & 2.84 & 0.77 & 18592 & 5 & 3 & 5 & 3 & 2 & 3 & 5 & 4 \\
\hline 68 & 444771 & 5028207 & D099 & $07-18$ & 6 & 3 & 2.47 & 0.86 & 18592 & 7 & 7 & 7 & 7 & 6 & 3 & 4 & 3 \\
\hline 68 & 444771 & 5028207 & E758 & $09-30$ & 6 & 3 & 2.76 & 0.93 & 41047 & 6 & 7 & 2 & 2 & 1 & 2 & 5 & 4 \\
\hline 69 & 452769 & 5033065 & 6901 & $07-19$ & 8 & 5 & 9.83 & 1.53 & 58634 & 5 & 3 & 7 & 7 & 6 & 5 & 4 & 4 \\
\hline 69 & 452769 & 5033065 & 6902 & 07-19 & 8 & 5 & 9.07 & 1.60 & 58634 & 4 & 4 & 3 & 6 & 6 & 3 & 5 & 5 \\
\hline 69 & 452769 & 5033065 & 6903 & $07-19$ & 8 & 5 & 8.82 & 1.63 & 58634 & 7 & 6 & 7 & 7 & 6 & 5 & 4 & 4 \\
\hline 69 & 452769 & 5033065 & 6904 & 07-19 & 8 & 5 & 7.38 & 1.71 & 58634 & 6 & 6 & 6 & 7 & 6 & 5 & 5 & 5 \\
\hline 69 & 452769 & 5033065 & 6905 & 07-19 & 8 & 5 & 7.53 & 1.70 & 58634 & 6 & 6 & 6 & 6 & 6 & 4 & 4 & 5 \\
\hline 69 & 452769 & 5033065 & 6906 & 07-19 & 8 & 5 & 8.71 & 1.64 & 58634 & 7 & 6 & 7 & 7 & 7 & 5 & 4 & 4 \\
\hline 69 & 452769 & 5033065 & 6907 & 07-19 & 8 & 5 & 7.41 & 1.80 & 27787 & 7 & 7 & 6 & 7 & 6 & 5 & 5 & 5 \\
\hline 69 & 452769 & 5033065 & 6908 & $07-19$ & 8 & 5 & 6.81 & 1.79 & 27787 & 7 & 6 & 6 & 7 & 6 & 4 & 4 & 3 \\
\hline
\end{tabular}




\begin{tabular}{|c|c|c|c|c|c|c|c|c|c|c|c|c|c|c|c|c|c|}
\hline Site & Easting & Northing & User ID & Date & Abun. & Rich. & Tree & Water & Inc. & Q1 & Q2 & Q3 & Q4 & Q5 & Q6 & Q7 & Q8 \\
\hline 69 & 452769 & 5033065 & 6909 & $07-19$ & 8 & 5 & 6.34 & 1.79 & 27787 & 6 & 7 & 6 & 7 & 6 & 5 & 5 & 5 \\
\hline 69 & 452769 & 5033065 & 6910 & 07-19 & 8 & 5 & 6.75 & 1.76 & 27787 & 3 & 7 & 6 & 5 & 6 & 5 & 5 & 4 \\
\hline 69 & 452769 & 5033065 & D126 & $07-20$ & 8 & 5 & 8.93 & 1.62 & 58634 & 6 & 6 & 7 & 7 & 6 & 1 & 3 & 3 \\
\hline 69 & 452769 & 5033065 & D127 & $07-19$ & 8 & 5 & 9.34 & 1.59 & 58634 & 5 & 6 & 7 & 6 & 4 & 2 & 2 & 2 \\
\hline 70 & 453404 & 5033746 & 7001 & 07-19 & 18 & 9 & 4.73 & 0.98 & 45563 & 6 & 6 & 6 & 7 & 5 & 3 & 4 & 4 \\
\hline 70 & 453404 & 5033746 & 7002 & $07-19$ & 18 & 9 & 4.53 & 1.10 & 45563 & 6 & 6 & 6 & 6 & 7 & 4 & 5 & 4 \\
\hline 70 & 453404 & 5033746 & 7003 & $07-19$ & 18 & 9 & 5.10 & 1.08 & 45563 & 7 & 7 & 7 & 6 & 7 & 2 & 5 & 5 \\
\hline 70 & 453404 & 5033746 & 7004 & $07-19$ & 18 & 9 & 5.16 & 1.08 & 45563 & 6 & 7 & 7 & 7 & 7 & 1 & 4 & 3 \\
\hline 70 & 453404 & 5033746 & 7005 & $07-19$ & 18 & 9 & 4.97 & 0.98 & 45563 & 6 & 6 & 7 & 5 & 5 & 1 & 5 & 5 \\
\hline 70 & 453404 & 5033746 & 7006 & $07-19$ & 18 & 9 & 4.86 & 0.96 & 45563 & 6 & 6 & 6 & 6 & 5 & 3 & 4 & 5 \\
\hline 70 & 453404 & 5033746 & 7007 & $07-19$ & 18 & 9 & 5.01 & 0.99 & 45563 & 7 & 7 & 6 & 7 & 6 & 4 & 5 & 4 \\
\hline 70 & 453404 & 5033746 & 7008 & 07-19 & 18 & 9 & 5.05 & 1.01 & 45563 & 6 & 6 & 7 & 7 & 7 & 4 & 5 & 5 \\
\hline 70 & 453404 & 5033746 & 7009 & $07-19$ & 18 & 9 & 5.20 & 1.08 & 45563 & 6 & 7 & 7 & 7 & 6 & 4 & 5 & 5 \\
\hline 70 & 453404 & 5033746 & 7010 & 07-19 & 18 & 9 & 5.24 & 1.19 & 45563 & 6 & 5 & 7 & 6 & 7 & 5 & 4 & 5 \\
\hline 70 & 453404 & 5033746 & D143 & $07-24$ & 18 & 9 & 4.87 & 0.96 & 45563 & 6 & 6 & 6 & 6 & 6 & 3 & 4 & 4 \\
\hline 70 & 453404 & 5033746 & D163 & $07-28$ & 18 & 9 & 5.13 & 1.13 & 45563 & 5 & 3 & 6 & 7 & 5 & 3 & 4 & 3 \\
\hline 70 & 453404 & 5033746 & D169 & $07-20$ & 18 & 9 & 5.10 & 1.05 & 45563 & 5 & 6 & 7 & 6 & 6 & 3 & 3 & 3 \\
\hline 71 & 443620 & 5021994 & 7101 & $07-20$ & 7 & 5 & 2.86 & 1.31 & 30739 & 6 & 6 & 7 & 7 & 7 & 5 & 5 & 5 \\
\hline 71 & 443620 & 5021994 & 7102 & $07-20$ & 7 & 5 & 2.66 & 1.26 & 30739 & 7 & 7 & 7 & 6 & 6 & 5 & 5 & 5 \\
\hline 71 & 443620 & 5021994 & 7103 & $07-20$ & 7 & 5 & 3.16 & 1.39 & 30739 & 6 & 6 & 7 & 6 & 4 & 3 & 4 & 4 \\
\hline 71 & 443620 & 5021994 & 7104 & $07-20$ & 7 & 5 & 2.70 & 1.42 & 30739 & 6 & 7 & 5 & 7 & 6 & 4 & 5 & 4 \\
\hline 71 & 443620 & 5021994 & 7105 & $07-20$ & 7 & 5 & 2.54 & 1.45 & 30739 & 5 & 6 & 7 & 7 & 6 & 5 & 5 & 5 \\
\hline 71 & 443620 & 5021994 & 7106 & $07-20$ & 7 & 5 & 2.98 & 1.44 & 30739 & 6 & 7 & 7 & 6 & 6 & 5 & 5 & 5 \\
\hline 71 & 443620 & 5021994 & 7107 & $07-20$ & 7 & 5 & 2.89 & 1.32 & 30739 & 6 & 5 & 6 & 6 & 5 & 2 & 3 & 3 \\
\hline 71 & 443620 & 5021994 & 7108 & $07-20$ & 7 & 5 & 2.90 & 1.33 & 30739 & 7 & 7 & 6 & 6 & 5 & 2 & 4 & 3 \\
\hline
\end{tabular}




\begin{tabular}{|c|c|c|c|c|c|c|c|c|c|c|c|c|c|c|c|c|c|}
\hline Site & Easting & Northing & User ID & Date & Abun. & Rich. & Tree & Water & Inc. & Q1 & Q2 & Q3 & Q4 & Q5 & Q6 & Q7 & Q8 \\
\hline 71 & 443620 & 5021994 & 7109 & $07-20$ & 7 & 5 & 2.87 & 1.35 & 30739 & 3 & 5 & 6 & 6 & 5 & 4 & 5 & 4 \\
\hline 71 & 443620 & 5021994 & 7110 & $07-20$ & 7 & 5 & 2.99 & 1.47 & 50594 & 7 & 7 & 7 & 6 & 6 & 4 & 5 & 4 \\
\hline 72 & 439065 & 5022161 & 7201 & $07-20$ & 30 & 12 & 3.18 & 2.24 & 48923 & 7 & 7 & 6 & 6 & 5 & 5 & 5 & 4 \\
\hline 72 & 439065 & 5022161 & 7202 & $07-20$ & 30 & 12 & 3.24 & 2.24 & 48923 & 7 & 7 & 7 & 7 & 6 & 4 & 5 & 4 \\
\hline 72 & 439065 & 5022161 & 7203 & $07-20$ & 30 & 12 & 3.12 & 2.37 & 48923 & 7 & 7 & 7 & 6 & 6 & 2 & 5 & 5 \\
\hline 72 & 439065 & 5022161 & 7204 & $07-20$ & 30 & 12 & 3.41 & 2.32 & 48923 & 7 & 7 & 7 & 7 & 5 & 5 & 5 & 4 \\
\hline 72 & 439065 & 5022161 & 7205 & $07-20$ & 30 & 12 & 3.12 & 2.37 & 48923 & 7 & 6 & 7 & 6 & 6 & 4 & 4 & 5 \\
\hline 72 & 439065 & 5022161 & 7206 & $07-20$ & 30 & 12 & 3.28 & 2.40 & 48923 & 7 & 6 & 7 & 7 & 5 & 3 & 3 & 4 \\
\hline 72 & 439065 & 5022161 & 7207 & $07-20$ & 30 & 12 & 2.91 & 2.48 & 29502 & 6 & 6 & 7 & 6 & 5 & 5 & 5 & 5 \\
\hline 72 & 439065 & 5022161 & 7208 & $07-20$ & 30 & 12 & 3.02 & 2.22 & 48923 & 6 & 4 & 5 & 3 & 5 & 1 & 4 & 3 \\
\hline 72 & 439065 & 5022161 & 7209 & $07-20$ & 30 & 12 & 2.80 & 2.12 & 33254 & 7 & 6 & 6 & 7 & 5 & 1 & 3 & 3 \\
\hline 72 & 439065 & 5022161 & 7210 & $07-20$ & 30 & 12 & 3.51 & 2.20 & 48923 & 2 & 2 & 6 & 6 & 6 & 1 & 3 & 4 \\
\hline 72 & 439065 & 5022161 & 7211 & $07-20$ & 30 & 12 & 3.51 & 2.20 & 48923 & 6 & 6 & 7 & 6 & 6 & 5 & 4 & 4 \\
\hline 72 & 439065 & 5022161 & D242 & $07-29$ & 30 & 12 & 3.53 & 2.26 & 48923 & 7 & 7 & 7 & 7 & 6 & 3 & 5 & 4 \\
\hline 72 & 439065 & 5022161 & D258 & $07-21$ & 30 & 12 & 3.75 & 2.42 & 48923 & 7 & 7 & 7 & 7 & 6 & 3 & 4 & 5 \\
\hline 72 & 439065 & 5022161 & D277 & $07-20$ & 30 & 12 & 2.94 & 2.33 & 29502 & 6 & 6 & 6 & 7 & 6 & 4 & 5 & 5 \\
\hline 73 & 438115 & 5022350 & 7301 & $07-21$ & 37 & 12 & 3.69 & 1.46 & 39124 & 6 & 6 & 5 & 6 & 5 & 4 & 5 & 5 \\
\hline 73 & 438115 & 5022350 & 7302 & $07-21$ & 37 & 12 & 4.10 & 1.48 & 46273 & 6 & 6 & 7 & 7 & 6 & 1 & 1 & 1 \\
\hline 73 & 438115 & 5022350 & 7303 & $07-21$ & 37 & 12 & 4.17 & 1.42 & 46273 & 6 & 7 & 6 & 7 & 6 & 3 & 4 & 4 \\
\hline 73 & 438115 & 5022350 & 7304 & $07-21$ & 37 & 12 & 4.20 & 1.39 & 46273 & 6 & 6 & 7 & 7 & 6 & 4 & 5 & 5 \\
\hline 73 & 438115 & 5022350 & 7305 & $07-21$ & 37 & 12 & 4.35 & 1.38 & 46273 & 7 & 6 & 6 & 7 & 7 & 1 & 4 & 4 \\
\hline 73 & 438115 & 5022350 & 7306 & $07-21$ & 37 & 12 & 4.22 & 1.44 & 46273 & 6 & 6 & 7 & 7 & 7 & 4 & 5 & 4 \\
\hline 73 & 438115 & 5022350 & 7307 & $07-21$ & 37 & 12 & 4.41 & 1.27 & 46273 & 5 & 5 & 5 & 4 & 4 & 1 & 3 & 3 \\
\hline 73 & 438115 & 5022350 & 7308 & $07-21$ & 37 & 12 & 3.47 & 1.39 & 39124 & 6 & 6 & 5 & 5 & 4 & 4 & 5 & 4 \\
\hline 73 & 438115 & 5022350 & 7309 & $07-21$ & 37 & 12 & 3.70 & 1.29 & 17848 & 7 & 6 & 6 & 6 & 6 & 5 & 5 & 4 \\
\hline
\end{tabular}




\begin{tabular}{|c|c|c|c|c|c|c|c|c|c|c|c|c|c|c|c|c|c|}
\hline Site & Easting & Northing & User ID & Date & Abun. & Rich. & Tree & Water & Inc. & Q1 & Q2 & Q3 & Q4 & Q5 & Q6 & Q7 & Q8 \\
\hline 73 & 438115 & 5022350 & D322 & $07-25$ & 37 & 12 & 4.18 & 1.41 & 46273 & 6 & 6 & 7 & 7 & 6 & 3 & 4 & 3 \\
\hline 73 & 438115 & 5022350 & D335 & $07-22$ & 37 & 12 & 4.50 & 1.35 & 46273 & 2 & 2 & 6 & 7 & 7 & 5 & 5 & 5 \\
\hline 74 & 437416 & 5021414 & 7401 & $07-21$ & 20 & 8 & 3.81 & 1.49 & 44024 & 7 & 7 & 7 & 6 & 5 & 4 & 5 & 5 \\
\hline 74 & 437416 & 5021414 & 7402 & $07-21$ & 20 & 8 & 4.06 & 1.61 & 73492 & 6 & 7 & 7 & 6 & 7 & 1 & 5 & 4 \\
\hline 74 & 437416 & 5021414 & 7403 & $07-21$ & 20 & 8 & 4.26 & 1.58 & 73492 & 7 & 7 & 6 & 7 & 6 & 4 & 5 & 5 \\
\hline 74 & 437416 & 5021414 & 7404 & $07-21$ & 20 & 8 & 4.25 & 1.60 & 73492 & 7 & 7 & 6 & 6 & 6 & 1 & 5 & 5 \\
\hline 74 & 437416 & 5021414 & 7405 & $07-21$ & 20 & 8 & 4.10 & 1.55 & 73492 & 6 & 6 & 7 & 5 & 6 & 3 & 4 & 4 \\
\hline 74 & 437416 & 5021414 & 7406 & $07-21$ & 20 & 8 & 4.14 & 1.54 & 73492 & 7 & 7 & 6 & 6 & 5 & 2 & 4 & 4 \\
\hline 74 & 437416 & 5021414 & 7407 & $07-21$ & 20 & 8 & 3.89 & 1.48 & 56665 & 6 & 7 & 7 & 7 & 6 & 1 & 3 & 3 \\
\hline 74 & 437416 & 5021414 & 7408 & $07-21$ & 20 & 8 & 4.20 & 1.45 & 56665 & 4 & 6 & 7 & 6 & 7 & 4 & 5 & 4 \\
\hline 74 & 437416 & 5021414 & 7409 & $07-21$ & 20 & 8 & 4.33 & 1.45 & 56665 & 4 & 3 & 6 & 5 & 6 & 4 & 5 & 5 \\
\hline 74 & 437416 & 5021414 & 7410 & $07-21$ & 20 & 8 & 3.90 & 1.43 & 56665 & 5 & 6 & 6 & 6 & 6 & 5 & 5 & 4 \\
\hline 74 & 437416 & 5021414 & D412 & $07-21$ & 20 & 8 & 3.78 & 1.50 & 44024 & 6 & 6 & 6 & 7 & 6 & 4 & 4 & 5 \\
\hline 75 & 448184 & 5031151 & 7501 & $07-25$ & 30 & 6 & 2.65 & 0.63 & 20086 & 6 & 6 & 6 & 6 & 4 & 2 & 3 & 4 \\
\hline 75 & 448184 & 5031151 & 7502 & $07-25$ & 30 & 6 & 2.43 & 0.70 & 20086 & 7 & 6 & 6 & 6 & 6 & 3 & 5 & 4 \\
\hline 75 & 448184 & 5031151 & 7503 & $07-25$ & 30 & 6 & 2.60 & 0.65 & 20086 & 6 & 6 & 6 & 6 & 6 & 4 & 5 & 4 \\
\hline 75 & 448184 & 5031151 & 7504 & $07-25$ & 30 & 6 & 2.36 & 0.68 & 20086 & 5 & 5 & 4 & 4 & 4 & 2 & 4 & 3 \\
\hline 75 & 448184 & 5031151 & 7505 & $07-25$ & 30 & 6 & 2.47 & 0.62 & 20086 & 6 & 6 & 5 & 6 & 4 & 1 & 3 & 3 \\
\hline 75 & 448184 & 5031151 & 7506 & $08-17$ & 30 & 6 & 2.61 & 0.66 & 36331 & 6 & 6 & 3 & 3 & 4 & 1 & 5 & 5 \\
\hline 75 & 448184 & 5031151 & 7507 & $08-17$ & 30 & 6 & 2.41 & 0.44 & 37107 & 4 & 6 & 4 & 6 & 3 & 5 & 4 & 4 \\
\hline 75 & 448184 & 5031151 & 7508 & 08-17 & 30 & 6 & 2.29 & 0.40 & 37107 & 5 & 3 & 6 & 3 & 5 & 5 & 5 & 5 \\
\hline 75 & 448184 & 5031151 & 7509 & 08-17 & 30 & 6 & 2.23 & 0.38 & 37107 & 6 & 6 & 1 & 1 & 3 & 1 & 4 & 5 \\
\hline 75 & 448184 & 5031151 & 7510 & 08-17 & 30 & 6 & 2.56 & 0.77 & 24987 & 6 & 4 & 6 & 6 & 6 & 4 & 4 & 4 \\
\hline 75 & 448184 & 5031151 & E841 & 09-18 & 30 & 6 & 2.14 & 0.41 & 37107 & 7 & 7 & 7 & 3 & 2 & 3 & 5 & 5 \\
\hline 76 & 447299 & 5026372 & 7601 & $07-26$ & 8 & 7 & 4.89 & 0.23 & 18552 & 6 & 6 & 6 & 6 & 6 & 5 & 4 & 4 \\
\hline
\end{tabular}




\begin{tabular}{|c|c|c|c|c|c|c|c|c|c|c|c|c|c|c|c|c|c|}
\hline Site & Easting & Northing & User ID & Date & Abun. & Rich. & Tree & Water & Inc. & Q1 & Q2 & Q3 & Q4 & Q5 & Q6 & Q7 & Q8 \\
\hline 76 & 447299 & 5026372 & 7602 & $07-26$ & 8 & 7 & 5.49 & 0.25 & 18552 & 6 & 7 & 7 & 7 & 4 & 2 & 1 & 3 \\
\hline 76 & 447299 & 5026372 & 7603 & $07-26$ & 8 & 7 & 5.52 & 0.51 & 36260 & 7 & 7 & 6 & 6 & 4 & 3 & 5 & 3 \\
\hline 76 & 447299 & 5026372 & 7604 & $07-26$ & 8 & 7 & 6.19 & 0.44 & 36260 & 7 & 6 & 7 & 7 & 7 & 4 & 5 & 5 \\
\hline 76 & 447299 & 5026372 & 7605 & $07-26$ & 8 & 7 & 5.82 & 0.44 & 36260 & 6 & 7 & 5 & 5 & 6 & 4 & 3 & 3 \\
\hline 76 & 447299 & 5026372 & D440 & $07-30$ & 8 & 7 & 5.01 & 0.32 & 18552 & 6 & 6 & 7 & 6 & 6 & 3 & 2 & 2 \\
\hline 77 & 449404 & 5029559 & 7701 & $07-26$ & 30 & 10 & 4.21 & 1.31 & 34459 & 6 & 7 & 6 & 6 & 6 & 3 & 5 & 5 \\
\hline 77 & 449404 & 5029559 & 7702 & $07-26$ & 30 & 10 & 4.09 & 1.26 & 34459 & 6 & 6 & 7 & 7 & 7 & 5 & 5 & 4 \\
\hline 77 & 449404 & 5029559 & 7703 & $07-26$ & 30 & 10 & 3.86 & 1.22 & 34459 & 7 & 7 & 7 & 7 & 6 & 2 & 5 & 5 \\
\hline 77 & 449404 & 5029559 & 7704 & $07-26$ & 30 & 10 & 4.13 & 1.38 & 34459 & 4 & 6 & 7 & 7 & 4 & 4 & 5 & 3 \\
\hline 77 & 449404 & 5029559 & 7705 & $07-26$ & 30 & 10 & 4.25 & 1.38 & 34459 & 7 & 7 & 6 & 6 & 4 & 4 & 4 & 5 \\
\hline 77 & 449404 & 5029559 & 7706 & $07-26$ & 30 & 10 & 4.83 & 1.38 & 34459 & 6 & 6 & 6 & 6 & 5 & 2 & 4 & 5 \\
\hline 77 & 449404 & 5029559 & 7707 & $07-26$ & 30 & 10 & 4.34 & 1.38 & 34459 & 5 & 5 & 6 & 4 & 6 & 2 & 5 & 5 \\
\hline 77 & 449404 & 5029559 & 7708 & $07-26$ & 30 & 10 & 4.73 & 1.42 & 34459 & 6 & 5 & 6 & 6 & 5 & 5 & 5 & 5 \\
\hline 77 & 449404 & 5029559 & D484 & $07-31$ & 30 & 10 & 3.86 & 1.27 & 34459 & 7 & 7 & 6 & 5 & 4 & 2 & 3 & 2 \\
\hline 77 & 449404 & 5029559 & D487 & $07-31$ & 30 & 10 & 3.96 & 1.30 & 34459 & 7 & 6 & 7 & 6 & 6 & 4 & 5 & 4 \\
\hline 78 & 446718 & 5022959 & 7802 & $07-27$ & 13 & 8 & 3.49 & 0.60 & 43679 & 6 & 7 & 7 & 7 & 6 & 4 & 5 & 5 \\
\hline 78 & 446718 & 5022959 & 7803 & $07-27$ & 13 & 8 & 3.42 & 0.56 & 43679 & 6 & 6 & 6 & 6 & 6 & 4 & 4 & 4 \\
\hline 78 & 446718 & 5022959 & 7804 & $07-27$ & 13 & 8 & 3.39 & 0.62 & 43679 & 6 & 6 & 7 & 7 & 6 & 2 & 4 & 4 \\
\hline 78 & 446718 & 5022959 & 7805 & $07-27$ & 13 & 8 & 3.41 & 0.64 & 43679 & 4 & 6 & 6 & 6 & 6 & 3 & 4 & 4 \\
\hline 78 & 446718 & 5022959 & 7806 & $07-27$ & 13 & 8 & 4.48 & 0.58 & 37232 & 6 & 6 & 7 & 7 & 6 & 3 & 4 & 4 \\
\hline 78 & 446387 & 5023059 & 7807 & $07-27$ & 15 & 9 & 3.53 & 0.49 & 37232 & 5 & 7 & 7 & 6 & 7 & 5 & 5 & 5 \\
\hline 78 & 446718 & 5022959 & 7808 & $07-27$ & 13 & 8 & 3.43 & 0.54 & 43679 & 6 & 6 & 6 & 7 & 6 & 4 & 5 & 5 \\
\hline 78 & 446718 & 5022959 & 7809 & $07-27$ & 13 & 8 & 5.95 & 0.65 & 37232 & 7 & 7 & 6 & 6 & 6 & 5 & 5 & 4 \\
\hline 78 & 446718 & 5022959 & 7810 & $07-27$ & 13 & 8 & 6.16 & 0.61 & 37232 & 5 & 5 & 6 & 6 & 6 & 5 & 5 & 4 \\
\hline 78 & 446718 & 5022959 & D550 & $07-27$ & 13 & 8 & 6.23 & 0.78 & 37232 & 7 & 7 & 7 & 7 & 6 & 3 & 4 & 3 \\
\hline
\end{tabular}




\begin{tabular}{|c|c|c|c|c|c|c|c|c|c|c|c|c|c|c|c|c|c|}
\hline Site & Easting & Northing & User ID & Date & Abun. & Rich. & Tree & Water & Inc. & Q1 & Q2 & Q3 & Q4 & Q5 & Q6 & Q7 & Q8 \\
\hline 79 & 445995 & 5021189 & 7901 & $07-27$ & 22 & 12 & 4.27 & 0.45 & 55405 & 6 & 6 & 7 & 6 & 4 & 5 & 5 & 5 \\
\hline 79 & 445995 & 5021189 & 7901 & $07-27$ & 22 & 12 & 4.27 & 0.45 & 55405 & 7 & 7 & 7 & 7 & 7 & 5 & 5 & 5 \\
\hline 79 & 445995 & 5021189 & 7902 & $07-27$ & 22 & 12 & 4.22 & 0.45 & 55405 & 5 & 5 & 7 & 6 & 6 & 3 & 4 & 3 \\
\hline 79 & 445995 & 5021189 & 7902 & $07-27$ & 22 & 12 & 4.22 & 0.45 & 55405 & 6 & 6 & 7 & 7 & 6 & 5 & 4 & 4 \\
\hline 79 & 445995 & 5021189 & 7903 & $07-27$ & 22 & 12 & 4.20 & 0.41 & 55405 & 6 & 7 & 6 & 6 & 6 & 3 & 5 & 5 \\
\hline 79 & 445995 & 5021189 & 7904 & $07-27$ & 22 & 12 & 4.16 & 0.38 & 55405 & 6 & 7 & 5 & 6 & 5 & 5 & 5 & 4 \\
\hline 79 & 445995 & 5021189 & 7905 & $07-27$ & 22 & 12 & 4.36 & 0.39 & 55405 & 6 & 5 & 6 & 7 & 5 & 2 & 4 & 1 \\
\hline 79 & 445995 & 5021189 & 7906 & $07-27$ & 22 & 12 & 4.34 & 0.38 & 55405 & 7 & 7 & 7 & 7 & 6 & 3 & 3 & 3 \\
\hline 79 & 445995 & 5021189 & 7907 & $07-27$ & 22 & 12 & 4.33 & 0.30 & 54647 & 7 & 6 & 7 & 7 & 4 & 3 & 5 & 5 \\
\hline 79 & 445995 & 5021189 & 7908 & $07-27$ & 22 & 12 & 4.33 & 0.30 & 54647 & 6 & 6 & 6 & 6 & 6 & 4 & 3 & 3 \\
\hline 79 & 445995 & 5021189 & 7909 & $07-27$ & 22 & 12 & 4.33 & 0.30 & 54647 & 7 & 7 & 7 & 6 & 6 & 5 & 5 & 5 \\
\hline 79 & 445995 & 5021189 & 7910 & $07-27$ & 22 & 12 & 4.33 & 0.30 & 54647 & 7 & 7 & 7 & 6 & 6 & 4 & 5 & 5 \\
\hline 79 & 445995 & 5021189 & D578 & $07-27$ & 22 & 12 & 4.32 & 0.38 & 55405 & 6 & 6 & 7 & 7 & 7 & 4 & 5 & 5 \\
\hline 80 & 442313 & 5026590 & 8001 & $07-28$ & 5 & 5 & 5.46 & 1.99 & 58171 & 6 & 6 & 7 & 7 & 7 & 4 & 5 & 5 \\
\hline 80 & 442313 & 5026590 & 8002 & $07-28$ & 5 & 5 & 5.42 & 1.99 & 58171 & 6 & 7 & 7 & 6 & 6 & 3 & 5 & 4 \\
\hline 80 & 442313 & 5026590 & 8003 & $07-28$ & 5 & 5 & 5.34 & 1.98 & 58171 & 7 & 7 & 7 & 7 & 7 & 5 & 5 & 5 \\
\hline 80 & 442313 & 5026590 & 8004 & $07-28$ & 5 & 5 & 5.59 & 1.96 & 58171 & 6 & 6 & 6 & 6 & 4 & 1 & 4 & 2 \\
\hline 80 & 442313 & 5026590 & 8005 & $07-28$ & 5 & 5 & 6.62 & 1.90 & 58171 & 7 & 7 & 3 & 6 & 6 & 5 & 5 & 5 \\
\hline 80 & 442313 & 5026590 & 8006 & $07-28$ & 5 & 5 & 5.96 & 1.87 & 58171 & 7 & 6 & 6 & 7 & 6 & 4 & 5 & 5 \\
\hline 80 & 442313 & 5026590 & 8007 & $07-28$ & 5 & 5 & 5.93 & 1.89 & 58171 & 6 & 7 & 6 & 6 & 7 & 4 & 5 & 4 \\
\hline 80 & 442313 & 5026590 & 8008 & $07-28$ & 5 & 5 & 6.09 & 2.00 & 58171 & 6 & 6 & 7 & 7 & 6 & 4 & 5 & 5 \\
\hline 80 & 442313 & 5026590 & 8009 & $07-28$ & 5 & 5 & 4.85 & 2.04 & 58171 & 7 & 7 & 7 & 6 & 6 & 4 & 5 & 4 \\
\hline 80 & 442313 & 5026590 & 8010 & $07-28$ & 5 & 5 & 5.71 & 1.91 & 58171 & 6 & 6 & 7 & 6 & 6 & 2 & 3 & 2 \\
\hline 80 & 442313 & 5026590 & D606 & $07-30$ & 5 & 5 & 6.56 & 1.87 & 58171 & 6 & 7 & 7 & 6 & 5 & 4 & 5 & 5 \\
\hline 80 & 442313 & 5026590 & D610 & $07-28$ & 5 & 5 & 6.57 & 1.94 & 58171 & 6 & 6 & 6 & 6 & 6 & 4 & 4 & 4 \\
\hline
\end{tabular}




\begin{tabular}{|c|c|c|c|c|c|c|c|c|c|c|c|c|c|c|c|c|c|}
\hline Site & Easting & Northing & User ID & Date & Abun. & Rich. & Tree & Water & Inc. & Q1 & Q2 & Q3 & Q4 & Q5 & Q6 & Q7 & Q8 \\
\hline 81 & 439316 & 5025678 & 8101 & $07-28$ & 13 & 6 & 3.75 & 0.18 & 47898 & 6 & 6 & 7 & 7 & 6 & 3 & 5 & 4 \\
\hline 81 & 439316 & 5025678 & 8102 & $07-28$ & 13 & 6 & 3.92 & 0.19 & 47898 & 7 & 7 & 6 & 7 & 7 & 5 & 5 & 5 \\
\hline 81 & 439316 & 5025678 & 8103 & $07-28$ & 13 & 6 & 4.29 & 0.24 & 47898 & 6 & 6 & 6 & 6 & 7 & 4 & 5 & 5 \\
\hline 81 & 439316 & 5025678 & 8104 & $07-28$ & 13 & 6 & 4.21 & 0.24 & 47898 & 7 & 7 & 6 & 6 & 6 & 4 & 3 & 4 \\
\hline 81 & 439316 & 5025678 & 8105 & $07-28$ & 13 & 6 & 4.06 & 0.22 & 47898 & 6 & 7 & 7 & 7 & 7 & 5 & 5 & 5 \\
\hline 81 & 439316 & 5025678 & 8106 & $07-28$ & 13 & 6 & 3.68 & 0.17 & 47898 & 6 & 7 & 6 & 7 & 7 & 5 & 5 & 5 \\
\hline 81 & 439316 & 5025678 & 8107 & $07-28$ & 13 & 6 & 3.52 & 0.13 & 47898 & 7 & 7 & 4 & 4 & 6 & 4 & 4 & 4 \\
\hline 81 & 439316 & 5025678 & 8108 & $07-28$ & 13 & 6 & 4.22 & 0.29 & 47898 & 6 & 6 & 7 & 7 & 7 & 4 & 5 & 4 \\
\hline 81 & 439316 & 5025678 & 8109 & $07-28$ & 13 & 6 & 4.01 & 0.22 & 47898 & 6 & 6 & 6 & 6 & 6 & 4 & 5 & 5 \\
\hline 81 & 439316 & 5025678 & 8110 & $07-28$ & 13 & 6 & 4.02 & 0.23 & 47898 & 6 & 6 & 3 & 6 & 7 & 4 & 5 & 5 \\
\hline 81 & 439316 & 5025678 & D637 & $08-02$ & 13 & 6 & 3.99 & 0.21 & 47898 & 6 & 6 & 7 & 7 & 7 & 3 & 4 & 4 \\
\hline 81 & 439316 & 5025678 & D655 & $07-28$ & 13 & 6 & 4.23 & 0.27 & 47898 & 6 & 6 & 7 & 7 & 7 & 4 & 3 & 4 \\
\hline 81 & 439316 & 5025678 & D673 & 08-05 & 13 & 6 & 4.19 & 0.28 & 47898 & 6 & 6 & 7 & 7 & 6 & 2 & 4 & 4 \\
\hline 82 & 450274 & 5032050 & 8201 & $07-31$ & 9 & 6 & 4.81 & 2.60 & 49560 & 6 & 6 & 7 & 7 & 6 & 3 & 3 & 3 \\
\hline 82 & 450274 & 5032050 & 8202 & $07-31$ & 9 & 6 & 4.92 & 2.64 & 49560 & 7 & 7 & 7 & 6 & 4 & 4 & 5 & 5 \\
\hline 82 & 450274 & 5032050 & 8203 & $07-31$ & 9 & 6 & 4.71 & 2.61 & 49560 & 6 & 6 & 6 & 6 & 6 & 3 & 5 & 5 \\
\hline 82 & 450274 & 5032050 & 8204 & $07-31$ & 9 & 6 & 4.62 & 2.62 & 49560 & 6 & 7 & 7 & 7 & 6 & 4 & 5 & 5 \\
\hline 82 & 450274 & 5032050 & 8205 & $07-31$ & 9 & 6 & 4.91 & 2.66 & 49560 & 7 & 7 & 7 & 6 & 7 & 4 & 5 & 5 \\
\hline 82 & 450274 & 5032050 & 8206 & $07-31$ & 9 & 6 & 4.79 & 2.56 & 49560 & 6 & 5 & 7 & 7 & 7 & 4 & 4 & 4 \\
\hline 82 & 450274 & 5032050 & 8207 & $07-31$ & 9 & 6 & 4.66 & 2.55 & 49560 & 7 & 7 & 7 & 7 & 6 & 4 & 5 & 4 \\
\hline 82 & 450274 & 5032050 & 8208 & $07-31$ & 9 & 6 & 5.75 & 2.77 & 49560 & 7 & 7 & 7 & 7 & 5 & 4 & 5 & 4 \\
\hline 82 & 450274 & 5032050 & 8209 & $07-31$ & 9 & 6 & 5.06 & 2.70 & 49560 & 6 & 2 & 5 & 2 & 4 & 2 & 3 & 4 \\
\hline 82 & 450274 & 5032050 & 8210 & $07-31$ & 9 & 6 & 3.88 & 2.50 & 40998 & 7 & 7 & 7 & 6 & 6 & 4 & 4 & 4 \\
\hline 82 & 450274 & 5032050 & D684 & $08-16$ & 9 & 6 & 4.67 & 2.57 & 49560 & 7 & 6 & 7 & 7 & 6 & 4 & 5 & 5 \\
\hline 82 & 450274 & 5032050 & D694 & 08-01 & 9 & 6 & 5.34 & 2.71 & 49560 & 6 & 7 & 7 & 7 & 7 & 5 & 4 & 5 \\
\hline
\end{tabular}




\begin{tabular}{|c|c|c|c|c|c|c|c|c|c|c|c|c|c|c|c|c|c|}
\hline Site & Easting & Northing & User ID & Date & Abun. & Rich. & Tree & Water & Inc. & Q1 & Q2 & Q3 & Q4 & Q5 & Q6 & Q7 & Q8 \\
\hline 82 & 450274 & 5032050 & D699 & $07-31$ & 9 & 6 & 5.04 & 2.64 & 49560 & 4 & 5 & 6 & 6 & 6 & 2 & 5 & 5 \\
\hline 82 & 450274 & 5032050 & D730 & 08-09 & 9 & 6 & 5.92 & 2.80 & 49560 & 6 & 6 & 6 & 6 & 6 & 4 & 4 & 3 \\
\hline 83 & 446845 & 5028422 & 8301 & $07-31$ & 27 & 9 & 3.40 & 0.22 & 55115 & 6 & 6 & 6 & 6 & 6 & 3 & 3 & 4 \\
\hline 83 & 446845 & 5028422 & 8302 & $07-31$ & 27 & 9 & 3.70 & 0.21 & 55115 & 5 & 7 & 7 & 7 & 7 & 4 & 5 & 5 \\
\hline 83 & 446845 & 5028422 & 8303 & $07-31$ & 27 & 9 & 3.43 & 0.20 & 55115 & 6 & 7 & 7 & 7 & 6 & 5 & 5 & 5 \\
\hline 83 & 446845 & 5028422 & 8304 & $07-31$ & 27 & 9 & 3.85 & 0.14 & 55115 & 6 & 6 & 7 & 5 & 5 & 2 & 3 & 3 \\
\hline 83 & 446845 & 5028422 & 8305 & $07-31$ & 27 & 9 & 3.51 & 0.10 & 55115 & 7 & 7 & 7 & 7 & 6 & 4 & 5 & 5 \\
\hline 83 & 446845 & 5028422 & 8306 & $07-31$ & 27 & 9 & 3.44 & 0.12 & 55115 & 7 & 7 & 7 & 6 & 7 & 4 & 5 & 4 \\
\hline 83 & 446845 & 5028422 & 8307 & $07-31$ & 27 & 9 & 3.44 & 0.13 & 55115 & 7 & 6 & 7 & 7 & 7 & 4 & 5 & 4 \\
\hline 83 & 446845 & 5028422 & 8308 & $07-31$ & 27 & 9 & 3.38 & 0.10 & 52951 & 6 & 6 & 6 & 5 & 4 & 3 & 4 & 3 \\
\hline 83 & 446845 & 5028422 & 8309 & $07-31$ & 27 & 9 & 3.32 & 0.19 & 55115 & 2 & 2 & 6 & 6 & 5 & 3 & 5 & 4 \\
\hline 83 & 446845 & 5028422 & 8310 & $07-31$ & 27 & 9 & 3.78 & 0.27 & 52951 & 6 & 7 & 6 & 6 & 7 & 3 & 4 & 4 \\
\hline 83 & 446845 & 5028422 & D771 & 08-01 & 27 & 9 & 3.62 & 0.11 & 55115 & 7 & 7 & 7 & 6 & 6 & 3 & 5 & 5 \\
\hline 84 & 438920 & 5022809 & 8401 & $08-02$ & 20 & 7 & 2.96 & 1.67 & 50636 & 6 & 6 & 7 & 6 & 6 & 4 & 5 & 4 \\
\hline 84 & 438920 & 5022809 & 8402 & $08-02$ & 20 & 7 & 3.10 & 1.67 & 50636 & 6 & 7 & 7 & 6 & 4 & 1 & 4 & 2 \\
\hline 84 & 438920 & 5022809 & 8403 & $08-02$ & 20 & 7 & 2.46 & 1.75 & 50636 & 6 & 6 & 6 & 7 & 7 & 5 & 5 & 5 \\
\hline 84 & 438920 & 5022809 & 8404 & $08-02$ & 20 & 7 & 2.40 & 1.75 & 50636 & 7 & 7 & 7 & 7 & 7 & 3 & 3 & 3 \\
\hline 84 & 438920 & 5022809 & 8405 & 08-02 & 20 & 7 & 4.23 & 1.57 & 39124 & 5 & 2 & 6 & 6 & 6 & 3 & 4 & 4 \\
\hline 84 & 438920 & 5022809 & 8406 & 08-02 & 20 & 7 & 2.95 & 1.51 & 56223 & 6 & 6 & 7 & 7 & 6 & 3 & 3 & 4 \\
\hline 84 & 438920 & 5022809 & 8407 & 08-02 & 20 & 7 & 3.56 & 1.59 & 50636 & 7 & 7 & 7 & 7 & 7 & 4 & 4 & 4 \\
\hline 84 & 438920 & 5022809 & D825 & 08-02 & 20 & 7 & 2.41 & 1.75 & 50636 & 2 & 2 & 7 & 7 & 6 & 5 & 5 & 5 \\
\hline 84 & 438920 & 5022809 & D860 & 08-03 & 20 & 7 & 3.32 & 1.59 & 50636 & 6 & 6 & 7 & 6 & 6 & 3 & 4 & 4 \\
\hline 84 & 438920 & 5022809 & D864 & 08-07 & 20 & 7 & 3.77 & 1.59 & 50636 & 4 & 4 & 5 & 7 & 6 & 3 & 3 & 4 \\
\hline 85 & 442826 & 5025339 & 8501 & 08-02 & 6 & 6 & 3.03 & 2.11 & 20809 & 4 & 4 & 4 & 3 & 4 & 2 & 3 & 2 \\
\hline 85 & 442826 & 5025339 & 8502 & $08-02$ & 6 & 6 & 3.11 & 2.11 & 20809 & 6 & 6 & 6 & 5 & 3 & 4 & 5 & 4 \\
\hline
\end{tabular}




\begin{tabular}{|c|c|c|c|c|c|c|c|c|c|c|c|c|c|c|c|c|c|}
\hline Site & Easting & Northing & User ID & Date & Abun. & Rich. & Tree & Water & Inc. & Q1 & Q2 & Q3 & Q4 & Q5 & Q6 & Q7 & Q8 \\
\hline 85 & 442826 & 5025339 & 8503 & 08-02 & 6 & 6 & 3.15 & 2.10 & 20809 & 5 & 6 & 6 & 7 & 6 & 4 & 5 & 4 \\
\hline 85 & 442826 & 5025339 & 8504 & $08-02$ & 6 & 6 & 3.16 & 2.05 & 20809 & 7 & 6 & 6 & 2 & 3 & 4 & 3 & 3 \\
\hline 85 & 442826 & 5025339 & 8505 & $08-02$ & 6 & 6 & 3.16 & 2.05 & 20809 & 6 & 6 & 5 & 6 & 4 & 2 & 4 & 4 \\
\hline 85 & 442826 & 5025339 & 8506 & 08-02 & 6 & 6 & 3.16 & 2.05 & 20809 & 6 & 6 & 6 & 7 & 7 & 4 & 5 & 5 \\
\hline 85 & 442826 & 5025339 & 8507 & $08-02$ & 6 & 6 & 3.31 & 1.96 & 21099 & 4 & 4 & 5 & 5 & 3 & 4 & 4 & 4 \\
\hline 85 & 442826 & 5025339 & 8508 & $08-02$ & 6 & 6 & 3.31 & 1.96 & 21099 & 6 & 4 & 5 & 7 & 6 & 2 & 4 & 4 \\
\hline 85 & 442826 & 5025339 & 8509 & $08-02$ & 6 & 6 & 3.31 & 1.96 & 21099 & 6 & 7 & 7 & 7 & 7 & 5 & 4 & 5 \\
\hline 85 & 442826 & 5025339 & 8510 & $08-02$ & 6 & 6 & 3.31 & 1.96 & 21099 & 4 & 2 & 2 & 5 & 4 & 4 & 3 & 3 \\
\hline 86 & 446315 & 5029089 & 8601 & 08-04 & 3 & 2 & 2.91 & 0.12 & 26638 & 2 & 7 & 7 & 7 & 4 & 4 & 5 & 5 \\
\hline 86 & 446315 & 5029089 & 8602 & 08-04 & 3 & 2 & 3.06 & 0.09 & 26638 & 6 & 7 & 7 & 6 & 6 & 4 & 5 & 5 \\
\hline 86 & 446315 & 5029089 & 8603 & 08-04 & 3 & 2 & 3.13 & 0.07 & 26638 & 6 & 6 & 7 & 7 & 7 & 4 & 5 & 5 \\
\hline 86 & 446315 & 5029089 & 8604 & 08-04 & 3 & 2 & 2.78 & 0.17 & 26638 & 4 & 6 & 6 & 6 & 4 & 3 & 4 & 3 \\
\hline 86 & 446315 & 5029089 & 8605 & 08-04 & 3 & 2 & 3.25 & 0.15 & 26638 & 7 & 7 & 7 & 7 & 7 & 3 & 4 & 5 \\
\hline 86 & 446315 & 5029089 & 8606 & 08-04 & 3 & 2 & 3.39 & 0.15 & 26638 & 5 & 5 & 6 & 6 & 7 & 3 & 4 & 3 \\
\hline 86 & 446315 & 5029089 & 8607 & 08-04 & 3 & 2 & 3.30 & 0.18 & 26638 & 6 & 6 & 6 & 5 & 4 & 5 & 5 & 5 \\
\hline 86 & 446315 & 5029089 & 8608 & 08-04 & 3 & 2 & 3.25 & 0.19 & 26638 & 6 & 6 & 6 & 7 & 6 & 4 & 5 & 3 \\
\hline 86 & 446315 & 5029089 & 8609 & 08-04 & 3 & 2 & 3.19 & 0.20 & 26638 & 4 & 4 & 3 & 3 & 4 & 1 & 5 & 5 \\
\hline 86 & 446315 & 5029089 & 8610 & 08-04 & 3 & 2 & 2.57 & 0.20 & 26638 & 6 & 6 & 6 & 5 & 4 & 3 & 4 & 5 \\
\hline 86 & 446315 & 5029089 & D920 & 08-04 & 3 & 2 & 2.48 & 0.17 & 26638 & 5 & 5 & 3 & 5 & 3 & 5 & 4 & 5 \\
\hline 86 & 446315 & 5029089 & D947 & 08-04 & 3 & 2 & 3.44 & 0.14 & 26638 & 7 & 7 & 6 & 6 & 6 & 5 & 5 & 5 \\
\hline 87 & 448172 & 5033105 & 8701 & 08-04 & 6 & 5 & 9.30 & 0.31 & 55068 & 7 & 7 & 7 & 7 & 7 & 5 & 5 & 5 \\
\hline 87 & 448172 & 5033105 & 8702 & 08-04 & 6 & 5 & 9.57 & 0.32 & 55068 & 6 & 6 & 6 & 6 & 7 & 4 & 5 & 5 \\
\hline 87 & 448172 & 5033105 & 8703 & 08-04 & 6 & 5 & 8.79 & 0.39 & 55068 & 5 & 5 & 6 & 7 & 6 & 5 & 5 & 5 \\
\hline 87 & 448237 & 5033410 & 8704 & 08-04 & 6 & 4 & 7.22 & 0.24 & 55068 & 6 & 7 & 7 & 7 & 7 & 4 & 4 & 4 \\
\hline 87 & 448172 & 5033105 & 8705 & 08-04 & 6 & 5 & 8.55 & 0.18 & 70484 & 6 & 7 & 7 & 7 & 6 & 4 & 5 & 5 \\
\hline
\end{tabular}




\begin{tabular}{|c|c|c|c|c|c|c|c|c|c|c|c|c|c|c|c|c|c|}
\hline Site & Easting & Northing & User ID & Date & Abun. & Rich. & Tree & Water & Inc. & Q1 & Q2 & Q3 & Q4 & Q5 & Q6 & Q7 & Q8 \\
\hline 87 & 448172 & 5033105 & 8706 & 08-04 & 6 & 5 & 7.29 & 0.05 & 70484 & 6 & 7 & 7 & 6 & 7 & 5 & 5 & 4 \\
\hline 87 & 448172 & 5033105 & 8707 & 08-04 & 6 & 5 & 7.80 & 0.13 & 70484 & 7 & 7 & 6 & 6 & 6 & 4 & 5 & 4 \\
\hline 87 & 448172 & 5033105 & 8708 & 08-04 & 6 & 5 & 8.86 & 0.15 & 70484 & 7 & 7 & 6 & 7 & 7 & 4 & 4 & 5 \\
\hline 87 & 448172 & 5033105 & 8709 & 08-04 & 6 & 5 & 8.09 & 0.44 & 55068 & 6 & 6 & 6 & 6 & 6 & 3 & 3 & 4 \\
\hline 87 & 448172 & 5033105 & 8710 & 08-04 & 6 & 5 & 7.51 & 0.47 & 55068 & 5 & 6 & 6 & 6 & 5 & 1 & 1 & 1 \\
\hline 87 & 448237 & 5033410 & D969 & 08-09 & 6 & 4 & 7.05 & 0.10 & 70484 & 6 & 6 & 7 & 7 & 7 & 4 & 4 & 4 \\
\hline 87 & 448172 & 5033105 & D975 & $08-05$ & 6 & 5 & 11.25 & 0.23 & 70484 & 7 & 7 & 7 & 7 & 7 & 3 & 4 & 4 \\
\hline 88 & 450917 & 5026912 & 8801 & 08-08 & 16 & 7 & 4.31 & 3.40 & 37283 & 5 & 5 & 3 & 6 & 5 & 2 & 5 & 5 \\
\hline 88 & 450917 & 5026912 & 8802 & 08-08 & 16 & 7 & 4.60 & 3.41 & 37283 & 4 & 4 & 6 & 5 & 4 & 4 & 5 & 5 \\
\hline 88 & 450917 & 5026912 & 8803 & 08-08 & 16 & 7 & 3.95 & 3.38 & 32111 & 7 & 7 & 6 & 6 & 5 & 3 & 4 & 5 \\
\hline 88 & 450917 & 5026912 & 8804 & 08-08 & 16 & 7 & 3.67 & 3.34 & 32111 & 7 & 7 & 7 & 7 & 6 & 4 & 4 & 4 \\
\hline 88 & 450917 & 5026912 & 8805 & 08-08 & 16 & 7 & 3.93 & 3.33 & 32111 & 5 & 3 & 6 & 6 & 6 & 3 & 4 & 3 \\
\hline 88 & 450917 & 5026912 & 8806 & 08-08 & 16 & 7 & 4.16 & 3.26 & 32111 & 7 & 7 & 7 & 7 & 6 & 4 & 5 & 5 \\
\hline 88 & 450917 & 5026912 & 8807 & 08-08 & 16 & 7 & 5.05 & 3.23 & 41419 & 3 & 5 & 5 & 5 & 3 & 3 & 4 & 4 \\
\hline 88 & 450917 & 5026912 & 8808 & 08-08 & 16 & 7 & 5.06 & 3.31 & 41419 & 6 & 6 & 6 & 6 & 4 & 3 & 5 & 5 \\
\hline 88 & 450917 & 5026912 & 8809 & 08-08 & 16 & 7 & 4.95 & 3.35 & 41419 & 5 & 5 & 6 & 5 & 6 & 4 & 5 & 4 \\
\hline 88 & 450917 & 5026912 & 8810 & 08-08 & 16 & 7 & 4.65 & 3.44 & 37283 & 7 & 7 & 7 & 7 & 6 & 1 & 3 & 4 \\
\hline 88 & 450917 & 5026912 & E032 & $08-11$ & 16 & 7 & 4.54 & 3.30 & 32111 & 7 & 7 & 7 & 7 & 7 & 4 & 5 & 5 \\
\hline 88 & 450917 & 5026912 & E034 & 08-09 & 16 & 7 & 4.22 & 3.31 & 32111 & 4 & 4 & 7 & 7 & 6 & 1 & 3 & 3 \\
\hline 89 & 448767 & 5024132 & 8901 & 08-08 & 46 & 13 & 1.77 & 2.14 & 17793 & 6 & 6 & 6 & 6 & 5 & 3 & 4 & 4 \\
\hline 89 & 448767 & 5024132 & 8902 & 08-08 & 46 & 13 & 2.36 & 2.10 & 17793 & 7 & 7 & 5 & 5 & 1 & 3 & 5 & 4 \\
\hline 89 & 448767 & 5024132 & 8903 & 08-08 & 46 & 13 & 2.31 & 2.30 & 17793 & 6 & 5 & 6 & 6 & 5 & 4 & 4 & 4 \\
\hline 89 & 448767 & 5024132 & 8904 & 08-08 & 46 & 13 & 1.94 & 2.24 & 17793 & 5 & 5 & 3 & 5 & 5 & 4 & 5 & 5 \\
\hline 89 & 448767 & 5024132 & 8905 & 08-08 & 46 & 13 & 3.14 & 2.09 & 30543 & 6 & 6 & 6 & 5 & 6 & 3 & 4 & 5 \\
\hline 89 & 448767 & 5024132 & 8906 & 08-08 & 46 & 13 & 2.51 & 2.23 & 17793 & 4 & 4 & 4 & 6 & 4 & 1 & 3 & 5 \\
\hline
\end{tabular}




\begin{tabular}{|c|c|c|c|c|c|c|c|c|c|c|c|c|c|c|c|c|c|}
\hline Site & Easting & Northing & User ID & Date & Abun. & Rich. & Tree & Water & Inc. & Q1 & Q2 & Q3 & Q4 & Q5 & Q6 & Q7 & Q8 \\
\hline 90 & 441269 & 5026308 & 9001 & 08-09 & 6 & 5 & 4.38 & 1.17 & 54011 & 6 & 7 & 6 & 6 & 5 & 3 & 4 & 5 \\
\hline 90 & 441269 & 5026308 & 9002 & 08-09 & 6 & 5 & 4.43 & 1.15 & 54011 & 6 & 7 & 6 & 6 & 6 & 5 & 5 & 3 \\
\hline 90 & 441269 & 5026308 & 9003 & 08-09 & 6 & 5 & 4.27 & 1.10 & 54011 & 6 & 6 & 5 & 7 & 5 & 3 & 5 & 5 \\
\hline 90 & 441269 & 5026308 & 9004 & 08-09 & 6 & 5 & 4.34 & 1.08 & 54011 & 7 & 6 & 7 & 7 & 6 & 3 & 5 & 4 \\
\hline 90 & 441269 & 5026308 & 9005 & 08-09 & 6 & 5 & 5.19 & 1.01 & 61028 & 6 & 5 & 7 & 7 & 6 & 4 & 5 & 5 \\
\hline 90 & 441269 & 5026308 & 9006 & 08-09 & 6 & 5 & 5.11 & 1.10 & 54011 & 6 & 6 & 7 & 6 & 5 & 3 & 5 & 5 \\
\hline 90 & 441269 & 5026308 & 9007 & 08-09 & 6 & 5 & 4.89 & 0.94 & 53488 & 6 & 6 & 6 & 6 & 5 & 4 & 5 & 5 \\
\hline 90 & 441269 & 5026308 & 9008 & 08-09 & 6 & 5 & 4.17 & 1.09 & 54011 & 5 & 6 & 6 & 5 & 6 & 4 & 4 & 3 \\
\hline 90 & 441269 & 5026308 & 9009 & 08-09 & 6 & 5 & 4.22 & 1.05 & 53488 & 6 & 6 & 6 & 7 & 6 & 3 & 4 & 5 \\
\hline 90 & 441269 & 5026308 & 9010 & 08-09 & 6 & 5 & 4.87 & 0.90 & 53488 & 7 & 6 & 7 & 7 & 6 & 3 & 5 & 5 \\
\hline 90 & 441269 & 5026308 & E183 & $08-21$ & 6 & 5 & 4.43 & 1.17 & 54011 & 6 & 6 & 6 & 5 & 5 & 4 & 4 & 2 \\
\hline 90 & 441269 & 5026308 & E185 & 08-09 & 6 & 5 & 4.31 & 1.14 & 54011 & 6 & 6 & 7 & 7 & 7 & 5 & 3 & 2 \\
\hline 90 & 441269 & 5026308 & E190 & $08-10$ & 6 & 5 & 4.86 & 1.09 & 61028 & 3 & 5 & 6 & 5 & 6 & 4 & 1 & 1 \\
\hline 90 & 441269 & 5026308 & E219 & $08-20$ & 6 & 5 & 4.84 & 0.95 & 53488 & 6 & 6 & 7 & 7 & 7 & 4 & 4 & 3 \\
\hline 91 & 439182 & 5023836 & 9101 & 08-09 & 16 & 10 & 3.22 & 1.10 & 42902 & 6 & 6 & 7 & 7 & 6 & 3 & 4 & 4 \\
\hline 91 & 439182 & 5023836 & 9102 & 08-09 & 16 & 10 & 3.23 & 1.07 & 42902 & 6 & 6 & 7 & 6 & 5 & 4 & 5 & 5 \\
\hline 91 & 439182 & 5023836 & 9103 & 08-09 & 16 & 10 & 3.28 & 1.00 & 42902 & 6 & 6 & 6 & 6 & 4 & 3 & 4 & 2 \\
\hline 91 & 439182 & 5023836 & 9104 & 08-09 & 16 & 10 & 3.25 & 1.01 & 42902 & 7 & 7 & 7 & 6 & 5 & 4 & 4 & 4 \\
\hline 91 & 439182 & 5023836 & 9105 & 08-09 & 16 & 10 & 3.10 & 1.02 & 42902 & 7 & 6 & 7 & 6 & 6 & 4 & 5 & 5 \\
\hline 91 & 439182 & 5023836 & 9106 & 08-09 & 16 & 10 & 3.25 & 1.06 & 42902 & 5 & 7 & 7 & 5 & 4 & 3 & 5 & 5 \\
\hline 91 & 439182 & 5023836 & 9107 & 08-09 & 16 & 10 & 3.26 & 1.06 & 42902 & 6 & 6 & 7 & 6 & 7 & 5 & 5 & 4 \\
\hline 91 & 439182 & 5023836 & 9108 & 08-09 & 16 & 10 & 3.44 & 1.10 & 42902 & 5 & 5 & 6 & 5 & 5 & 5 & 5 & 4 \\
\hline 91 & 439182 & 5023836 & 9109 & 08-09 & 16 & 10 & 3.91 & 1.23 & 42902 & 6 & 7 & 7 & 7 & 6 & 5 & 5 & 4 \\
\hline 91 & 439182 & 5023836 & 9110 & 08-09 & 16 & 10 & 3.76 & 1.25 & 50531 & 6 & 7 & 7 & 7 & 6 & 2 & 5 & 5 \\
\hline 91 & 439182 & 5023836 & E240 & 08-09 & 16 & 10 & 3.26 & 1.05 & 42902 & 6 & 6 & 6 & 6 & 4 & 4 & 5 & 5 \\
\hline
\end{tabular}




\begin{tabular}{|c|c|c|c|c|c|c|c|c|c|c|c|c|c|c|c|c|c|}
\hline Site & Easting & Northing & User ID & Date & Abun. & Rich. & Tree & Water & Inc. & Q1 & Q2 & Q3 & Q4 & Q5 & Q6 & Q7 & Q8 \\
\hline 91 & 439182 & 5023836 & E262 & $08-23$ & 16 & 10 & 3.56 & 1.17 & 42902 & 6 & 6 & 7 & 6 & 5 & 3 & 4 & 5 \\
\hline 91 & 439182 & 5023836 & E264 & $08-25$ & 16 & 10 & 3.71 & 1.19 & 42902 & 6 & 6 & 6 & 6 & 5 & 2 & 3 & 4 \\
\hline 92 & 451505 & 5033549 & 9201 & $08-10$ & 20 & 12 & 5.26 & 1.14 & 47492 & 6 & 6 & 7 & 7 & 7 & 4 & 5 & 4 \\
\hline 92 & 451505 & 5033549 & 9202 & $08-10$ & 20 & 12 & 8.28 & 0.92 & 71658 & 7 & 7 & 7 & 7 & 6 & 5 & 5 & 5 \\
\hline 92 & 451505 & 5033549 & 9203 & $08-10$ & 20 & 12 & 7.16 & 0.99 & 71658 & 5 & 4 & 7 & 7 & 7 & 5 & 5 & 4 \\
\hline 92 & 451505 & 5033549 & 9204 & $08-10$ & 20 & 12 & 8.94 & 0.87 & 71658 & 7 & 7 & 7 & 7 & 7 & 5 & 5 & 5 \\
\hline 92 & 451505 & 5033549 & E288 & $08-24$ & 20 & 12 & 8.43 & 0.92 & 71658 & 3 & 5 & 5 & 7 & 7 & 5 & 5 & 5 \\
\hline 93 & 446545 & 5033606 & 9301 & $08-10$ & 15 & 7 & 6.91 & 0.39 & 69404 & 6 & 6 & 7 & 7 & 7 & 5 & 5 & 4 \\
\hline 93 & 446545 & 5033606 & 9302 & $08-10$ & 15 & 7 & 7.01 & 0.33 & 69404 & 7 & 7 & 7 & 7 & 7 & 5 & 5 & 5 \\
\hline 93 & 446545 & 5033606 & 9303 & $08-10$ & 15 & 7 & 7.10 & 0.39 & 69404 & 6 & 7 & 7 & 7 & 7 & 4 & 5 & 5 \\
\hline 94 & 449855 & 5028460 & 9401 & $08-11$ & 9 & 6 & 5.01 & 1.86 & 50171 & 6 & 7 & 6 & 6 & 6 & 2 & 5 & 5 \\
\hline 94 & 449855 & 5028460 & 9402 & 08-11 & 9 & 6 & 4.64 & 1.79 & 50171 & 7 & 7 & 7 & 7 & 6 & 2 & 4 & 5 \\
\hline 94 & 449855 & 5028460 & 9403 & $08-11$ & 9 & 6 & 4.54 & 1.83 & 50171 & 7 & 5 & 7 & 7 & 6 & 5 & 5 & 5 \\
\hline 94 & 449855 & 5028460 & 9404 & 08-11 & 9 & 6 & 5.35 & 1.83 & 49275 & 6 & 6 & 7 & 6 & 6 & 5 & 4 & 3 \\
\hline 94 & 449855 & 5028460 & 9405 & $08-11$ & 9 & 6 & 5.42 & 1.92 & 49275 & 6 & 7 & 6 & 7 & 7 & 5 & 5 & 4 \\
\hline 94 & 449855 & 5028460 & 9406 & $08-11$ & 9 & 6 & 5.38 & 1.96 & 49275 & 6 & 7 & 6 & 7 & 7 & 5 & 4 & 4 \\
\hline 94 & 449855 & 5028460 & 9407 & 08-11 & 9 & 6 & 5.53 & 1.91 & 49275 & 6 & 6 & 5 & 5 & 5 & 4 & 3 & 4 \\
\hline 94 & 449855 & 5028460 & 9408 & $08-11$ & 9 & 6 & 5.57 & 1.87 & 49275 & 6 & 6 & 6 & 6 & 6 & 4 & 4 & 4 \\
\hline 94 & 449855 & 5028460 & 9409 & 08-11 & 9 & 6 & 5.28 & 1.82 & 49275 & 6 & 7 & 7 & 6 & 7 & 4 & 5 & 5 \\
\hline 94 & 449855 & 5028460 & 9410 & $08-11$ & 9 & 6 & 5.58 & 1.94 & 49749 & 3 & 3 & 5 & 5 & 5 & 3 & 5 & 4 \\
\hline 94 & 449855 & 5028460 & E357 & 08-11 & 9 & 6 & 5.59 & 1.99 & 49275 & 6 & 6 & 7 & 7 & 6 & 5 & 3 & 3 \\
\hline 94 & 449855 & 5028460 & E364 & 08-19 & 9 & 6 & 5.55 & 1.86 & 49275 & 6 & 6 & 6 & 6 & 6 & 5 & 5 & 5 \\
\hline 95 & 452320 & 5030702 & 9501 & 08-11 & 19 & 13 & 4.51 & 4.01 & 36810 & 6 & 7 & 6 & 7 & 7 & 5 & 4 & 5 \\
\hline 95 & 452320 & 5030702 & 9502 & 08-11 & 19 & 13 & 4.59 & 4.16 & 25630 & 6 & 6 & 7 & 5 & 4 & 5 & 5 & 4 \\
\hline 95 & 452320 & 5030702 & 9503 & 08-11 & 19 & 13 & 4.57 & 4.06 & 25630 & 7 & 6 & 6 & 6 & 6 & 5 & 5 & 5 \\
\hline
\end{tabular}




\begin{tabular}{|c|c|c|c|c|c|c|c|c|c|c|c|c|c|c|c|c|c|}
\hline Site & Easting & Northing & User ID & Date & Abun. & Rich. & Tree & Water & Inc. & Q1 & Q2 & Q3 & Q4 & Q5 & Q6 & Q7 & Q8 \\
\hline 95 & 452320 & 5030702 & 9504 & 08-11 & 19 & 13 & 3.93 & 3.91 & 25630 & 6 & 7 & 7 & 5 & 4 & 2 & 4 & 4 \\
\hline 95 & 452320 & 5030702 & 9505 & 08-11 & 19 & 13 & 4.21 & 4.13 & 25630 & 5 & 7 & 5 & 3 & 3 & 3 & 4 & 4 \\
\hline 96 & 439660 & 5020858 & 9601 & 08-14 & 11 & 4 & 4.47 & 2.56 & 56040 & 6 & 6 & 6 & 6 & 7 & 4 & 5 & 5 \\
\hline 96 & 439660 & 5020858 & 9602 & 08-14 & 11 & 4 & 4.55 & 2.54 & 56040 & 5 & 4 & 6 & 6 & 5 & 1 & 5 & 3 \\
\hline 96 & 439660 & 5020858 & 9603 & 08-14 & 11 & 4 & 4.78 & 2.52 & 56040 & 6 & 6 & 6 & 6 & 6 & 4 & 5 & 4 \\
\hline 96 & 439660 & 5020858 & 9604 & 08-14 & 11 & 4 & 4.60 & 2.62 & 58866 & 6 & 6 & 7 & 7 & 6 & 4 & 5 & 5 \\
\hline 96 & 439660 & 5020858 & 9605 & 08-14 & 11 & 4 & 4.33 & 2.68 & 56040 & 6 & 4 & 5 & 2 & 4 & 1 & 5 & 3 \\
\hline 96 & 439660 & 5020858 & 9606 & 08-14 & 11 & 4 & 4.24 & 2.66 & 56040 & 6 & 6 & 6 & 7 & 6 & 4 & 4 & 2 \\
\hline 96 & 439660 & 5020858 & 9607 & 08-14 & 11 & 4 & 4.38 & 2.65 & 56040 & 6 & 6 & 7 & 6 & 6 & 4 & 5 & 4 \\
\hline 96 & 439660 & 5020858 & 9608 & 08-14 & 11 & 4 & 4.44 & 2.56 & 56040 & 6 & 6 & 7 & 6 & 6 & 2 & 4 & 4 \\
\hline 96 & 439660 & 5020858 & 9609 & 08-14 & 11 & 4 & 4.19 & 2.46 & 56040 & 7 & 7 & 7 & 7 & 6 & 2 & 5 & 5 \\
\hline 96 & 439660 & 5020858 & 9610 & 08-14 & 11 & 4 & 4.26 & 2.69 & 56040 & 6 & 6 & 6 & 7 & 5 & 4 & 4 & 3 \\
\hline 96 & 439660 & 5020858 & E447 & 08-14 & 11 & 4 & 4.41 & 2.60 & 56040 & 2 & 6 & 7 & 7 & 6 & 3 & 3 & 3 \\
\hline 96 & 439660 & 5020858 & E494 & 09-14 & 11 & 4 & 4.33 & 2.51 & 58866 & 7 & 6 & 7 & 7 & 6 & 4 & 5 & 5 \\
\hline 97 & 434689 & 5022401 & 9701 & 08-14 & 37 & 13 & 3.65 & 0.15 & 54758 & 6 & 3 & 7 & 6 & 7 & 5 & 5 & 5 \\
\hline 97 & 434689 & 5022401 & 9702 & 08-14 & 37 & 13 & 4.26 & 0.11 & 40660 & 6 & 7 & 7 & 7 & 7 & 1 & 5 & 4 \\
\hline 97 & 434689 & 5022401 & 9703 & 08-14 & 37 & 13 & 4.45 & 0.19 & 40660 & 7 & 7 & 7 & 7 & 6 & 4 & 5 & 5 \\
\hline 97 & 434689 & 5022401 & 9704 & 08-14 & 37 & 13 & 4.48 & 0.19 & 40660 & 7 & 7 & 6 & 6 & 5 & 3 & 5 & 4 \\
\hline 97 & 434689 & 5022401 & 9705 & 08-14 & 37 & 13 & 4.53 & 0.16 & 40660 & 6 & 6 & 6 & 1 & 4 & 4 & 5 & 5 \\
\hline 97 & 434689 & 5022401 & 9706 & $08-14$ & 37 & 13 & 3.80 & 0.25 & 37184 & 6 & 6 & 7 & 7 & 6 & 5 & 5 & 5 \\
\hline 97 & 434689 & 5022401 & 9707 & 08-14 & 37 & 13 & 3.72 & 0.27 & 37184 & 7 & 7 & 7 & 7 & 7 & 5 & 5 & 5 \\
\hline 97 & 434689 & 5022401 & 9708 & 08-14 & 37 & 13 & 3.61 & 0.29 & 37184 & 7 & 7 & 7 & 7 & 6 & 4 & 5 & 5 \\
\hline 97 & 434689 & 5022401 & 9709 & 08-14 & 37 & 13 & 3.94 & 0.16 & 54758 & 6 & 6 & 6 & 6 & 7 & 5 & 5 & 4 \\
\hline 97 & 434689 & 5022401 & 9710 & 08-14 & 37 & 13 & 3.80 & 0.30 & 37184 & 7 & 4 & 7 & 7 & 6 & 4 & 5 & 4 \\
\hline 97 & 434689 & 5022401 & E505 & $08-20$ & 37 & 13 & 3.47 & 0.14 & 54758 & 7 & 6 & 7 & 7 & 6 & 3 & 4 & 4 \\
\hline
\end{tabular}




\begin{tabular}{|c|c|c|c|c|c|c|c|c|c|c|c|c|c|c|c|c|c|}
\hline Site & Easting & Northing & User ID & Date & Abun. & Rich. & Tree & Water & Inc. & Q1 & Q2 & Q3 & Q4 & Q5 & Q6 & Q7 & Q8 \\
\hline 98 & 451732 & 5027501 & 9801 & $08-15$ & 38 & 8 & 3.47 & 3.81 & 29220 & 7 & 7 & 6 & 6 & 3 & 1 & 5 & 5 \\
\hline 98 & 451732 & 5027501 & 9802 & $08-15$ & 38 & 8 & 4.31 & 4.03 & 30053 & 7 & 7 & 7 & 7 & 7 & 5 & 5 & 5 \\
\hline 98 & 451732 & 5027501 & 9803 & $08-15$ & 38 & 8 & 4.40 & 3.93 & 30053 & 6 & 7 & 6 & 6 & 3 & 2 & 2 & 2 \\
\hline 98 & 451732 & 5027501 & 9804 & $08-15$ & 38 & 8 & 4.46 & 3.93 & 30053 & 6 & 6 & 6 & 7 & 7 & 2 & 4 & 4 \\
\hline 98 & 451732 & 5027501 & 9805 & $08-15$ & 38 & 8 & 4.63 & 4.06 & 30053 & 6 & 7 & 6 & 6 & 5 & 3 & 4 & 5 \\
\hline 98 & 451732 & 5027501 & 9806 & $08-15$ & 38 & 8 & 3.43 & 3.79 & 29220 & 6 & 6 & 6 & 7 & 4 & 4 & 5 & 5 \\
\hline 98 & 451732 & 5027501 & 9807 & $08-15$ & 38 & 8 & 3.84 & 3.85 & 29220 & 7 & 6 & 7 & 6 & 6 & 4 & 4 & 4 \\
\hline 98 & 451732 & 5027501 & 9808 & $08-15$ & 38 & 8 & 4.30 & 3.90 & 29220 & 6 & 6 & 7 & 7 & 6 & 4 & 5 & 5 \\
\hline 98 & 451732 & 5027501 & 9809 & $08-15$ & 38 & 8 & 3.47 & 3.81 & 29220 & 6 & 6 & 6 & 6 & 4 & 1 & 3 & 3 \\
\hline 98 & 451732 & 5027501 & 9810 & $08-15$ & 38 & 8 & 3.47 & 3.81 & 29220 & 6 & 6 & 7 & 7 & 6 & 5 & 5 & 4 \\
\hline 98 & 451732 & 5027501 & E591 & $08-16$ & 38 & 8 & 4.71 & 4.10 & 30053 & 7 & 7 & 7 & 7 & 6 & 4 & 4 & 4 \\
\hline 98 & 451732 & 5027501 & E594 & $08-15$ & 38 & 8 & 4.63 & 3.94 & 30053 & 6 & 6 & 6 & 5 & 6 & 2 & 2 & 4 \\
\hline 99 & 450334 & 5031101 & 9901 & $08-15$ & 3 & 3 & 4.57 & 2.61 & 32851 & 7 & 6 & 7 & 7 & 7 & 5 & 5 & 5 \\
\hline 99 & 450334 & 5031101 & 9902 & $08-15$ & 3 & 3 & 4.57 & 2.61 & 32851 & 5 & 6 & 3 & 6 & 1 & 5 & 5 & 5 \\
\hline 99 & 450334 & 5031101 & 9903 & $08-15$ & 3 & 3 & 4.57 & 2.61 & 32851 & 5 & 4 & 5 & 5 & 4 & 4 & 3 & 5 \\
\hline 99 & 450334 & 5031101 & 9904 & $08-15$ & 3 & 3 & 4.57 & 2.61 & 32851 & 6 & 6 & 6 & 5 & 3 & 3 & 3 & 3 \\
\hline 99 & 450334 & 5031101 & 9905 & $08-15$ & 3 & 3 & 6.07 & 2.71 & 33333 & 6 & 5 & 6 & 5 & 4 & 1 & 5 & 4 \\
\hline 99 & 450334 & 5031101 & 9906 & $08-15$ & 3 & 3 & 4.57 & 2.61 & 32851 & 6 & 6 & 3 & 6 & 3 & 5 & 5 & 4 \\
\hline 99 & 450334 & 5031101 & 9907 & $08-15$ & 3 & 3 & 4.57 & 2.61 & 32851 & 4 & 4 & 3 & 5 & 3 & 3 & 4 & 4 \\
\hline 99 & 450334 & 5031101 & 9908 & $08-15$ & 3 & 3 & 6.07 & 2.71 & 33333 & 6 & 6 & 6 & 6 & 5 & 2 & 3 & 2 \\
\hline 99 & 450334 & 5031101 & 9909 & $08-15$ & 3 & 3 & 6.62 & 2.69 & 33333 & 6 & 6 & 4 & 6 & 6 & 4 & 4 & 4 \\
\hline 99 & 450334 & 5031101 & 9910 & $08-15$ & 3 & 3 & 3.36 & 2.48 & 27638 & 7 & 7 & 3 & 3 & 3 & 1 & 5 & 5 \\
\hline 100 & 449077 & 5028039 & 10001 & $08-16$ & 8 & 5 & 6.94 & 1.37 & 16200 & 6 & 6 & 7 & 7 & 4 & 5 & 5 & 5 \\
\hline
\end{tabular}


Table B: Parameter values used for predicting probabilities as seen in Figures 3-6. Data sets were created where each parameter is held constant except for the parameter of interest. Intercept was set to 1 . Bird abundance and species richness, tree canopy cover (ha), distance to water $(\mathrm{km})$, and median yearly income were set at the mean of all 1035 samples.

Disposition1-6) was evaluated at the median answer ("Moderately happy") using orthogonal polynomial contrast coding.

\begin{tabular}{|l|r|}
\hline Parameter & \multicolumn{1}{|c|}{ Value } \\
\hline Intercept & 1 \\
Abundance & 15.637680 \\
Richness & 7.058937 \\
Tree & 4.212934 \\
Water & 1.303990 \\
Income & 42197.73 \\
Disposition $_{1}$ & 0.37796450 \\
Disposition $_{2}$ & 0.00000000 \\
Disposition $_{3}$ & -0.40824830 \\
Disposition $_{4}$ & -0.56407610 \\
Disposition $_{5}$ & -0.43643580 \\
Disposition $_{6}$ & -0.19738551 \\
\hline
\end{tabular}



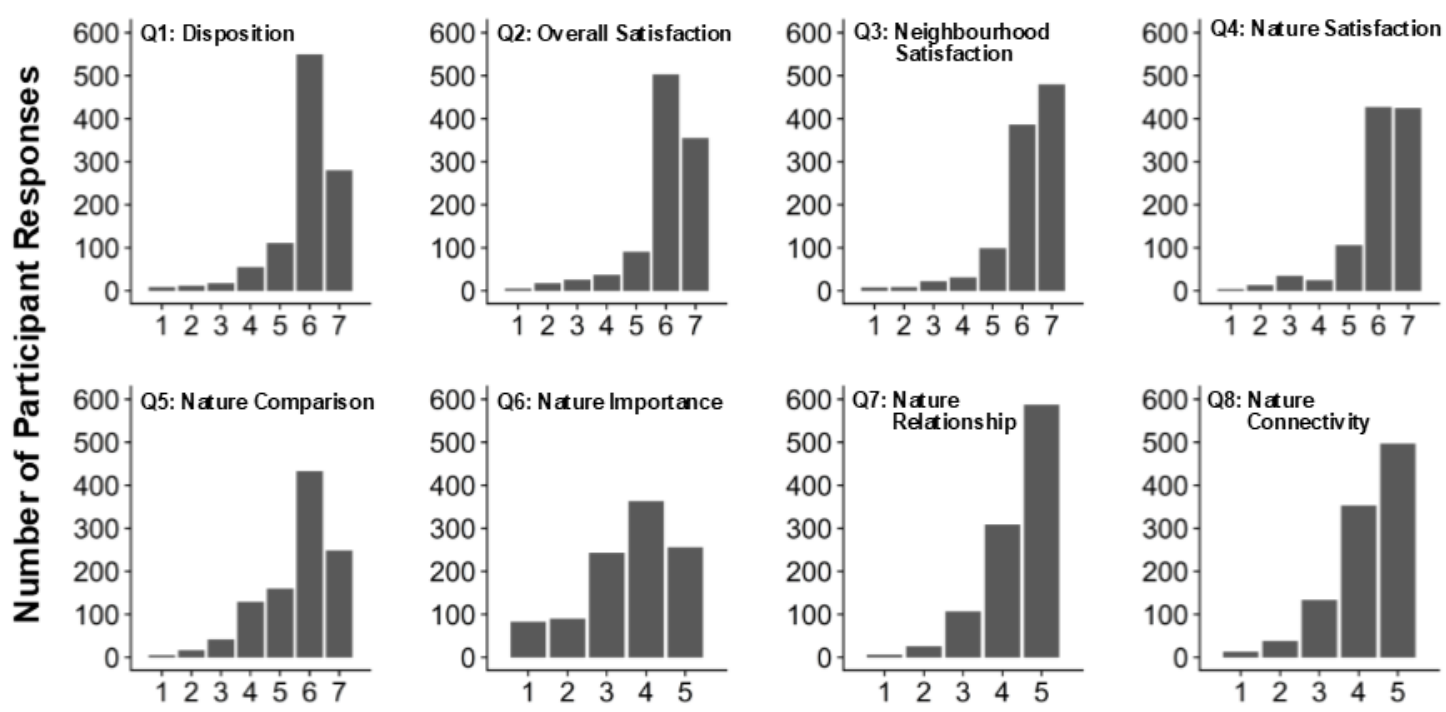

Figure B: Histograms of participant responses to survey questions 1-8 (see Table 1). Responses are scored with 1 being the least positive response. Residents in Ottawa, Canada were surveyed about their life satisfaction and their thoughts about their local environment. Participants were surveyed at 100 sites distributed across the city (Figure 1). Each site had a $250 \mathrm{~m}$ radius centred around a pre-existing bird point count location from the Ottawa Bird Count (OBC). Sites were chosen to reduce correlation between predictor values (bird abundance and species richness, tree canopy cover, distance to water, and median income). 
Table C: Pearson correlation coefficients between site predictor variables and response rates. There were 100 total sites distributed across the residential Ottawa area. Each site had a $250 \mathrm{~m}$ radius and was centred on a pre-exisiting bird point count location from the Ottawa Bird Count (OBC). Predictor variables measured at the site include bird abundance and species richness, tree canopy cover (ha), distance to water $(\mathbf{k m})$, and median individual yearly income. Residents who lived in the site were surveyed door-to-door and flyers were distributed to boost sample size. Sites were surveyed until either there were 10 participants or until there were no more residential addresses to visit. In-person response rate is the number of individuals who participated from door-to-door surveying divided by the total number of people who were spoken to. The flyer response rate is the number of individuals who responded to the flyer divided by the total number of flyers left at residences. The overall response rate is the total number of participants divided by the total number of people contacted (either in-person or by flyer).

\begin{tabular}{|l|c|c|c|}
\hline $\begin{array}{l}\text { Predictor } \\
\text { Variable }\end{array}$ & $\begin{array}{c}\text { In-person } \\
\text { Response Rate }\end{array}$ & $\begin{array}{c}\text { Flyer } \\
\text { Response Rate }\end{array}$ & $\begin{array}{c}\text { Overall } \\
\text { Response Rate }\end{array}$ \\
\hline Abundance & -0.110 & -0.113 & -0.040 \\
Richness & -0.091 & -0.083 & -0.048 \\
Tree & -0.001 & -0.050 & 0.055 \\
Water & -0.285 & -0.287 & -0.207 \\
Income & 0.409 & 0.223 & 0.358 \\
\hline
\end{tabular}


Table D: Parameter coefficients for all models. Models were fit using ordered probit mixed models where site was treated as a random effect. Predictor variables included bird abundance and species richness, tree canopy cover (ha), distance to water $(\mathrm{km})$, median individual yearly income and disposition. Models either included disposition as a predictor or did not.

Disposition was measured as the participant's response to question 1 (Table 1) If disposition was included as a predictor it was coded using orthogonal polynomial contrasts up to the sixth power. Each model only included one bird variable at a time, either bird abundance or bird species richness. Significance level is denoted by asterisks where: ${ }^{*} \mathbf{p}<0.05, * * \mathbf{p}<0.01, * * * \mathbf{p}<$ 0.001.

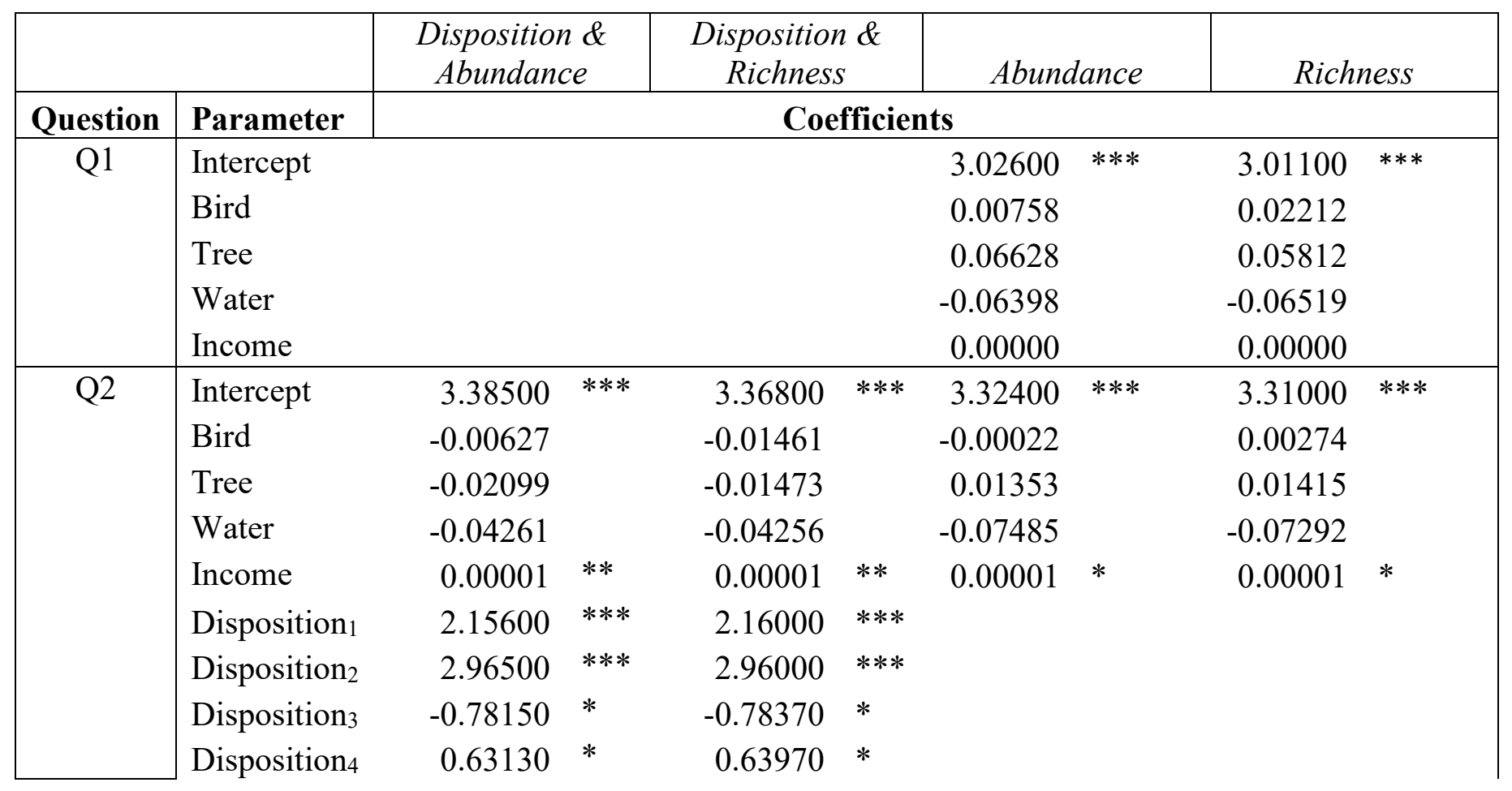




\begin{tabular}{|c|c|c|c|c|c|c|c|c|c|}
\hline & $\begin{array}{l}\text { Disposition}_{5} \\
\text { Disposition }_{6}\end{array}$ & $\begin{array}{l}-0.34910 \\
-0.05446\end{array}$ & & $\begin{array}{l}-0.36050 \\
-0.04752\end{array}$ & & & & & \\
\hline \multirow[t]{11}{*}{ Q3 } & Intercept & 2.19900 & $* * *$ & 2.10200 & $* * *$ & 2.42000 & $* * *$ & 2.32800 & $* * *$ \\
\hline & Bird & 0.00952 & & 0.04230 & $*$ & 0.01170 & $*$ & 0.04735 & $*$ \\
\hline & Tree & 0.03339 & & 0.02078 & & 0.05427 & & 0.04022 & \\
\hline & Water & -0.06040 & & -0.05837 & & -0.07720 & & -0.07522 & \\
\hline & Income & 0.00002 & $* * *$ & 0.00002 & $* * *$ & 0.00002 & $* * *$ & 0.00002 & $* * *$ \\
\hline & Disposition $_{1}$ & 1.14700 & $* * *$ & 1.15800 & $* * *$ & & & & \\
\hline & Disposition $_{2}$ & 0.81510 & $* *$ & 0.80830 & $* *$ & & & & \\
\hline & Disposition $_{3}$ & 0.19530 & & 0.20070 & & & & & \\
\hline & Disposition $_{4}$ & -0.02998 & & -0.04119 & & & & & \\
\hline & Disposition $_{5}$ & -0.23150 & & -0.21290 & & & & & \\
\hline & Disposition $_{6}$ & 0.09538 & & 0.07983 & & & & & \\
\hline \multirow[t]{11}{*}{ Q4 } & Intercept & 2.42100 & $* * *$ & 2.35900 & $* * *$ & 2.53000 & $* * *$ & 2.47200 & $* * *$ \\
\hline & Bird & 0.01025 & & 0.03734 & $*$ & 0.01172 & $*$ & 0.04089 & $*$ \\
\hline & Tree & 0.23740 & $* * *$ & 0.22540 & $* * *$ & 0.23730 & $* * *$ & 0.22410 & $* * *$ \\
\hline & Water & -0.09111 & & -0.09082 & & -0.09829 & & -0.10050 & \\
\hline & Income & 0.00001 & & 0.00001 & & 0.00001 & & 0.00001 & \\
\hline & Disposition $_{1}$ & 0.49500 & & 0.49960 & & & & & \\
\hline & Disposition $_{2}$ & 0.85960 & $* *$ & 0.85290 & $* *$ & & & & \\
\hline & Disposition $_{3}$ & 0.23610 & & 0.24720 & & & & & \\
\hline & Disposition $_{4}$ & -0.60740 & $*$ & -0.62730 & $*$ & & & & \\
\hline & Disposition $_{5}$ & 0.20800 & & 0.22970 & & & & & \\
\hline & Disposition $_{6}$ & 0.06286 & & 0.04530 & & & & & \\
\hline \multirow[t]{2}{*}{ Q5 } & Intercept & 2.06200 & $* * *$ & 2.08000 & $* * *$ & 2.19200 & $* * *$ & 2.22500 & $* * *$ \\
\hline & Bird & 0.01023 & & 0.03073 & & 0.01152 & $*$ & 0.03408 & \\
\hline
\end{tabular}




\begin{tabular}{|c|c|c|c|c|c|c|c|c|c|}
\hline & Tree & 0.23430 & $* * *$ & 0.22420 & $* * *$ & 0.23300 & $* * *$ & 0.22170 & $* * *$ \\
\hline & Water & -0.19740 & $* *$ & -0.20080 & $* *$ & -0.20620 & $* * *$ & -0.20860 & $* *$ \\
\hline & Income & 0.00002 & $* * *$ & 0.00002 & $* * *$ & 0.00002 & $* * *$ & 0.00002 & $* * *$ \\
\hline & Disposition $_{1}$ & 0.17840 & & 0.19170 & & & & & \\
\hline & Disposition $_{2}$ & 1.00700 & $* * *$ & 1.00100 & $* *$ & & & & \\
\hline & Disposition $_{3}$ & -0.17560 & & -0.16940 & & & & & \\
\hline & Disposition $_{4}$ & -0.30160 & & -0.31620 & & & & & \\
\hline & Disposition $_{5}$ & 0.18700 & & 0.20510 & & & & & \\
\hline & Disposition $_{6}$ & -0.06171 & & -0.07103 & & & & & \\
\hline Q6 & Intercept & 1.55100 & $* * *$ & 1.47900 & $* * *$ & 1.56800 & $* * *$ & 1.48300 & $* * *$ \\
\hline & Bird & -0.00111 & & 0.00853 & & -0.00065 & & 0.01019 & \\
\hline & Tree & 0.14260 & $* * *$ & 0.14320 & $* * *$ & 0.14580 & $* * *$ & 0.14530 & $* * *$ \\
\hline & Water & -0.17100 & $* *$ & -0.16970 & $* * *$ & -0.17280 & $* * *$ & -0.16980 & $* * *$ \\
\hline & Income & 0.00000 & & 0.00000 & & 0.00000 & & 0.00000 & \\
\hline & Disposition $_{1}$ & 0.02126 & & 0.02127 & & & & & \\
\hline & Disposition $_{2}$ & 0.31030 & & 0.30270 & & & & & \\
\hline & Disposition $_{3}$ & 0.14820 & & 0.15630 & & & & & \\
\hline & Disposition $_{4}$ & -0.25780 & & -0.26560 & & & & & \\
\hline & Disposition $_{5}$ & -0.07751 & & -0.06941 & & & & & \\
\hline & Disposition $_{6}$ & 0.51540 & $*$ & 0.51250 & $*$ & & & & \\
\hline Q7 & Intercept & 3.40200 & $* * *$ & 3.38800 & $* * *$ & 3.46300 & $* * *$ & 3.45800 & $* * *$ \\
\hline & Bird & -0.00006 & & -0.00027 & & 0.00071 & & 0.00266 & \\
\hline & Tree & 0.04407 & & 0.04387 & & 0.05515 & & 0.05395 & \\
\hline & Water & -0.08205 & & -0.08206 & & -0.08869 & & -0.08866 & \\
\hline & Income & 0.00000 & & 0.00000 & & 0.00000 & & 0.00000 & \\
\hline & Disposition $_{1}$ & 0.47140 & & 0.47360 & & & & & \\
\hline
\end{tabular}




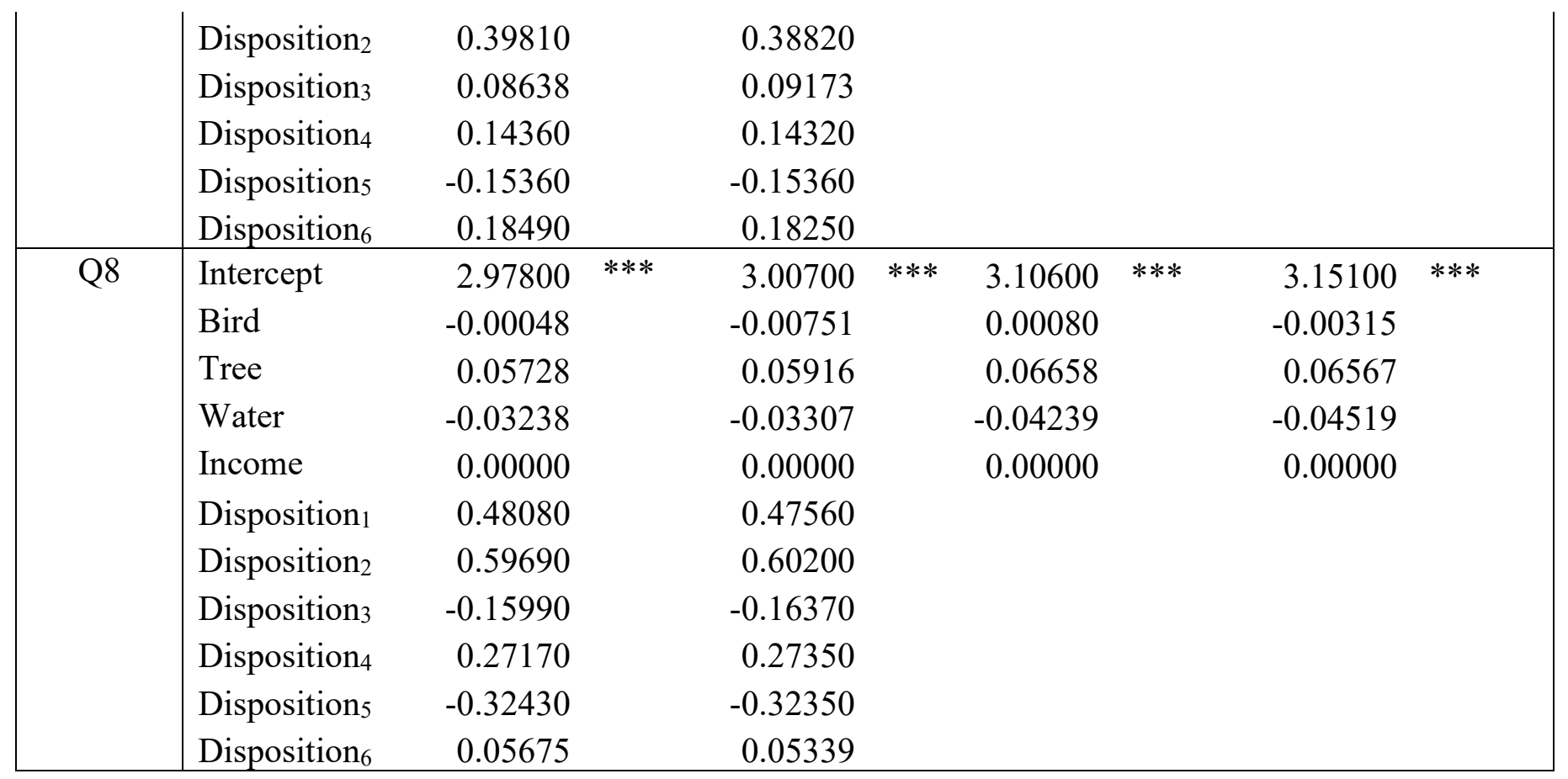


Model Comparison for Q5
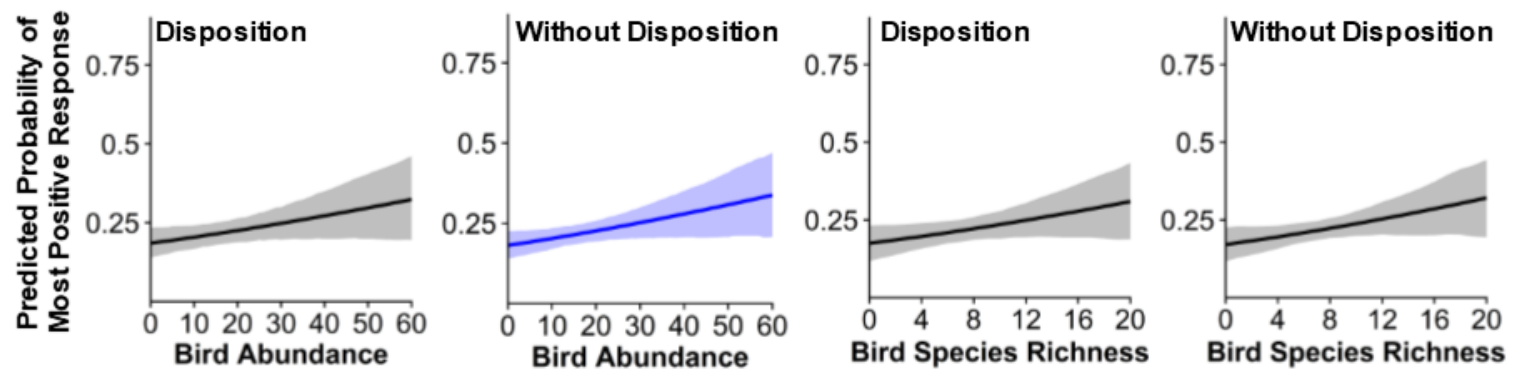

Figure C: Comparison between the models with and without disposition for the bird variables. The independent effects of each of bird abundance and species richness, after controlling for the effects of tree canopy cover, distance to water and income, on the probability (+/- 95\% credible intervals) of a participant answering the most positive option ("Far Above Average") for question 5 ("How would you rate the quality of your neighbourhood's natural environment compared to other areas in Ottawa?"). Each plot shows the effect of one predictor, while all other predictors are held constant at their means (median for disposition). Effects are plotted in blue if the $95 \%$ credible intervals around their coefficient estimates do not overlap 0. 